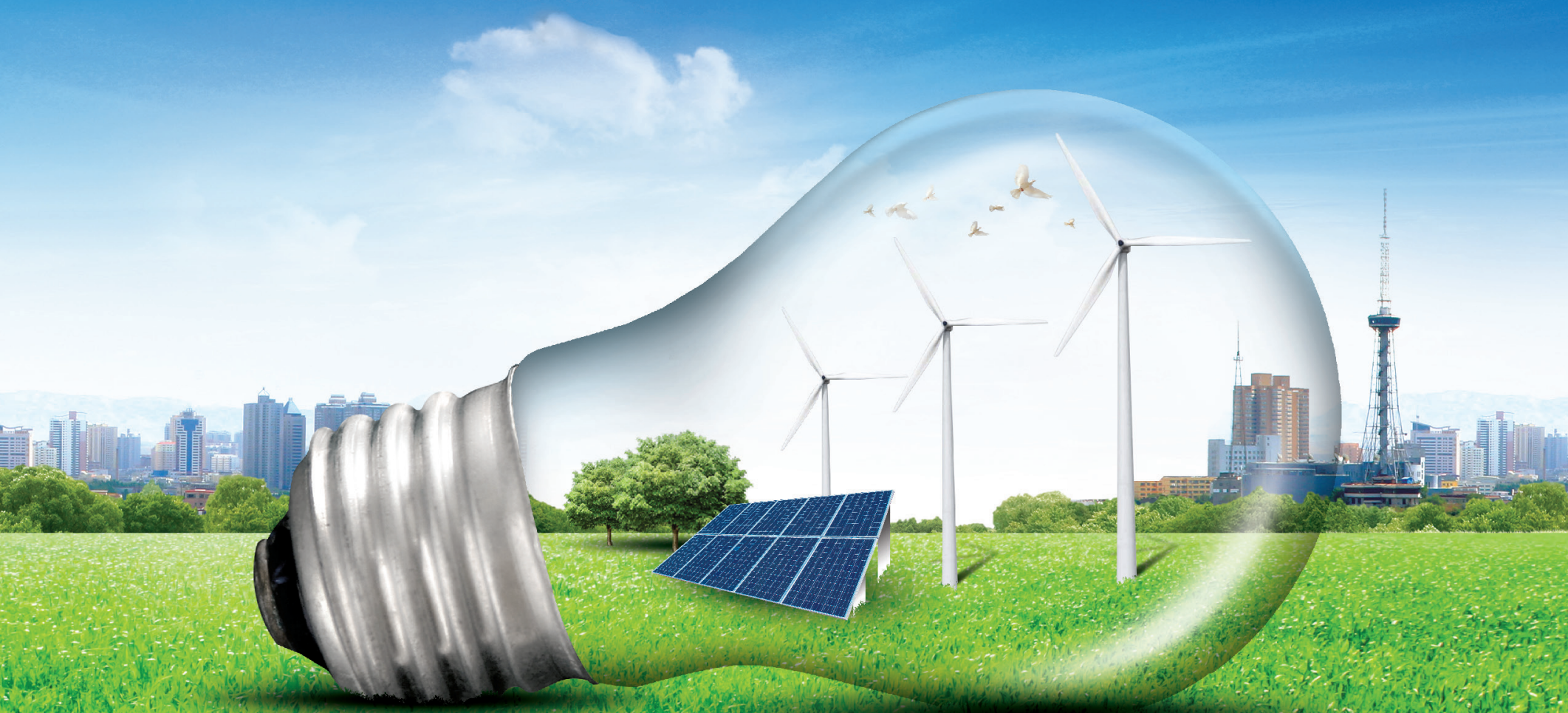
E.

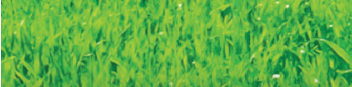

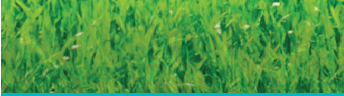

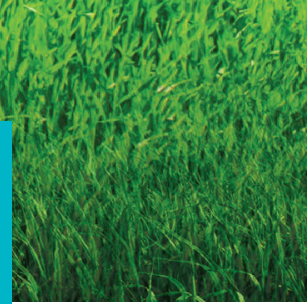

RENEWABLE ENERGY

FINANCING SCHEMES

FOR INDONESIA

NOVEMBER 2019 


\section{RENEWABLE ENERGY FINANCING SCHEMES FOR INDONESIA}

NOVEMBER 2019 
(C) 2019 Asian Development Bank

6 ADB Avenue, Mandaluyong City, 1550 Metro Manila, Philippines

Tel +632 8632 4444; Fax +63286362444

www.adb.org

Some rights reserved. Published in 2019.

ISBN 978-92-9261-832-2 (print), 978-92-9261-833-9 (electronic)

Publication Stock No. TCS190522

DOI: http://dx.doi.org/10.22617/TCS190522

The views expressed in this publication are those of the authors and do not necessarily reflect the views and policies of the Asian Development Bank (ADB) or its Board of Governors or the governments they represent.

ADB does not guarantee the accuracy of the data included in this publication and accepts no responsibility for any consequence of their use. The mention of specific companies or products of manufacturers does not imply that they are endorsed or recommended by ADB in preference to others of a similar nature that are not mentioned.

By making any designation of or reference to a particular territory or geographic area, or by using the term "country" in this document, $A D B$ does not intend to make any judgments as to the legal or other status of any territory or area.

This work is available under the Creative Commons Attribution 3.0 IGO license (CC BY 3.0 IGO)

https://creativecommons.org/licenses/by/3.0/igo/. By using the content of this publication, you agree to be bound by the terms of this license. For attribution, translations, adaptations, and permissions, please read the provisions and terms of use at https://www.adb.org/terms-use\#openaccess.

This CC license does not apply to non-ADB copyright materials in this publication. If the material is attributed to another source, please contact the copyright owner or publisher of that source for permission to reproduce it. ADB cannot be held liable for any claims that arise as a result of your use of the material.

Please contact pubsmarketing@adb.org if you have questions or comments with respect to content, or if you wish to obtain copyright permission for your intended use that does not fall within these terms, or for permission to use the ADB logo.

Corrigenda to ADB publications may be found at http://www.adb.org/publications/corrigenda.

Note:

In this publication, "\$” refers to United States dollars.

Cover design by Francis Manio. 


\section{Contents}

Tables, Figures, and Boxes

I. Introduction and Background 1

II. Current Situation 4

III. Challenges 8

IV. Definition of Design Parameters and Design Options 11

A. Viability Gap or Lack of Profitability 11

B. High Transaction Costs, Risks of Project Development, and Limited
Capacity by Developers and Financial Institutions

C. High Perceived Risk by Banks and Other Financial Institutions 14

V. Evaluation and Recommendations on Financing Instruments for Identified Financial Intervention Needs $\quad 16$

A. Viability Gap Funding 16

1. Option Viability Gap Funding 1: Fixed Tariff 16

2. Option Viability Gap Funding 2: Fixed Premium 17

3. Option Viability Gap Funding 3: Competitive Auction of Power

Purchase Agreements 18

4. Option Viability Gap Funding 4: Competitive Auction of Premium 19

5. Option Viability Gap Funding 5: Investment Grant 20

6. Summary, Conclusions, and Recommendations 21

B. Project Development Funding 22

1. Option Project Development Funding 1: Technical Assistance and
Capacity Building

2. Option Project Development Funding 2: Project Development Grants 23

3. Option Project Development Funding 3: Project Development Risk Finance 24

4. Summary, Conclusions, and Recommendations 25

C. Credit Enhancement Fund 26

1. Option Credit Enhancement Fund 1: Guarantee 26

2. Option Credit Enhancement Fund 2: Onlending or Credit Line 28

3. Option Credit Enhancement Fund 3: Colending, Syndication, A/B Loans 29

4. Option Credit Enhancement Fund 4: Stand-Alone Debt Fund 30

5. Option Credit Enhancement Fund 5: Interest Rate Subsidy 31

6. Summary, Conclusions, and Recommendations 31 
VI. Brief Summary of Similar Schemes Applied in Other Countries 34

A. Introduction 34

B. Global Energy Transfer Feed-in Tariff, Uganda 35

1. Background $\quad 35$

2. Description of the Scheme 35

3. Governance Structure and Funding Sources 36

4. Relevance and Lessons for Indonesia 37

C. Private Finance Advisory Network, Global 38

1. Background 38

2. Description of the Scheme 38

3. Governance Structure and Funding Sources 39

4. Relevance and Lessons for Indonesia 40

D. Renewable Energy Performance Platform, Sub-Saharan Africa $\quad 40$

1. Background 40

2. Description of the Scheme 40

3. Governance Structure and Funding Sources 41

4. Relevance and Lessons for Indonesia 42

E. Competitive Bidding of Long-Term Premium Tariff, Finland 43

1. Background 43

2. Description of the Scheme 43

3. Governance Structure and Funding Sources 43

4. Relevance and Lessons for Indonesia 44

F. Accelerating Renewable Energy in Central America 44

1. Background 44

2. Description of the Scheme 45

3. Governance Structure and Funding Sources 46

4. Relevance and Lessons for Indonesia 47

G. Turkey Sustainable Energy Financing Facility, European Bank for

Reconstruction and Development 48

1. Background 48

2. Description of the Scheme 48

3. Governance Structure and Funding Sources 50

4. Relevance and Lessons for Indonesia 50

VII. Governance Structure of the Energy Resilience Fund 52

A. Introduction 52

B. Governance and Organizational Structure of the Energy Resilience Fund 53

VIII. Concept Design of the Viability Gap Fund 59

A. Description of the Instrument 59

B. Eligibility Criteria $\quad 59$

C. Determination of the Premium Tariff 60

D. Competitive Bidding Process, Ranking, and Contract Award 61

E. Timing and Volume Considerations 63

F. Sanctions and Incentives 64 
IX. Concept Design of the Project Development Fund 66

A. Description of the Instrument 66

B. Eligibility Criteria 66

C. Main Terms and Conditions of the Project Development Fund 67

D. Selection Process 68

E. Timing and Volume Considerations 70

F. Technical Assistance Linked to the Project Development Fund 71

X. Concept Design of the Credit Enhancement Fund 73

A. Description of the Instrument 73

B. Eligibility Criteria 73

C. Main Terms and Conditions of the Credit Enhancement Fund 74

D. Selection Process 76

E. Timing and Volume Considerations 76

F. Technical Assistance Linked to the Credit Enhancement Fund 77

XI. Capitalization Structure and Potential Sources of Funding 79

A. Viability Gap Funding $\quad 79$

1. Type of Viability Gap Funding 79

2. Sizing of Viability Gap Funding $\quad 80$

3. Sources of Viability Gap Funding 81

B. Project Development Funding 82

1. Type of Project Development Funding 82

2. Sizing of Project Development Funding 83

3. Potential Sources of Project Development Funding 84

C. Credit Enhancement Funding 85

1. Type of Credit Enhancement Funding 85

2. Sizing of Credit Enhancement Funding 86

3. Potential Sources of Credit Enhancement Funding 86

$\begin{array}{ll}\text { D. Summary } & 87\end{array}$

XII. Conclusions 88

A. General 88

B. Viability Gap Fund $\quad 88$

C. Project Development Fund 90

D. Credit Enhancement Fund 91

E. Other Approaches 91

$\begin{array}{ll}\text { XIII. References } & 93\end{array}$ 


\section{Tables, Figures, and Boxes}

\section{Tables}

1 Summary of Similar Schemes in Other Countries Included in the Review 34

2 Illustrative Timeline for One Bidding Round

3 Illustration of Potential Viability Gap Fund Sizing at Different Assumptions on Support per Megawatt-Hour and Targeted Cumulative Capacity

4 Basic Structuring and Capitalization of the Project Development Fund

5 Basic Structuring and Capitalization of the Credit Enhancement Fund

6 Summary of the Capitalization vis-a-vis Components of the Energy Resilience Fund

\section{Figures}

1 Development of Power Demand and Installed Generation Capacity

2 Development of the Power Generation Mix in Indonesia in 2009-2016

3 Investment Barriers and Relevant Stakeholders to Address Them

4 Proposed Three Types of Financial Interventions, and

Potential Solutions for Each

5 Governance Structure and Organization of the GET FiT Program

6 Main Level Governance and Organizational Structure of the Energy Resilience Fund, Option 1

7 Main Level Governance and Organizational Structure of the Energy Resilience Fund, Option 2

8 Main Level Governance and Organizational Structure of the Energy Resilience Fund, Option 3

$9 \quad$ Illustrative Example of Bid Premium Tariff Levels in a Bidding Process

\section{Boxes}

1 Recommendation for the Viability Gap Fund Window of the Energy Resilience Fund

2 Recommendation for the Project Development Fund Window of the Energy Resilience Fund

3 Recommendation for the Credit Enhancement Fund Window of the Energy Resilience Fund 


\section{Introduction and Background}

T he Government of Indonesia is exploring alternatives to introduce new energy efficiency and clean energy technology regulations that are of high importance to the Sustainable and Inclusive Energy Program of the Asian Development Bank (ADB). In particular, the government is looking at new financing and incentive models to increase the deployment of clean and efficient technologies.

The increase and promotion of renewable energy generation resources are the priorities of the government under the National Energy Policy and the Medium-Term Development Plan 2015-2019. However, recent policy changes have led to mixed results for renewable energy development as the rules, regulations, and financial incentives enacted by the government created an uneven playing field for renewable depending on the location, and created questions over the long-term bankability and viability of projects. The high cost of financing and the low power purchase agreement (PPA) tariffs are serious concerns and roadblocks to renewable energy development in the country, which is why the government intends to provide financial incentives for renewable energy developers via an Energy Resilience Fund (ERF).

ADB has commissioned a study and a proposal by an independent consultant on possible financing schemes for such an ERF, the rules and criteria governing access to the ERF, and supporting the drafting of an initial concept for the ERF. An important premise for the assignment is to avoid a complex financial structure and aim at a time-limited support scheme that helps jump-start the development of renewable energy generation resources and can be implemented on a fast-track basis.

It is important to understand that the ERF in this context does not have to mean a separate new fund entity and structure, but the proposed ERF concept(s) can also be embedded into one or more existing or planned structures in Indonesia.

The tasks of this study include but are not limited to the following:

(i) presentation of options for an ERF based on international experiences and a review of Indonesia's current situation;

(ii) suggestions for a basic structure and rules and criteria for access to the ERF; and

(iii) draft concept paper for an easy establishment and use of funding scheme.

This report summarizes the analysis, findings, and recommendations by the consultant regarding a possible scope, structure, institutional design, as well as functioning and 
operation of an ERF. The report also discusses the potential sources of funding, based on the nature and sizing of the financing instruments included in the ERF concept.

The current situation is described in chapter II. The data and analysis are based on available reports and statistics concerning the Indonesian energy sector and finance sector as well as bilateral discussions with various stakeholders. Most of these stakeholder discussions were held during a fact-finding mission on 13-16 August 2018.

The barriers faced by renewable energy power generation projects in Indonesia are idenfitifed and summarized in chapter III. Some of the barriers can be addressed by various financing instruments, whereas some of them are of such nature that the means of intervention other than financing have to be used. Therefore, many but not all barriers can be addressed by the ERF concept presented in this report, but if other issues are not addressed, the financing instruments alone might not help to jumpstart the renewable energy power generation market.

Chapter IV categorizes the barriers faced and identifies the main types of financial interventions available to address such barriers. These interventions include (i) viability gap funding, (ii) project development funding, and (iii) credit enhancement funding.

Description and analysis of pros and cons of possible financing instruments for each type of financial intervention are provided in chapter $\mathrm{V}$. The list of financial instruments identified and evaluated in the chapter is not exhaustive (theoretically, there could be an indefinite number of instruments), but it makes an attempt to list the main instruments mostly used to address similar investment barriers in renewable energy markets in other countries. Chapter $V$ also makes a suggestion on preferred financial instrument(s) for each type of financial intervention needed.

Chapter VI includes a review of similar schemes in other countries. The chapter takes the suggestions in chapter $\bigvee$ as a starting point, and provides successful real-life examples of each proposed financial instrument from other countries. The description and evaluation of instruments and experiences in other countries also include an assessment to which extent these experiences are applicable in the context of Indonesia.

Chapter VII makes a proposal for institutional setup, governance structure, organization, and a rough assessment of needed resources and expertise of the ERF.

The more detailed concept for each of the three funding windows of the ERF (Viability Gap Fund [VGF], Project Development Fund [PGF], and Credit Enhancement Fund [ECF], and the technical assistance embedded in these) is presented separately for each funding window in chapter VII to chapter X. The concept design addresses the following topics separately for each proposed window (or financing instrument): 
(i) description of the instrument,

(ii) eligibility criteria,

(iii) main terms and conditions of the instrument,

(iv) solicitation and selection process,

(v) timing and volume considerations, and

(vi) technical assistance needs.

Chapter XI addresses the challenges to capitalize the ERF and potential sources of funding. Since the funding instruments are fundamentally different from each other (especially the VGF), this discussion is split in separate subchapters for each of the three instruments. The discussion includes the type of funding needed for each financing instrument, volume and sizing aspects, as well as potential sources available for each type of funding and possible blending of different types of financing within the ERF. 


\section{Current Situation}

W

ith its over 255 million people, Indonesia has the fourth largest population in the world. At the same time, the per capita power consumption is low, about 1 megawatt-hour (MWh) in 2016, leading to total power demand of 234 terawatt-hours (TWh), total installed capacity of about 60 gigawatts (GW) and power generation of about 290 TWh, according to PricewaterhouseCoopers (PwC 2017).

The economy of Indonesia is estimated to grow at 5\% per annum in the next 10 years (The Economist 2018). At the same time, the growth of power consumption is estimated to be as high as $8.4 \%$, leading to more than doubling of electricity demand to 483 TWh by 2026 and installed power generation capacity to $137 \mathrm{GW}$ as shown in Figure 1 (PT Perusahaan Listrik Negara 2017). In other words, by 2026 the power consumption will increase by about $250 \mathrm{TWh}$ and the installed capacity by $77 \mathrm{GW}$.

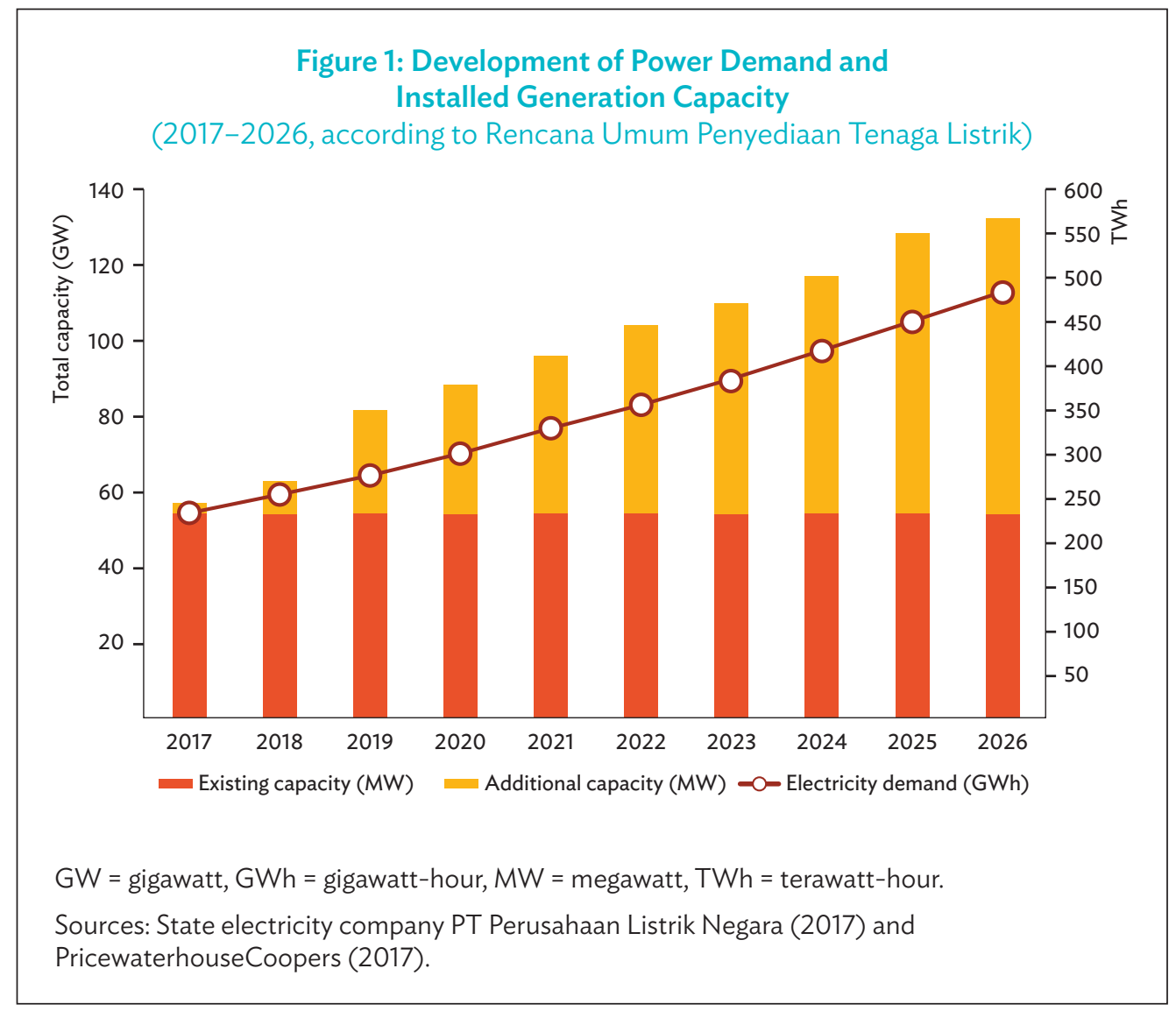


Another challenge in the power sector in Indonesia is the rapid increase of the use of coal and generally high dependence on fossil fuels, as shown in Figure 2.

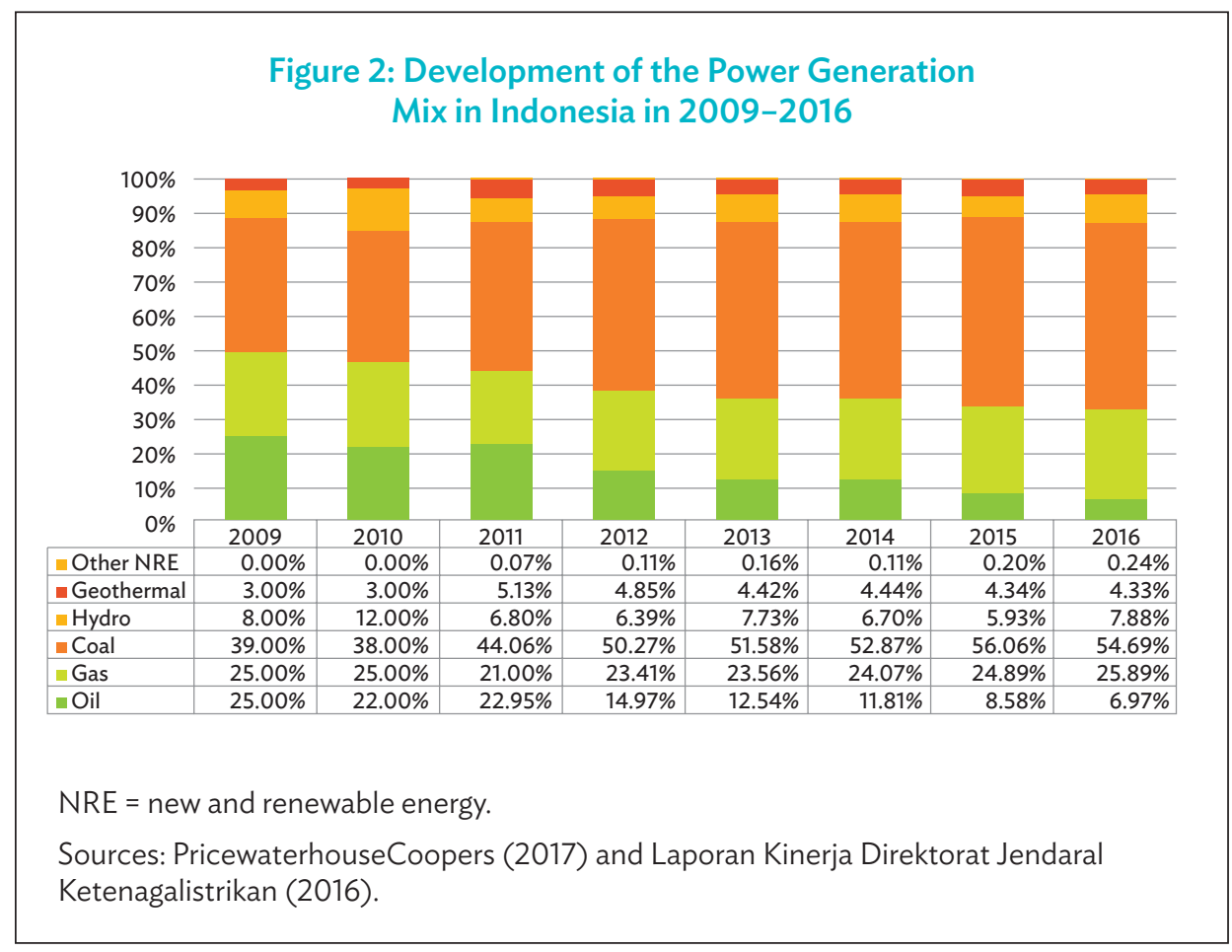

Although Indonesia is committed to a $29 \%$ greenhouse gas emission reduction target from the baseline in its Nationally Determined Contribution to the Paris climate agreement under the United Nations Framework on Climate Change (UNFCCC), and has a conditional commitment to $41 \%$ reduction with international climate finance (IRENA 2017), it has not been able to remarkably increase the share of low-carbon power generation in its power generation mix. Instead, the share of coal has increased from below $40 \%$ to about $55 \%$ today, and the share of all fossil fuels in power generation mix has remained close to $90 \%$ during the whole decade.

Increasing the share of renewable energy in the total energy mix would be good not only for Indonesia's greenhouse gas emission reduction targets but also for gross domestic product, employment, trade balance, and welfare. According to IRENA (2017), accelerated renewable energy deployment to double the share of renewable energy in the energy mix from 2015 to 2030 could increase Indonesia's gross domestic product by $0.3 \%-1.3 \%$ in 2030 compared with baseline, mainly as a result of higher overall levels of investment in the energy sector. Indonesia's trade balance could improve by $0.9 \%-1.6 \%$ by 2030 . The number of renewable energy-related jobs in Indonesia could increase to 1.3 million by 2030 , respectively, compared with about 100,000 in 2015. At present, more than $90 \%$ of renewable energy jobs are in the labor-intensive palm oil-based biodiesel industry, but mobilizing investment in the electricity and industry sectors, for example, would lead to diversification of renewable energy-related jobs in Indonesia. The increased share of renewable energy would also lead to positive social and environmental impacts, such as reduction of 
local pollution and related negative health impacts and environmental and material degradation.

However, renewable energy power generation is facing a number of challenges that are prohibiting project development pipeline from being implemented. For example, currently, there are 43 small-scale renewable energy projects and project developers under the independent power producer (IPP) scheme that have signed a PPA with the PT Perusahaan Listrik Negara (PLN, State Electricity Company), but which face challenges to implement the projects. Some of these challenges are attributable to the resources and capabilities of the project developers to develop bankable projects, but it is also widely accepted that the PPAs signed between IPPs and the PLN are not bankable. One reason in many cases is the very low-price level, but also other terms and conditions are posing prohibitive challenges to raise financing to implement these projects. Also, PLN's lack of experience in managing variable renewable energy generation as part of the power mix is seen as a challenge by some stakeholders. These challenges are identified and discussed more in the next chapter.

Further, based on the stakeholder discussions during the fact-finding mission, it is not likely that, in the short term, the existing or new PPAs signed by the PLN would be modified to have cost-reflective tariffs making the internal rates of return (IRRs) of the projects sufficient to make them bankable. It was also considered unrealistic by various stakeholders to propose a new regular competitive auction scheme for renewable energy, whereby the PLN would invite bids and award bankable long-term PPAs through IPP or public-private partnership (PPP) schemes. Therefore, in the near future, any fund structure should be based on the current state of unoptimal and (at least in many cases) non-bankable PPAs with too low prices. According to stakeholder meetings during the fact-finding mission, the same applies to the concessions under the electrification scheme, which is another current and important part of the renewable energy project pipeline in Indonesia.

Reflecting the current situation against the design criteria for the contemplated Renewable Energy Fund (REF), specifically that the REF should "avoid a complex financial structure and aim at a time-limited support scheme that helps jump-start the development of renewable energy generation resources and can be implemented on a fast-track basis," it can be concluded that:

(i) the REF concept should not assume project development and PPA procedures, nor the terms of PPAs, as currently applied by PLN to be changed, but the REF should work in the current context;

(ii) the same applies to other renewable energy sectors, including concessions under the electrification scheme;

(iii) therefore, the most feasible way forward to jump-start the renewable energy market with a time-limited support scheme implemented on a fast-track basis is to create "PPA- and concession-external" interventions only;

(iv) jump-starting the market fast also indicates that the intervention should target the existing project pipelines - instead of proposing to create new project pipelines, which is time consuming; 
(v) even if the current project pipelines consist mostly of small-scale projects (such as IPP and electrification schemes), this seems to be a needed step to help create and mobilize the renewable energy market in Indonesia, and also beneficial from PLN's perspective to gain experience and track record to manage variable renewable energy generation in its power system;

(vi) therefore, the REF concept proposed in this report could also be called "phase 1 interventions";

(vii) if the proposed "phase 1 interventions" in this report are implemented and turned out to be effective, the target, scope, and resources of the REF can be expanded in the next phase to provide more funding to a larger number of larger projects;

(viii) therefore, one of the first steps of jump-starting the market is likely to be a demonstration and piloting phase in the range of $100 \mathrm{MW}$ and less than 1 TWh of new generation, while the needed scale of tens of gigawatts should be targeted in the next phases; and

(ix) therefore, the objective of the REF is building the market and capabilities as much as adding new renewable energy capacity, which should be clearly seen in the structure, modalities, and resource allocation of the REF. 


\section{Challenges}

he main challenges for financing renewable energy power generation investments have been analyzed in earlier studies and identified as:

(i) low tariffs, making renewable energy investments unprofitable in many cases;

(ii) high interest rates of loans, further reducing the returns of typically capitalintensive renewable energy investments;

(iii) high collateral requirements and absence of project finance, making it difficult to raise debt financing for renewable energy investments;

(iv) build-own-operate-transfer (BOOT) structure in PPAs, instead of build-ownoperate structure;

(v) project scale of small and medium-sized projects increases the project development and transaction costs, and related risks in relation to investment cost, creating challenges to do high-quality project development work, which reduces options in financial structuring and arrangements (especially project finance);

(vi) capacity of project developers (technical and financial) and financial institutions (technical) is too limited on average, making it challenging to develop highquality projects by developers, and evaluating projects and structuring finance by financiers;

(vii) local content requirements make it challenging to design projects in a costefficient way; and

(viii) uncertainty related to requirements, timelines, and outcomes of licensing and permitting procedures create unreasonably high risks for project developers.

Removing or mitigating the above investment barriers requires work by and cooperation between multiple stakeholders in various forms. In fact, removing a single barrier often requires more than just one intervention by one stakeholder. Therefore, also a potential REF could help overcome many but not all of the challenges, and not all of them alone. Figure 3 summarizes the relevant investment barriers, and the primary stakeholder groups needed to address each of them.

Financial institutions-private or public - are not capable of efficiently solving challenges related to local content, license, and permit issues. These need to be addressed by the government and regulators, preferably in cooperation with project developers and sponsors. In contrast, the first six challenges can be directly addressed by financial interventions and institutions, especially public financial institutions, and in close cooperation with the government and the power utility in most cases. 
Figure 3: Investment Barriers and Relevant Stakeholders to Address Them

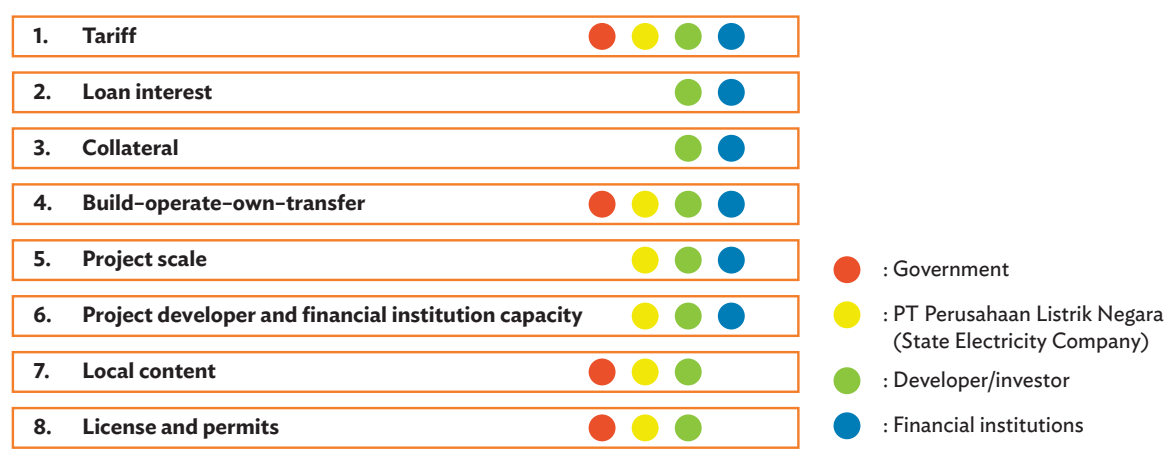

Source: ADB.

Theoretically, some of these barriers would be most efficiently addressed by improving the investment frameworks to reduce the real underlying risks and internalize external costs and benefits. However, in a second-best world, such barriers may exist, therefore justifying the need for financial interventions. This does not mean that the government, electricity utility, regulators, developers, sponsors, banks, and other stakeholders should not work toward developing a better investment framework to reduce the need for specific financial interventions and direct subsidies. In fact, as mentioned, one of the main objectives of the proposed ERF concept is to help the relevant stakeholders build capabilities and improve market and investment frameworks.

The proposed ERF concept seeks to find solutions to mitigate, or contribute positively to the mitigation of, the following investment barriers labeled with blue dot in Figure 3:

(i) typically, too low tariff (e.g., PPAs or concessions), making the internal rate of return (IRR) of renewable energy investments too low for investors;

(ii) high interest rates of debt, leading to high cost of finance of projects, therefore reducing the (equity) IRR further and making the investments less attractive to investors;

(iii) high collateral requirements by banks, making it difficult to raise debt in the absence of large balance sheets by developers and project sponsors;

(iv) BOOT structure of PPAs limiting the potential revenue-generation period of projects;

(v) project scale and related high development and transaction costs in relation to size of the total investment, combined with generally high-risk profile of project development; and

(vi) limited financial and technical capacity of project developers, and limited technical capacity, experience, and track record of financial institutions. 
The following section will elaborate each of these challenges separately and present potential solutions to them. The list of financial instruments or approaches is not exhaustive since, theoretically, there could be an indefinitive amount of financial interventions. The objective is to list all the main instruments that are mostly used to address similar barriers in various countries around the world. The defined design parameter that is "easy-to-implement" also justifies using experiences and lessons from existing and tested solutions in other countries as much as possible. 


\section{Definition of Design Parameters and Design Options}

S ome of the listed barriers share same features and/or causes. Therefore, it may be feasible to try to cluster the barriers. This enables both finding suitable financial interventions and reducing the amount of the financial interventions; some of the barriers can be addressed by one type of intervention. The identified barriers that can be targeted through financial interventions can be grouped into three, which will be discussed in this chapter:

(i) viability gap or lack of profitability,

(ii) lack of technical and financial resources during project development stage, and

(iii) lack of debt finance at reasonable terms and conditions.

\section{A. Viability Gap or Lack of Profitability}

In Indonesia, the renewable energy power tariffs in grid-connected projects depend on the location and are generally set at maximum $85 \%$ or $100 \%$ of the prevailing tariff in the same region as applied by the PLN. In many cases, this tariff level is too low to provide sufficiently high return for project sponsors on their investment. In addition, the definition of "maximum tariff" means that PLN, as the offtaker, has certain level of freedom to negotiate these tariffs case by case, making the pricing process intransparent and the resulting PPA prices difficult to estimate beforehand by developers. These are fundamental issues that have to be solved by defining a tariff level that is sufficient for project sponsors to make an investment decision, and the level of which is established in a clear and transparent way.

The main approaches to address the viability and profitability issues in other countries are:

(i) fixed feed-in tariff,

(ii) fixed premium,

(iii) competitive auctioning of long-term PPAs,

(iv) competitive auctioning of a top-up premium on top of predetermined tariff or market price, and

(v) investment grants.

Among the most fundamental differences is the award or selection process. Traditionally, during the previous decade, the "first come, first served" approach was more popular, i.e., developers and sponsors whose projects met certain predetermined eligibility criteria were automatically granted the predetermined fixed feed-in tariff or premium tariff, or were awarded this tariff after case-by-case evaluation against such eligibility criteria. 
In this decade, different types of competitive auctioning procedures have come to dominate the selection and award processes of PPAs and premium tariffs, both in developed and developing country renewable energy markets. Typically, auctioning is arranged so that the lowest bids until the targeted volume is contracted will be awarded a bankable long-term PPA at the price ( $\$ / M W h)$ the bidder indicated in its bid (pay-as-bid). Subsequently, the national utility or other market operator is required (as the counterparty to the PPA) to off-take the power generated by the project at the specified pay-as-bid price.

In rarer cases, the competitive auctioning has concerned a premium that is paid on top of the prevailing tariff or PPA or a wholesale power market price. In such schemes, the awarded projects will sell the power in the market (or under the PPA) according to normal regulations or the market price and will receive a premium on top of the market price or prevailing regulated tariff (i.e., primary revenue stream). The reasons for auctioning the premium instead of the total price of electricity have been twofold in different countries.

First, premium tariffs have been seen as less market-distorting in more privatized and competitive electricity markets where the market price fluctuates and the producers have to continuously respond to the price signal provided by the changes in supply and demand balance. If the renewable energy producers were awarded a fixedprice PPA (instead of a premium on top of the market price), the renewable energy producers would have no market price risk and not need to take the fluctuations in supply and demand and the resulting price fluctuations into account; thereby lowering the average market price, increasing the price volatility in the market, and causing market distortions. This is one of the reasons why, for example, Finland chose to go for competitive auctioning of long-term premium rather than PPA for renewable energy projects.

Second, in some cases, it may be useful to clearly and transparently separate the subsidy or incentive component from the base power price or tariff. This is related to the funding of the scheme. Again, for example, in Finland where the additional cost is charged to taxpayers, it has been seen important to distinguish clearly the subsidy component from the market price component (in addition to aiming for less market-distortion). Similarly, in some developing countries where development finance institutions may provide funding to support such schemes, it is important to distinguish the base tariff or PPA price and the premium component clearly, and in an unambiguous manner since the funding for these revenue streams come from different sources.

Of the PPA auctions, there is a vast amount of increasingly encouraging examples, and, in fact, it has become globally the main approach to award PPAs and determine price levels in the renewable energy sector. Of the premium auctions, the Global Energy Transfer Feed-in Tariff (GET FiT) scheme of German development cooperation through Kreditanstalt für Wiederaufbau (KfW, Credit Institute for Reconstruction) in Uganda and Zambia, as well as the auctioning scheme to be implemented in Finland in 2018 are good examples, and will be described in more detail later in this report. 
Investment grants have been more popular in the early days of renewable energy technologies and are still used often in the context of newer and still unproven technologies. However, investment grants are less typical when promoting mature renewable energy technologies; the profitability is typically stimulated by enhancing the cash flows of the project rather than contributing to the initial investment cost directly. But both systems exist and, in some cases, are even used as a combination, as will be shown later.

\section{B. High Transaction Costs, Risks of Project Development, and Limited Capacity by Developers and Financial Institutions}

Renewable energy investments are often (although not always) smaller compared with conventional power generation projects. More often, the renewable energy projects are in the range of single- and double-digit MW of installed capacity, whereas the conventional power generation projects are in the range of double- or three-digit MW of installed capacity, or more. For example, in project finance (also known as non- or limited-recourse lending), smaller banks often have a lower limit of $\$ 20$ million- $\$ 50$ million for projects, and in larger banks the lower limit can be in the range of $\$ 50$ million- $\$ 100$ million because of high transaction costs of project finance. Also, since permitting and other regulations tend to be less clear for newer renewable energy tehchnologies than they are for conventional power generation investments, the relative risks, project development, and transaction costs tend to be higher and lead times longer, reducing the incentive for project development, and increasing the required returns (i.e., cost of capital) and, therefore, the levelized cost of electricity for renewable energy investments.

Also, renewable energy project developers tend to be more diverse, many of them being small and medium-sized enterprises with limited financial (and sometimes also technical) capacity to produce high-quality documentation and develop high-quality projects that are solid enough to obtain needed permits, licenses, and financing.

The identified challenges can be bundled in a broad group of project development stage barriers and related financial challenges. In the context of renewable energy project development, typical financial interventions that have been used to address these challenges are the following:

(i) Technical assistance and capacity building, i.e., by providing external experts free of charge to help not only project developers but also lenders and regulators in project development process; this provision of external expertise can be both direct project-specific support and more general or programmatic activity, such as training and education.

(ii) Provision of grant funding for project developers, which help them to develop higher-quality projects and related documentation, especially by using external experts (technical, financial, legal, and others) to produce bankable resource analyses and production estimates, grid studies, environmental and social impact assessments (ESIAs), technical design 
documents, financial models and plans, drafting bankable agreements, and other required documentation.

(iii) Provision of risk finance for project developers to help them do the same.

Project development support has often been based on provision of technical assistance and cash grants on a discretionary basis after case-by-case evaluation. However, more recently, (i) more competitive selection procedures (e.g., so-called "challenge funds"), as well as (ii) use of more financial instruments and reimbursable grants can be observed.

\section{High Perceived Risk by Banks and Other Financial Institutions}

High perceived risk by lenders can result in higher required returns (i.e., interest rates) and stricter risk mitigation measures (including collateral, liquidity, and covenants). In this case, the main barriers resulting from high perceived risk are high interest rates required and short tenors allowed by financial institutions (Barrier 2) and excessive collateral requirements (Barrier 3). In addition to real risks, these issues can result from (i) lack of information, understanding, and track record; (ii) lack of or conflicting incentives; and (iii) lack of competition among financial institutions because of shallow domestic capital market.

In some stakeholder meetings, it has been observed that the banking sector in Indonesia is generally much more accustomed to corporate (balance sheet) finance and less to project finance.

In this context, typical financial interventions that have been used to address lending challenges are:

(i) providing partial guarantees for lenders either covering part of all credit risks, or covering certain specific risks;

(ii) colending between development finance institutions (who may have more experience and/or higher risk tolerance) and commercial lenders;

(iii) onlending whereby development finance institutions provide credit lines for commercial lenders on softer or concessional terms, who then can blend this funding with their own commercial funding when exending debt for renewable energy investing;

(iv) a debt fund operating as an independent lender, which may or may not invest together with commercial lenders;

(v) interest rate subsidy or interest rate buy-down as a direct subsidy for banks and project sponsors to pay part of the interest rate required by the banks that is seen excessive from projects' perspective, thereby lowering the cost of capital of renewable energy investments; and

(vi) capacity building for financial institutions to help them understand renewable energy investments and to support them in investment appraisal and financial structuring.

The aforementioned approaches may enable private financial institutions to (i) extend debt to renewable energy investments at reasonable terms and conditions 
even in the existence of high perceived risk and (ii) gain experience, build capacity, and track record to provide debt with limited or no support in further lending to similar investments. There are remarkable differences between the approaches. Guarantees on one hand are indirect funding, i.e., in the base case the funds are not disbursed at all, just committed to cover potential losses borne by lenders. Colending and onlending as well as stand-alone debt fund are direct financing in the sense that the funds are actually disbursed and used to implement projects, and become part of the renewable energy project's balance sheet, and will be gradually repaid with a return. Finally, the interest rate buy-down is a direct subsidy instead of a financing instrument. In contrast to guarantees and lending, it is not repaid or released and it will not generate returns; it is "lost money" by definition from the ERF's point of view.

This can also be seen as a rough order of prioritization between these instruments: the better functioning, deeper, and more liquid debt capital market, the more it usually makes sense to provide guarantees in the first place and let the debt capital market reprice the debt and do the lending. If the capital market is too shallow, illiquid, or otherwise nonfunctional, the case for direct colending and onlending, or a stand-alone debt fund, may become more relevant. Finally, if nothing else works, and a direct subsidy intervention is needed, the interest rate subsidy may be an option. However, it is recommendable and usually more cost efficient first to seek ways to reduce the real and perceived risk and incentivize the market to reduce the interest rates. 


\section{Evaluation and Recommendations}

on Financing Instruments for Identified Financial Intervention Needs

ased on the previous section, the main options for financial inverventions can be summarized as shown in Figure 4. It is proposed to establish three funding instruments/sub-funds under the ERF to address the specific barriers. In this chapter, the pros and cons of the main options, as listed under each sub-fund, are evaluated, and recommendations for preferred instrument(s) for each sub-fund will be proposed.

Figure 4: Proposed Three Types of Financial Interventions, and Potential Solutions for Each

\section{Viability Gap Funding}

1. Fixed tariff

2. Fixed premium

3. Competitive auction of PPAs

(i.e., tariff)

4. Competitive auction of premium

5. Investment grant

\section{Project Development Funding}

Technical assistance and

capacity building

2. Project development grants

3. Project development risk finance
Credit Enhancement for Investments

1. Guarantee

2. Onlending/credit line

3. Colending

4. Stand-alone debt fund

5. Interest rate subsidy

6. Technical assistance and capacity building

PPA = power purchase agreement.

Source: ADB.

\section{A. Viability Gap Funding}

\section{Option Viability Gap Funding 1: Fixed Tariff}

Pros:

- successful in initially establishing renewable energy markets "from scratch" in many countries

- incentivizes investors and lenders by securing long-term stable cash flow as long as the perceived technology risk is low, i.e., the technology is considered proven

- incentivizes project development by providing predetermined tariff level and eligibility criteria for developers; developers know already in project development stage that their project will be eligible for the tariff, which will also make it easier to secure financing, if they are able to carry out the needed studies and obtain the needed land-use rights, permits, licenses, and agreements

- usually simple, transparent, and clear 
Cons:

- setting tariffs is challenging; the political process often results in unoptimal level

- too low tariff will not encourage project development and investment, and can put the sector in a standstill

- too high tariff overstimulates the sector, leading both to high cost for the government in the form of excessive tariffs, encouraging implementation of projects in unoptimal locations as projects can be profitable even in lowresource locations, and possibly leading to bottlenecks in supply chains and increase of development and implementation costs

- political risk related to tariff levels and their stability in future can be questionable, especially if the energy or fiscal policies are unstable more generally

- difficult to take into account the development of the cost-competitiveness of technologies; sometimes an annual percentage reduction of tariffs for new projects is applied, but this cannot be accurately matched with the actual cost development of technologies

- would be a parallel and duplicate procedure for the current regulations in Indonesia, not complementing the existing ones

\section{Option Viability Gap Funding 2: Fixed Premium}

Pros:

- may be less distorting in a competitive or liberalized electricity market where prices fluctuate based on demand and supply, and where the generators have market price risk

- may be better than fixed tariff for the renewable energy sector in the long-term by incentivizing the renewable energy generators in market integration (both in terms of managing potential price risk as well as technical power system integration)

- makes the subsidy component in power pricing more transparent

- provides investors and lenders with higher revenues, but same market risk as for other forms of generation

- incentivizes project development by providing preset eligibility criteria for developers; developers know already in project development stage that their project will be eligible for the tariff, which will also make it easier to secure financing, if they are just able to get the needed land-use rights, permits, and licenses

- usually simple, transparent, and clear

- can work as a complementary mechanism to an existing market or revenue mechanism

Cons:

- compared with fixed tariffs, riskier for investors and lenders in markets where underlying market prices tend to fluctuate, leading to higher cost of capital, and sometimes even non-bankability of the projects because of too high expected cash flow volatility 
- in markets with price risk, leads to higher required subsidy, especially as renewable energy-based power generation is generally more capital intensive than conventional power generation

- setting tariffs is challenging; the political process often results in nonoptimal level

- too low tariff will not encourage project development and investment, and can put the sector into a halt

- too high tariff overstimulates the sector, leading both to high cost for the government in form of excessive tariffs, and encourages implementation of projects in nonoptimal locations as projects can be profitable even in lowresource locations

- political risk related to tariff levels and their stability in the future can be questionable, especially if the energy or fiscal policies are unstable more generally

- difficult to take into account the development of the cost-competitiveness of technologies; sometimes a fixed percentage reduction of tariffs for new projects is applied, but this cannot match with the actual cost development of technologies

- if the price setting procedures (through PPAs or fixed tariffs) are intransparent and speculative, the combination with a premium can cause unnecessary subvention; i.e., tariffs are negotiated lower by the off-taker than in the base case, in anticipation of higher premium or subsidy provided by the government or VGF

- in practice, has not be very widely used compared with fixed tariffs

\section{Option Viability Gap Funding 3: Competitive Auction of Power Purchase Agreements}

Pros:

- provides the investors and lenders with long-term cash flow certainty in the same way as fixed tariff scheme, therefore lowering the cost of capital and improving the bankability of projects

- after some unsuccessful and nonoptimal implementations in 1990s (such as in the United Kingdom), and after the "golden age of feed-in tariffs" in 2000-2009, competitive auctions of PPAs have been implemented increasingly successfully in increasing number of countries to promote renewable energy investments within this decade; a vast amount of good practices and success stories is available to be learned and applied

- many renewable energy developers, investors, and lenders are already knowledgeable and experienced in PPA auction systems and can participate routinely

- leads to more efficient price setting than fixed tariffs by compelling the developers and investors to reveal their true competitive price level

- tracks automatically the changes in cost-competitiveness of renewable energy technologies; a competitive setting prices of subsequent auctions are adjusted by the bidders to take into account lowered investment costs, higher productivity, and lower cost of capital of renewable energy technologies as they develop further 
- allocates resources more efficiently; projects in better locations and with better designs will be more competitive than those less professionally developed and located in less-attractive areas

- better government control than in fixed tariff and premium: it is possible to define a maximum price to cap the cost of the scheme, and possible for government to control the volume by capping the capacity to be contracted at a time and during a specified period

Cons:

- riskier for project developers and, therefore, does not provide as strong incentive for project development as fixed tariffs (or premium) since there is no similar certainty of cash flow as in these schemes. The developer or sponsor needs to compete against other market players.

- requires more market and renewable energy sector understanding from the regulator and the government in order to design a good scheme than fixed tariff and premium schemes

- requires more resources to plan, implement, and monitor the system than fixed tariff and premium schemes

- risk of opportunistic behavior; if the sanctions of nondelivery or delays are low or do not exist at all, can lead to extremely low pricing and unviable projects, which will finally not be implemented (as what happened in the United Kingdom's Non-Fossil Fuel Obligation scheme in 1990s)

- even appropriate sanctions in some countries have led to such a high level of competition and aggressive pricing that policy makers and regulators have become concerned about the viability of winning projects

- the bankability of a competitive auction system depends largely on the creditworthiness of the off-taker and the bankability of the PPA; if one of these are inadequate, some form of external support is required

- as a separate viability gap funding measure, duplicates the existing regulations and solicitation procedures instead of complementing them

\section{Option Viability Gap Funding 4: Competitive Auction of Premium}

Pros:

- similar to competitive auctioning of PPAs regarding efficient price setting, adapting to cost changes, governance requirements, and government control

- similar to fixed premium schemes regarding the market integration especially in more liberalized, open, and competitive electricity markets with fluctuating prices, and regarding making the subsidy component more transparent

- can work in context where the expected price level is higher than the prevailing market price or general tariff level, therefore complementing rather duplicating existing PPA solicitation and negotiation procedures

- if the price setting procedures (through PPAs or fixed tariffs) are intransparent and speculative, the combination with a premium can cause unnecessary subvention; i.e., tariffs are negotiated lower by the off-taker than in the base case, in anticipation of higher premium or subsidy provided by the government or a viability gap scheme 
Cons:

- much less used than competitive auctions of PPAs, therefore less experiences and lessons from schemes in other countries; however, examples can be found in Finland, Uganda, and Zambia

- not suitable in cases where renewable energy is expected to be cheaper than the prevailing market price or general tariff; in such case, the auction should lead to winning contracts at zero premium requested, unless negative premium is allowed. In order to materialize the cost-competitiveness of renewable energy, the scheme should be based on PPA auction (enabling bids lower than the market price/regulated tariff)

\section{Option Viability Gap Funding 5: Investment Grant}

Pros:

- from investor perspective, lower risk; allocates more risk from investors to the government or VGF since all cash is received upfront before the actual generation takes place, while the other schemes are more results based, i.e., rewarding according to the actual generation

- helps in financial arrangements directly and decreases the absolute amount of financing required as the funds are made available at the time of initial investment or construction stage already, whereas the other schemes support the financial arrangements of initial investment only indirectly

- in theory, if the government or VGF's cost of capital (and, therefore, discount factor applied) is lower than that of investor, investment grant would be cheaper for the former, and more valuable for the latter; lower total amount of subsidy would be required

- simple scheme from governance point of view

- vast amount of experiences and lessons from other countries

- typical instrument when supporting the demonstration and commercialization of new technologies

- can complement existing PPA solicitation procedures and other prevailing price setting mechanisms, rather than duplicating them and creating a parallel market.

Cons:

- upfront funding transfers risk from investor to government or viability gap scheme; less of a problem for proven low operational expenditure technologies such as solar, wind, and hydro, which will most likely maximize their generation in all scenarios, but can be an issue in case of bioenergy projects where generation could be lower than expected (or project totally terminated) because of high cost of unavailability of biofuel, or biofuel could be replaced by fossil fuels

- requires substantial upfront disbursements from the government or VGF in a relatively shorter term than in the other schemes where the cost acculumates over longer term; could be an issue from the budgeting perspective

- although the funds are disbursed faster, rules and monitoring of implementation must be in place also afterwards to ensure that the projects are implemented and operated according to the initial eligibility criteria 
- if the price setting procedures (through PPAs or fixed tariffs) are intransparent and speculative, the combination with investment grant can cause unnecessary subvention; i.e., tariffs are negotiated lower by the off-taker than in the base case, in anticipation of higher grant/subsidy provided by the government/VGF

\section{Summary, Conclusions, and Recommendations}

Currently, the revenues of renewable energy investments are based on a predefined tariff structure that, on the other hand, in many cases, is negotiable and therefore uncertain, and with a cap that in many cases is too low for investors to generate sufficient returns. On the other hand, in some locations, the tariff levels could be sufficient to justify an investment. The electricity market is noncompetitive, primarily a single-buyer market, where market-based (supply and demand balance) price fluctuations do not exist.

As there is no competitive electricity market and related price risk, market integration (or avoidance of distortion) is not as important as in countries with liberalized and competitive electricity market. Also, as long as the underlying power price (through PPA or concession tariffs) is not predefined, there is a risk that a premium (either fixed or competitive) or an investment grant can lead to "game-playing" where unnecessarily low tariffs/PPA prices emerge, with the anticipation of a viability gap funding scheme to cover larger part of the revenues of projects. Therefore, the scheme should be such that it gives the developers an incentive to always maximize the tariff in the PPA or other primary revenue streams determined in PPA negotiations (IPP scheme), concession tariffs (electrification scheme), or other.

Based on the fact-finding mission, currently it seems not possible to propose changes to the current PPA or concession procedures, and therefore a PPA or a fixed tariff scheme would need to be separate from the current procedures, and therefore would create a parallel market, which is not feasible. Probably, it would also require regulatory changes. Therefore, only way forward would be to work on the basis of the current PPAs and concessions and create a VGF mechanism (see Box 1) that would complement rather than duplicate/circumvent the current system. In practice, PPA auctions or fixed tariffs are not an option, and the remaining options are premium (fixed or auctioned) and investment grant.

Production-based premium or investment grant on top of the primary revenue stream would make the subsidy element more transparent for the government and funders of the VGF. Such scheme could be justified if the underlying power price was sufficiently transparent, and not affected by anticipated existence of a subsidy scheme. Also, it would be able to work independently from the current PPA or concession procedures by PLN and the government, complementing them instead of intervening them or creating a duplicate/parallel procedure.

Further, in some locations, if it is likely that some project types would be competitive against/cheaper than prevailing tariff levels, in some cases a premium should result to zero, and in fact theoretically be negative in order to materialize the cost-efficiency of renewable energy in best locations. Therefore, since the tariff levels and profitabilities 
between renewable energy projects can be expected to vary considerably, seeking to establish an efficient and competitive price premium for renewable energy projects would be reasonable. Projects that have a signed PPA, concession, or similar revenue stream will be able to calculate the lowest additional premium level they would need to make their projects profitable. Therefore, such projects could bid for premiums in a competitive process.

\section{Box 1: Recommendation for the Viability Gap Fund Window of the Energy Resilience Fund}

Based on the aforementioned considerations, it is proposed that competitive auctioning of premium payments would be selected for the main instrument of the viability gap funding, being available for projects that already have secured a clear and fixed revenue stream.

This secured, clear, and fixed revenue stream can mean power purchase agreements signed by developers under the independent power producer or IPP scheme, or developers with a concession and explicit power price under the electrification scheme. This would give the project developers an incentive to negotiate power purchase agreements or PPAs (or other revenue streams) as high as possible, therefore enabling competitiveness in a subsequent (possible) competitive bidding of a premium tariff. Such scheme would also not require formal changes or linking to the existing regulations and power purchase agreement solicitation procedures, but would complement them and work independently in the current context.

The auction could either aim at maximal cost-efficiency, having all projects bidding in same process, or, for example, there could be location-specific priorities (or prioritization of certain technologies). In the latter case, the auctioned volume would be allocated separately for different areas (or technologies), depending on which areas (or technologies) are prioritized for new generation capacity. This could lead to very different price levels in different regions (or technologies).

When considering splitting the total allocation, the level of competition needs to be carefully evaluated. For example, if there are very few eligible bidders in a certain region, it may not enable sufficient competition between bidders.

Source: ADB.

\section{B. Project Development Funding}

\section{Option Project Development Funding 1: Technical Assistance and Capacity Building}

Pros:

- The provider of the technical assistance and capacity building, such as the PDF in this case, has more control on the procurement and provision of the services. For example, it is possible to have a list of accredited service providers from which project developers can select, or the PDF can use competitive process to select suitable service providers. 
- The scope and costs of the technical assistance and capacity building, and therefore the budget of the PDF, can be known and planned better beforehand.

- The fund manager can be able to use/direct the use of funds more strategically from the sector point of view as a whole, therefore aiming at broader benefits than just project level support.

Cons:

- The procedure may not be flexible enough from the project developers' point of view, if they are not able to procure the services they need by themselves, from wherever they want. The eligible service providers might not include exactly the type of expertise as required by a developer from time to time.

- Timing of the services may not go exactly as wished by the developer, if the fund manager is actively involved, which may be an issue since timing can be critical in project development.

- May require deeper involvement and, therefore, resources from the fund manager to coordinate and manage the technical assistance/capacity building and can therefore also lead to delays and bottlenecks.

- In practice, this is grant funding, i.e., once the service provider has been paid for services, the money is used and lost from the PDF perspective.

\section{Option Project Development Funding 2: Project Development Grants}

Pros:

- Providing grants is relatively straightforward, and project evaluation, award, and disbursements can be done efficiently, enabling higher volume.

- Possibility to standardize the process (e.g., web-based online procedures, standard nonnegotiable agreements) can also make it easier for developers to apply funding

- It can be possible to arrange efficiently 1-4 calls for proposals per annum with several projects approved per call, resulting in a large number of approved grants per annum.

- Grant funding is attractive to developers and sponsors for obvious reasons; no repayment obligations, no risk of default, and larger impact on profitability compared with financial instruments.

- For the above reasons, grant financing does not only improve the bankability of the project or equity IRR but, unlike financial instruments, grant funding improves the underlying project IRR.

- Usually, grant funding is flexible also from the developers' point of view. They can procure services freely from capable service provider they want and when needed, as long as rules are met (such as procurement rules imposed by the ERF).

Cons:

- Compared with financial instruments/risk finance, where there is possibility for repayment and even returns, grants are inefficient from the ERF's perspective since, once used, the money is used and lost, with no option to reinvest, which can lower the effectiveness and leverage effect of grants compared with financial instruments. 
- When using grants in a context where, at least, some private finance can be available, there is a risk of market distortion, over-subsidizing, and crowding out of private finance. Therefore, project award should be done carefully in this sense, but is challenging in practice.

- Grant funding usually does not require as much from developers than risk finance. In the latter case, the evaluation, comments, and requirements are often tougher, thus often also improving the overall quality of the project. In some cases, it could be argued that grant funding has been "too lazy money."

\section{Option Project Development Funding 3: Project Development Risk Finance}

Pros:

- Risk finance (meaning in practice equity, quasi-equity, or mezzanine loans) can be more efficient from a broader perspective, i.e., be able to leverage more other finance, including private finance. Once a project development stage mezzanine loan is being repaid with interest (either in installments or at the financial close of the project) the funds can be reinvested in a new project. This can make the use of public funds more efficient.

- Depending on the risk profile/strategy of the PDF, it can aim at

o taking a lot of risk, thereby losing its capital gradually, but being able to recover and reinvest some of its funds more than once;

o aiming at self-sufficiency and cost-neutrality, i.e., the returns will cover its operating costs and losses, and the capital will be preserved in the long term; or

o being close to a commercial financial investor, pricing its financing to account for high risk and high administrative costs of the fund, and aiming at generating positive post-fees net returns.

- Risk finance can and needs to be tailored for the purpose, meaning that the project development status, available funding, expected schedule, and risks can be taken into account to structure the project development funding in the most meaningful way for the project. This will not only serve the interests of the project and the PDF, but can also help mobilize other finance, including private investors.

- Use of financial instrument can be less market-distorting than use of grants. Financial instruments can and should also be tailored from the financial market situation perspective too, meaning that, in more commercial cases, where private finance may also be involved, also the project development funding should apply more commercial features to avoid crowding-out effect, whereas in financially less-viable projects, where private funding is very unlikely, the project development funding can take softer forms.

- When investing in form of a financial instrument (in contrast to grants), there are often stricter due diligence process, stricter agreements, requirements, covenants, and other control mechanisms in place for the financier (i.e., PDF in this case). Although this may be seen critically by the project developer, it can improve the quality of the project and project development, and forces the developer to be clear, transparent, and professional in their procurement, use of money, and documentation. 
Cons:

- Since investing in form of financial instrument(s) requires more tailoring and structuring, the transaction costs tend to be higher than in grant facilities, and respectively the volume of funded projects may be lower than in case of a grant facility. In contrast, this may reduce the effectiveness and leverage of the PDF.

- If project development funding provided by PDF is repayable (possibly with interest), the cash flow to repay the project development funding is away from cash flow for other purposes. Therefore, compared with grants or technical assistance, it inevitably reduces the project IRR and equity IRR of the project, and it also affects negatively certain debt-related ratios such as debt service coverage ratio, meaning that the borrowing capacity of the project is reduced respectively. However, project development funding, and especially PDF's likely minor share of it, is typically small compared with the investment cost of the project itself. Therefore, in many cases, this impact is not remarkable, but needs to be addressed, however.

- Managing the financial investments requires more effort than monitoring of the use of disbursed grants. Especially, equity can be burdensome since (i) the shareholder role and possible board membership brings additional responsibilities in decision-making; and (ii) the exit of the equity investment needs to be separately planned and executed (in contrast to repayment of a loan), which can turn out to be very difficult or even impossible. Also managing a loan portfolio requires careful monitoring that debt servicing of projects happens as in loan agreements, but as long as there are no defaults of other special events, the debtor does not need to be involved with the portfolio companies, and in fact has no access to decision-making.

\section{Summary, Conclusions, and Recommendations}

Traditionally, the project development funding support has been based on technical assistance and grant funding, which are attractive for the developers as well as straightforward, easy, and cost-efficient to manage. On the other hand, grant funding may be an inefficient use of public funds in cases where there is a business case, and therefore does not achieve as high as possible leverage effect since, once money is used, it is lost from the funders' point of view. In the worst case, such grant finance may crowd out private commercial finance that would be available but will not be used since developers prefer "free and easy money" from grant facilities. Recently, an increasing amount of more market-based approaches and financial instruments have been used. However, even in one country and within one category of projects, there will be a lot of variation between individual projects, some being better able to absorb funding at commercial terms, while some will still require clearly subsidized funding.

Therefore, it may be advisable for the PDF to seek commercial financing options to promote project development activities, while also preserve the option to provide softer grant financing in cases where the projects' capability to absorb commercial finance is more limited. From instrumentation/structuring point of view, both grants and financial instruments can be structured in a more or less commercial way. For example, the PDF could be formally a grant facility, but to the extent possible 
distribute "reimbursable grants," possibly carrying an interest, meaning that, in case the project is successful, it would repay the grant, possibly with an interest/multiple, at the financial close, or the grant could be converted to a short-term loan, repayable during the operational phase from project cash flows. In this case, even if the funding was legally a grant, it would be structured as risk finance such as mezzanine loan/ quasi-equity. Alternatively, the PDF could provide grants and risk financing. The practical difference between these could eventually be limited, depending much on the detailed legal specifications of these (see Box 2).

This approach would enable more sophisticated tailoring opportunities on the project level funding. It would also lead to additional management resource requirements for the PDF. In such case, in contrast to more traditional grant finance, the PDF should have more personnel resources, including people with specific expertise in project development and financial structuring. This would both increase the transaction costs and reduce the volume of projects that can be taken through the PDF on an annual basis.

Therefore, the choice and detailed specifications of the PDF instrument depend greatly on the volume and timing targets of the ERF. If the size and volume targets of the ERF are large, it may be more efficient to (at least partly) formulate the PDF as a grant facility, possibly based on frequent online call for proposals (CfP) procedure. To the extent the volume targets of the ERF allow, it is recommendable that the PDF at least consider ways to use financial instruments and aim at higher leverage and less market distortion.

Bilateral first come, first served approach may be challenging from public funding point of view, which often prefers/requires competitive procedures such as calls for proposals. However, the former approach is preferred if financial instruments are used. The latter does not enable tailored structuring and the needed level of project evaluation and due diligence as required when using financial instruments. There are funds with public sources of funding using bilateral noncompetitive approaches, and it would be recommendable to seek for such solutions also in this case.

Primarily, the funding should be directed at more advanced projects where clear progress has been achieved already, and preferably with a relatively clear path towards bankability. The developer should demonstrate its skills in project development, including previous track record, and the applicant should also provide stong contribution to the remaining project development cost together with the PDF.

\section{Credit Enhancement Fund}

\section{Option Credit Enhancement Fund 1: Guarantee}

Pros:

- If the perceived risk by banks is high while the real risk is low, the case for a guarantee scheme is strong. This means that there is room for pricing of the guarantee, accounting for both expected losses and administrative costs, thereby improving the financial sustainability, leverage ratio, and impact of the guarantee fund. 
Box 2: Recommendation for the Project Development Fund Window of the Energy Resilience Fund

Based on the aforementioned considerations, it is proposed that project development funding can be provided through continuous project identification, bilaterally case by case either as grants, reimbursable grants, or financial instruments.

Financial instruments should be preferably in form of mezzanine debt rather than equity instrument to make the post-investment portfolio management more efficient. If equity is used, it should be structured so that it actually works like debt, in practice meaning no remarkable decision-making responsibilities on project company level as well as prenegotiated exits.

The Project Development Fund (PDF) could apply different levels of commerciality in its financing, depending on the commercial viability and investor interest in the project. This would serve the purposes of (i) using public funds in as efficient way as possible and preserving the capital to the extent possible; and (ii) maximize the leverage of other finance and minimizing the crowding-out effect and, thus, avoid unnecessary market distortions. In some more viable cases, the funding could apply almost normal commercial terms, whereas grants could be used in other less viable cases.

The operation of the PDF should primarily be based on case-by-case, bilaterial first come, first served process, i.e., the fund manager evaluating each project individually and making decisions based on predetermined eligibility criteria of projects, targets of the fund, and detailed set of key performance indicators steering fund manager's activities towards the desired direction at a desired pace.

Source: ADB.

- Guarantee is not direct funding, and the funds are never disbursed in the base case. The funds need to be committed and allocated to guarantee specific loans (often provided by commercial banks and development finance institutions). Funds need to be drawn on only in case a guaranteed debt is in default and the bank (or the project sponsor, depending on what is guaranteed) is making a claim to the guarantor according to the guarantee agreement.

- By this indirect involvement, it leaves the actual funding, funding process, and decisions to capital market.

- By incentivizing the debt capital market to provide loans, a guarantee scheme can also be very useful for capacity building and market creation purposes. The guarantee scheme offers cushioning for local banking sector in their first steps to get involved with renewable energy projects. It is typical and often useful to complement a guarantee scheme with a capacity building component.

- If a country has a sufficiently deep and well-functioning capital market, direct lending by a public funding instrument may lead to crowding out private financing, whereas guarantee scheme does not have such risk.

- Guarantee is relatively easy to administer. A guarantee fund can be able to leverage banks' due diligence processes (or vice versa), and the loan 
administration does not take much effort as long as there is no default situation, and even in these situations it is primarily the lender's responsibility to act.

Cons:

- Guarantee should not be for $100 \%$ of the outstanding debt, or it may lead to moral hazard. Some risk has to be left for the lenders and project sponsors to ensure prudent actions and operations. Having a balanced guarantee scheme, covering enough credit risk to incentivize lending but not too much in order to avoid moral hazard and agency problems may be challenging.

- In most cases, the expected default and loss rates can be very difficult to estimate beforehand since, typically, there is no relevant market information available to actually model these (since the very reason of the guarantee scheme is to kickstart the nonexistent market). Consequently, the sizing and pricing of the fund is challenging as it is not possible to say what the realistic leverage rate could be, i.e., how many dollars of debt $\$ 1$ of guarantee could support or mobilize.

- If the real risk (in contrast to perceived risk) of the investments is high, then real losses can be expected, and therefore the financial sustainability and the usefulness of a guarantee fund may be more limited; at least, its subsidy element will become higher.

- Sometimes there are unrealistic expectations for guarantee funds, i.e., that they could preserve the capital and generate returns even if the underlying projects have high real risk.

- To some extent, guarantee instrument helps, but if a bank is very unfamiliar with a new sector or otherwise sees remarkable risks, it may not be willing to provide debt even if partially covered by the third-party guarantee; a guarantee should not make a bad project look good.

- Guarantee brings an additional player to the financial structure, financing process, and negotiations, which can add to the complexity and transaction costs. If the guarantee scheme has very different and specific requirements compared with banks for example, this may cause problems in due diligence processes, fianncial structuring, and negotiating agreements.

\section{Option Credit Enhancement Fund 2: Onlending or Credit Line}

Pros:

- Receiving a credit line with softer terms from a development finance institution enables a local financial institution to extend loans at better terms to renewable energy projects.

- Using special credit lines, the banks can preserve their core capital requirements and risk positions even if they are providing debt for a sector that is perceived riskier.

- Credit lines enable capacity building, creating track record and expertise by the financing instutions by getting hands-on with renewable energy projects. It is typical and often useful to complement a credit line with a capacity building component. 
- Credit line as a form of direct financing can help if the domestic capital market is shallow and the market is seen as unattractive for international lenders. In such case, direct financing from a development finance instution that use credit lines can be efficient, and help leverage other finance, instead of crowding it out.

- A traditional arrangement with a vast amount of experience and lessons from different countries and by various development finance institutions.

Cons:

- The financial intermediary should have considerable own stake in the financing too, not only onlending the credit line. Otherwise, there is risk for moral hazard since the intermediary would not have the incentive to do due diligence, financing decision as well as portfolio management properly. On the other hand, too much own stake required may disencourage the financial intermediaries to utilize the credit line. Finding the balance may be challenging, as in the guarantee scheme.

- Indirect intervention will give less control for the CEF on the financing decisisions and portfolio management. As said above, there is the risk that the credit line will not be used in the first place and, second, that the due financing decisions will not sufficiently reflect the objectives of the fund. Channeling the objectives and the investment strategy of the CEF through the financial intermediaries to the project level financing needs to be carefully planned and communicated with sufficiently strict rules for financial intermediaries.

\section{Option Credit Enhancement Fund 3: Colending, Syndication, A/B Loans}

Pros:

- Colending or A/B loan structure remarkably lowers the threshold for banks and institutional investors to provide debt for projects. Led by a development finance institution, a loan syndication instrument could lead and coordinate the financing process towards a project, be the lender of record, carry out the necessary project appraisals and due diligence processes, and then syndicate this loan with commercial lenders.

- Depending on how the instrument is structured and governed, the banks and institutional investors as $B$ lenders could benefit from the possible preferred creditor status of the $\mathrm{A}$ lender, i.e., the development finance institution-led financing instrument.

- The structure helps the private financial institutions to get track record in renewable energy lending and, therefore, has capacity building benefits.

- From the CEF instrument and funders' perspective, syndication structure enables high control of transaction processes and portfolio management since the CEF instrument would be the sole counterparty (the lender of record) towards the project on behalf of the B lenders. Therefore, the management team could affect the deal volume and achievement of the targets with its own actions better than in the case of a guarantee scheme or credit line scheme.

- By lowering the risks and costs of lending for private financiers, these can provide debt at more attractive terms from projects' perspective. 
Cons:

- The fundamental reasons of the unattractiveness of renewable energy investments need to be identified and solved. These may still prohibit banks and institutional investors from providing debt even with the existence of the syndication instrument, in which case it will become difficult for the syndication vehicle to close any transactions.

- The operational responsibility of the scheme in this structure would be heavily dependent on the management team of the scheme. It can be an advantage by providing a higher degree of control, as mentioned above, but it can also be a weakness, in case the management entity or team is not capable of carrying out its tasks properly, it will put the whole scheme at risk. This risk is higher in the syndication and stand-alone fund CEF options, compared with other CEF options where the roles are distributed more on other financial institutions too.

- Since a syndication instrument would need to play a big role throughout the transactions and portfolio management, the resource requirements would be higher, respectively, both in terms of amount of people and special project finance deal structuring expertise.

- The capacity building impact might be lower compared with credit line option since a syndication fund manager would do much of banks' work in the deal process. However, this depends largely on the detailed procedures of how the fund works.

\section{Option Credit Enhancement Fund 4: Stand-Alone Debt Fund}

Pros:

- This may be easier and more straightforward from the individual project's point of view.

- Mobilization is likely to be faster and more straightforward than when working with or through local banks or other financial institutions since the fund could deal directly with projects.

- This could be easily outsourced to existing private fund manager(s) with strong track record, if needed, thus also contributing to faster implementation and mobilization

- Use of external private fund manager could also ensure the needed experience and track record when selecting a capable service provider through a competitive selection process.

- From the CEF funders' point of view, a standalone fund would provide more control of the actual terms of finance at project level, whereas working on a guarantee scheme or via local or commercial financial institutions, this control could be more limited or indirect.

- If the real risk is considered significantly lower than what is reflected in the pricing by the private sector, it could be possible to provide lower interest rate debt for renewable energy projects raised from development finance institutions. To some extent, these typically offer softer terms in their financing. However, in such case, serious consideration needs to be given to the market rates and the potential crowding-out effect. At some point a fund offering very concessional pricing and other terms can also be considered interest rate subsidy. 
Cons:

- Aspects of building the market and capacity (especially among capital markets) likely to be more limited since the fund would be an independent/stand-alone entity, operating as the sole lender in many cases, thereby not "radiating" the experiences more broadly in the sector.

- Additionality should be justified in each project; would a stand-alone debt fund promoted by development financiers be something more than what the private sector players should be able to do?

- If the additionality argument is based on some kind of softer elements in funding, risk of becoming too risk averse compared with the mandate of providing softer/riskier finance, and therefore not being able to achieve the real additionality and impact.

- In this scheme, the management entity/team would have higher control and responsibility of the success of the scheme (such as in the syndication scheme) whereas in other schemes, the roles are distributed to other financial institutions too.

- There could be a risk of crowding out other finance, especially in a country with a deep and well-functioning capital market.

- If the CEF funders were more of public sector financers, there is a risk of too close political influence at the project level, consequently compromising sound financial decision-making. This risk is present in all publicly funded financing schemes, programs, and instruments, but the risk seems to be larger the more direct control and intervention channels the policy makers have in the fund investment decision-making.

\section{Option Credit Enhancement Fund 5: Interest Rate Subsidy}

Pros:

- This is a direct way to intervene with high interest rates in cases where they are prohibitive.

- This is a traditional official development assistance mechanism widely used in a development finance context.

Cons:

- It does not tackle the underlying root causes of high interest rates.

- Due to the above reason, it may not be able to address the other possible probihitive terms and conditions of lending.

- It is a form of direct subsidy instead of financing.

- It can have more difficult issues (than the other options) regarding rules and regulations on state aid or international trade

- It could be the last option, if nothing else works.

\section{Summary, Conclusions, and Recommendations}

In principle, it would be advisable to only play an indirect role in mobilizing debt for renewable energy projects and let the capital market provide the needed debt. For example, this could be done by providing the needed VGF and PDF instruments, and then providing $C E F$ in the form of indirect intervention only, i.e., as guarantee 
instrument(s), liquidity facilities, capacity building. However, in practice, there may be lending barriers that are not related to renewable energy only but are more general challenges in the capital market (see Box 3).

Although Indonesia has an investment-grade credit rating, its central bank interest rates and government bonds are at a relatively high level, and the debt capital market of the country can be described as shallow and less liquid. Also, during the fact-finding mission, it became clear that there is a risk that some banks may already face their limits in energy sector lending because of heavy exposure to PLN credit risk. Even if such limits were not close, it was also mentioned that continuing to lend to PLN in the energy sector could still be the easiest option for banks which might not be willing to make the effort needed and use their balance sheets for other energy sector lending.

In addition to a guarantee scheme, an additional debt funding instrument in the CEF window of the fund should be considered. If the banks and institutional investors show interest towards the sector and it is likely that they would have interest to play an active role to develop their capabilities and the sector, a scheme based on credit lines could be considered, and this could bring a lot of leverage and capacity building impacts relatively efficiently.

On the other hand, if the assumption is that the capital market remains uninterested in the sector and a rather passive attitude can be expected, a syndication instrument could become more relevant. In this arrangement, the CEF instrument would play more active and leading role, such as in identifying and evaluating opportunities, doing the due diligence, carrying out negotiations, and managing the portfolio. This would give more control and responsibility for the fund manager but would not have as high expected leverage effect as an onlending/credit line instrument.

As the last option, a stand-alone debt fund can be considered. It also gives the fund manager good control and responsibility of the success of the scheme, and it may be useful to mobilize debt funding at the fund level. On the other hand, the capacity building and capital market development impacts would probably be more limited than in the case of syndication and credit line instruments. In all cases, but especially in the case of a stand-alone fund, it would be recommendable to put special coordinated effort to capacity building of the local capital market. It has to be kept in mind that building the market and improving the investment frameworks are, at least, as important objectives as the new installed capacity achieved in the context of the ERF. 


\section{Box 3: Recommendation for the Credit Enhancement Fund Window of the Energy Resilience Fund}

Based on the aforementioned considerations, it is proposed that the credit enhancement funding should consist of a guarantee and a credit line instrument.

The credit line should seek to mobilize the local capital market. It would do so by playing a central role in identification, evaluation, negotiation, and due diligence processes together with the banks "in the frontline" like in case of syndication, rather than playing a background role as a passive credit line provider. By definition, these instruments will involve banks and institutional investors in the project level deals and, therefore, help them get understanding, build track record, and gain experience in renewable energy sector.

This activity should be complemented with a strong, well-planned technical assistance and capacity building program targeted primarily at the lenders and developers, but also at other crucial stakeholders playing a role in making projects bankable.

Source: ADB. 


\section{B. Global Energy Transfer Feed-in Tariff, Uganda}

\section{Background}

GET FiT Uganda was launched in 2013 to address especially the low renewable energy tariffs and various high risks faced by investors and financiers in the field of renewable energy in Uganda. The core of the GET FiT scheme is a premium tariff offered for projects that could be bankable but are not profitable with the government-set price level in their PPAs. In addition to this premium, the scheme includes a partial risk guarantee as well as technical assistance to various stakeholders, especially public sector policy makers, regulator, and grid operator.

\section{Description of the Scheme}

\section{Competitive Premium Tariff}

The premium tariff aims at providing a "top-up" to the governmental feed-in tariff as set by the Energy Regulatory Authority (ERA) working under the supervision of the Ministry of Energy and Mineral Development. The scheme was launched in 2013 with three bidding rounds arranged for small hydro and biomass, and one solar photovoltaic-specific round in 2014. GET FiT has supported 15 small hydro, two solar photovoltaic, and one bagasse projects awarded the premium. The total installed capacity of these 18 projects is $158 \mathrm{MW}$, i.e., the average size of the projects is <10 MW.

The award procedure of the premium tariff is based on competitive bidding process. Each developer submits a proposal for the need of a premium they would need to make their projects profitable. As a result, the developers in need of lowest premiums are awarded the premium they are asking (pay-as-bid), and the volume of projects and support is determined by the availability of funds from donor countries. The premium is front-loaded, and $50 \%$ of it was paid as a lump-sum immediately after the commercial operation date (COD), and the remaining $50 \%$ was paid during the first 5 years of operation. Remarkable, this cash flow profile helps projects' debt servicing capacity in the early years of operation, and the first $50 \%$ part can actually be considered as an investment grant, or partial refinancing of construction stage finance.

The bidding process is a two-stage and multi-criteria procedure, where in the first phase (prequalification round) the interested developers will be scored according to their experience, track record, and capabilities, and the quality and readiness of the project. In the second stage (request for proposals [RfP]), the bidders are ranked based on price (70\% of total score) and technical/qualitative basis (30\% of total score).

The proposal phase documentation included the RfP, the PPA, premium payment contract (i.e., separate agreements and respective revenue streams from PPA with the utility and premium payment contract with GET FiT), implementation agreement, and the direct agreement. Financing for the project had to be tentatively in place, and the equity and debt providers had to sign a letter approving the above agreements. 
To avoid opportunistic proposals, the GET FiT required a bid bond (standby letter of credit from a bank) placed by bidders at the time of submitting their proposals, the amount being $\$ 10,000 / \mathrm{MW}$, which can be considered relatively high. Successful bidders then had to provide $\$ 20,000 / \mathrm{MW}$ completion and performance bond to show commitment to project implementation. In addition, delays were sanctioned by introducing a $\$ 2,000 /$ day penalty for delayed COD. Finally, both the PPA and the premium payment contract had performance-based sanctions; if the actual capacity of the plant was lower than indicated in the bid, the rates could be reduced and, after certain thresholds, the contracts could even be terminated.

The bidding schedule in the GET FiT was relatively relaxed. First, the bidders had 7 months to submit their bids and, after award decision, they had 9 months to reach the financial close. After the financial close, the projects had 13-16 months to reach the COD.

\section{Risk Mitigation Instruments}

The GET FiT scheme includes different types of risk mitigation instruments for the benefit of the lenders. First, the implementation agreement included effectively a government guarantee to support the utility's payment obligations, and the direct agreement (as usual) included provisions for step-in rights for the bank in case of debt service default by the project company. Moreover, the World Bank made its partial risk guarantee instrument available to projects, although none of the projects finally used it, probably because of high upfront cost.

\section{Grid Infrastructure Investment Costs}

In Uganda, the project owner is responsible for grid construction up to the connection point to the grid, whereas the transmission system operator is responsible for the so-called "deep works" to strengthen the grid. To support the latter, GET FiT worked together with the transmission system operator to help design and construct the needed grid reinforcements, and also paid part of these costs of the transmission system operator.

\section{Technical Assistance}

Technical assistance in the GET FiT scheme was provided primarily to the regulator, bidding process operator, and the grid company - not much to developers nor banks. As mentioned, the transmission system operator received help and even financing from GET FiT in planning, designing, and constructing the grid (deep connection costs). Especially the solar photovoltaic bidding processes included considerable support for the Energy Regulatory Authority (ERA) to design the standard templates for agreements, and detailed design of the bidding process. Moreover, the GET FiT donors paid the operative costs of the specific bidding agent working under the supervision of the energy sector regulator ERA, ensuring the availability of sufficient personnel resources and skills to run the process in a timely and professional manner.

\section{Governance Structure and Funding Sources}

The GET FiT was implemented under the Ministry of Energy and Mineral Development, the main responsibility of operationalization at the ERA, which hosted 
the GET FiT Secretariat. Supported by a private sector implementation consultant, the secretariat was mainly responsible for the daily operation and management of the GET FiT. The secretariat and implementation consultant were supervised by the GET FiT Steering Committee with the relevant ministries and funding donors as members. The Investment Committee consisting of the funders finally approved the projects based on the work and proposal by the secretariat. The governance structure of the GET FiT scheme is shown in Figure 5.

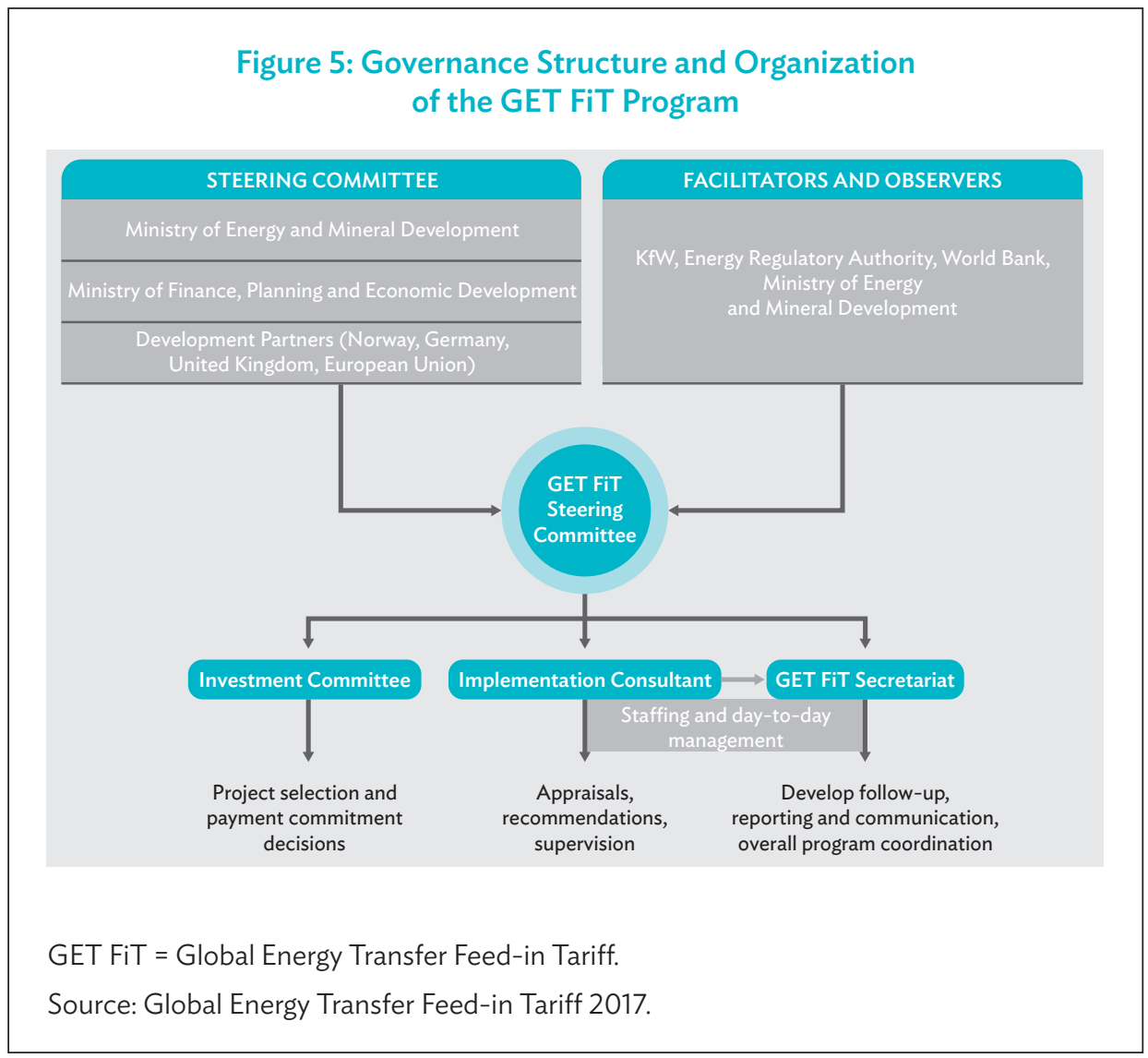

The lead-financier and the original inventor of the GET FiT concept is KfW from Germany. In addition, Norway, the United Kingdom, and the European Union have all provided funding and technical assistance to the scheme. The World Bank made its existing partial risk guarantee instrument available to winning projects. After successful experiences in Uganda, the GET FiT scheme is now being implemented in Zambia, targeting $100 \mathrm{MW}$ of new solar power generation.

\section{Relevance and Lessons for Indonesia}

Although Uganda is smaller and a generally less-developed country than Indonesia, the GET FiT scheme includes several interesting aspects. First, it applies a fully donorfunded premium tariff scheme based on competitive bidding. As also in Indonesia, one of the fundamental issues is the insufficient tariff level, the GET FiT represents one concrete example of how to tackle this challenge. 
The GET FiT projects were small, less than $10 \mathrm{MW}$ on average, and several projects about $5 \mathrm{MW}$. Also in Indonesia, especially the projects under the IPP scheme are of similar size. On the other hand, the electrification project can be remarkably smaller, whereas PPP projets can be remarkably larger. In principle, the projects can be larger too, mainly depending on the amount of funding available and the resulting capability of the scheme to support projects.

The GET FiT scheme provided broad-based support for the public entities having remarkable responsibilities in the scheme. It supported the grid operator in planning, designing, and construction to lower its threshold to play its role of connecting the plants. It also supported the ERA to establish and manage the GET FiT Secretariat, paid the costs of professional implementation consultant to help in project evaluation and recommendations, and GET FiT also provided the templates for key documentation to ensure the bankability of the documentation. All this would probably be needed in an Indonesian scheme too. In addition, it would be advisable to also provide support and project development funding for developers, and technical assistance to banks to encourage them to play an active role in the scheme.

For more information: https://www.getfit-uganda.org/.

\section{Private Finance Advisory Network, Global}

\section{Background}

The Private Finance Advisory Network (PFAN) was established in 2006. Its rationale is based on the observation of the so-called "missing middle" between the project developers and investors/financiers. Therefore, PFAN was established to facilitate interaction between these two key stakeholders by supporting developers in developing their projects and financial planning to meet investors' requirements and needs, preparing project pipelines and portfolios ready for investors, and identifying and making contacts with potential investors.

\section{Description of the Scheme}

PFAN is a multidonor program (with the United States Agency for International Development as the largest donor) that has developed a network of professional clean energy and climate sector financial advisors covering most of the developing countries and emerging markets. These advisors are experienced persons having worked in the sector and region for a long time, and therefore are approved by PFAN to be part of its global pool of financial advisors. The advisors usually do not work full-time for PFAN but receive part of their assignments and income through PFAN projects.

PFAN identifies and helps projects that are fundamentally sound and have good commercial potential, but which face project development and financing challenges. Projects are being identified and evaluated continuously on a case-by-case basis by the PFAN coordinators, based on an application template that the developers and entrepreneurs must use. In addition, projects are identified through calls for 
proposals. PFAN issues regular calls for proposals in different regions inviting project developers to submit applications.

Successful proponents will be provided with technical assistance in the form of a financial advisor to support them in project development, financial planning, and identification of and interaction with investors and financiers. The donor-based PFAN pays a smallish fixed upfront share of the fees of financial advisors on behalf of the developers, but PFAN and the local advisors also make a success fee agreement with developers, which is payable only in case the project is successful. With this blending and covering the upfront cost of hiring financial advisors, PFAN is able to mobilize financial advisors efficiently by using only a limited amount of public funding.

In addition to identifying projects and appointing financial advisors to projects the PFAN works actively with investors. It identifies investors and prepares project portfolios to be presented to them. Projects are being presented to investors in different ways, including bilaterally and publicly. A key match-making activity is PFAN's flagship event Clean Energy Financing Forum that is organized regularly in different regions. Potential investors and the most credible projects are invited to the events, where the project developers have the opportunity to pitch their projects to investors, and to have bilateral meetings with them.

Although PFAN focuses on the "missing middle," coaching and mentoring project developers in financial issues and training finance sector players in clean energy issues, PFAN also supports the energy transition to clean energy by actively engaging in policy dialogues. In this work, PFAN leverages its host organizations' and donors' activities, outreach, and resources in addition to its own resources.

\section{Governance Structure and Funding Sources}

Originally implemented under the Climate Technology Initiative (CTI) in cooperation with the United Nations Framework Convention on Climate Change Expert Group on Technology Transfer, the PFAN is nowadays (since 2016) hosted by the United Nations Industrial Development Organization (UNIDO) and the Renewable Energy and Energy Efficiency Partnership (REEEP). PFAN has a steering committee through which UNIDO, REEEP, and the funding governments are represented. PFAN has its own core staff, and is additionally supported by REEEP staff and UNIDO with regard to professional and administrative services. Also, PFAN has regional coordinators who coordinate project identification and facilitation activities in their respective regions. Individual financial advisors are appointed case by case to support specific projects selected for support by PFAN.

The current funding government partners of PFAN include the United States (United States Agency for International Development), Japan (Ministry of Economy, Trade and Industry), Sweden (Swedish International Development Cooperation Agency), Norway (Ministry for Foreign Affairs), and Australia (Department of Foreign Affairs and Trade). PFAN is also able to negotiate more targeted and temporary finance with donors; for example, for an individual donor country to support certain country or region for a more limited and specific period and scope. 


\section{Relevance and Lessons for Indonesia}

Already, PFAN is actively working in Indonesia, and in terms of projects supported by PFAN, Southeast Asia is the largest region for PFAN. In Indonesia, PFAN has an existing network of local individual financial advisors, and it has also financial institutions and advisory companies as network members, including the SMi and BAPPENAS as resource partners of PFAN.

Other Indonesian PFAN network members include Sucorlnvest, PermataBank, Bank Negara Indonesia (BNI), Bank Central Asia (BCA), Insight Investments Magements, Independent Research \& Advisory Indonesia (IRAI), Indonesian Electrical Power Society (MKI), Indonesian Renewable Energy Society (METI), and ADB's Energy for All Partnership Program.

PFAN's operations are well-established with strong proof of concept by $\$ 1.25$ billion leveraged finance in 102 projects in 25 countries. Its current project portfolio includes about 500 projects, of which more than 100 are in Southeast Asia.

Therefore, PFAN could be considered not only a potential model to be replicated, but an organization that actually links banks to the project development support services for developers and technical assistance offered by the REF. As an example, a donor country currently funding PFAN, or an entirely new donor country to PFAN, could provide targeted technical assistance funding for project developers through PFAN as part of the technical assistance activities of the REF.

For more information: http://pfan.net/.

\section{Renewable Energy Performance Platform, Sub-Saharan Africa}

\section{Background}

Renewable Energy Performance Platform (REPP) concept was initially developed by the European Investment Bank (EIB), although the funding is mainly provided by the Government of the United Kingdom. Also, the United Nations Environment Programme is part of the scheme and played a crucial role, especially in the design and implementation phase of REPP. The initiative was launched in 2015 with the aim to promote small and medium-sized renewable energy power generation projects up to $25 \mathrm{MW}$ in Sub-Saharan Africa, with a focus on project development support, viability gap funding, and facilitation of financial close. The current funding volume is $£ 48$ million (about $\$ 67$ million) and is provided by the United Kingdom Department of Business, Energy and Industrial Strategy.

\section{Description of the Scheme}

REPP focuses on projects in relatively advanced stage of development and provides these with funding and technical assistance to finalize project development stage and achieve bankability and financial close. The REPP manager is a private sector advisory company specializing in the sector and was selected through a competitive bidding process to run REPP. The team consists of about 10 experts. 
The main financing instruments of REPP are project development finance and viability gap finance for project developers. In addition, the REPP team provides help in connections with investors, financiers, and risk mitigation providers.

Project development finance is structured as risk finance to match with specific project development phase expenses of the projects as well as to be repaid with interest/return in case the project is successful. The project development funding has to be repaid if the project is successful. If the project is not successful, the developers do not have to repay the funding. To receive project development funding, the project should have an identifiable path and plan to bankability and financial close, including the specific activities, milestones, and related budget needed to finalize the project development stage. REPP funds specific well-defined expenses of the remaining project development activities, such as drafting of bankable PPA and ESIA, the developer also being requested to cover a share of these remaining expenses. In many cases, project development capital investments are in the range of $\$ 300,000$ $\$ 500,000$ per project, but in some cases can be even $\$ 700,000-\$ 900,000$.

In case the project is otherwise sound but there is a financing gap in the implementation phase or returns are not sufficient to compensate for the risk, REPP can also provide viability gap funding. This can be simple top-up premium, to complement the PPA the project has with the utility, or on top of the national feedin tariff price. In that sense, the REPP viability gap funding is similar with the GET FiT scheme described above. However, the REPP viability gap funding is provided on case-by-case basis, not through competitive bidding, and it can be much more flexible than GET FiT top-up premium. In case of every request, the team will carefully look at the project, its financial model, to see whether the viability gap financing could be tailored to be more commercial and repayable risk financing rather than a grant. For example, the funding can be provided as construction stage funding, then refinanced after COD or repayable from longer-term cash flows in case it is feasible from the project's cash flow perspective.

In addition to project development funding and viability gap funding, REPP team provides transaction support (i.e., technical assistance in financial issues). This includes help in financial structuring of the project, and identification of and matchmaking with suitable potential risk-mitigation providers, investors, and financiers.

\section{Governance Structure and Funding Sources}

The REPP Management Board is responsible for the high-level direction and strategic governance of the REPP. The Management Board includes one representative from all three founding partners of REPP: the EIB, United Kingdom Department of Business, Energy and Industrial Strategy, and UNEP Finance Initiative (UNEP FI).

The REPP Investment Committee assumes certain delegated responsibilities from the REPP Management Board, including the technical and financial assessments of individual projects. Its members represent the same three founding partners of REPP, and in addition the REPP manager. 
The REPP manager is responsible for the operation and implementation of the REPP. The REPP manager is a private sector financial advisory company specializing in clean energy finance in Africa and was awarded the REPP management contract based on a competitive bidding process. The REPP manager is responsible for creating and implementing the procedures for project identification, evaluation, structuring, negotiation, as well as portfolio management and monitoring. This work is done under the guidance by the REPP Management Board and Investment Committee. Based on approved strategic and other guidelines, the REPP manager operates independently and prepares financing proposals for approval by the REPP Investment Committee.

\section{Relevance and Lessons for Indonesia}

REPP is a good example of three interventions also needed to promote renewable energy investment in Indonesia: viability gap funding, project development funding, and technical assistance. It is interesting that REPP is fully based on case-by-case; bilateral; and first come, first served approach. For example, in contrast to GET FiT scheme as described above, REPP provides its viability gap funding case-by-case at the sole discretion of the REPP manager, therefore working almost like a private investor. The same approach is used in project development financing for projects.

The pros of this approach include that the financing can be better tailored as risk finance according to the specific features of each project, and in many cases is repayable in case the project is successful, therefore improving the financial sustainability of the fund. This also distorts the market less, as the finance is always "as commercial as possible." Also, the likelihood of achieving the financial close is higher as the project development financing is better planned, and REPP will look at the whole financing needs of project development, and ensure that REPP's and the developer's financial resources can realistically cover the remaining project development expenses to reach bankability. This is not necessarily as explicit in grant schemes based on calls for proposals. The expenses funded by REPP will not include salaries and costs of the developer, but is explicitly limited to procurement of certain well-defined professional services from third-party service providers, such as drafting of agreements and ESIAs.

The cons of this approach are that such case-by-case structuring is time-consuming and requires substantial personnel resources and skills. The approach works as long as the project volume is limited, such as below 10 projects per year. As the number of projects to be funded annually increases, the bilateral dealing with projects becomes increasingly burdensome, and it may be advisable to move to calls for proposals, meaning more standardization, less tailoring, but at the same time ability to provide funding for a larger number of projects. Another con of this approach is lack of competition, which can reach to unnecessarily high levels of funding, although to some extent this can be mitigated by professional evaluation, negotiation, and structuring by the management team. However, competitive bidding, when sufficient level of competition is available, can result to even lower amounts of funding requested by project developers. Case-by-case approach also leads to judgement calls without clear scoring or other decision-making criteria. This may be a challenge for some public sources of funding, which prefer clear and formal rules and criteria for project selection. 
For more information: https://repp.energy/.

\section{E. Competitive Bidding of Long-Term Premium Tariff, Finland}

\section{Background}

Finland introduced a feed-in tariff scheme for renewable energy in power generation in 2011. The target volume of 2,500 MW was achieved fast since the tariff level was considered generous. Consequently, the feed-in tariff scheme was replaced by a competitive auctioning of production premium. In this scheme, the renewable energy generators sell their generated electricity to wholesale power market at the prevailing market price (or separate contract with a wholesale buyer), and receive the premium on top of the price reveived from the market. This system is seen to be less market-distorting than the previous feed-in tariff scheme. The first premium auction round opened in November 2018, and the results were announced in the end of March 2019.

\section{Description of the Scheme}

The scheme is open for any renewable energy-based electricity generation project located in Finland that is not implemented before the auctioning. The scheme is technology netural in principle, although it is widely believed that the most competitive projects to be selected will be wind power projects. The bidders will bid for the premium they require on top of the electricity market price for 12 years of operation, and the lowest bids up to the volume to be auctioned are full. The target in the first auction will be annual estimated production of 1.4 TWh per annum, which in the good locations in Finland will mean about $400 \mathrm{MW}-500 \mathrm{MW}$ of installed capacity.

Unlike the premium tariff auction in Uganda GET FiT, the Finnish system does not include any qualitative criteria (such as domestic content), but will be solely based on price. The projects just need to fulfill certain minimum criteria regarding the technical specifications and readiness of the project to be implemented. Also, the bidders have to place a bid bond to avoid opportunistic bidders.

The scheme is a production subsidy without any other funding or technical assistance features, with the target being to contribute to the national renewable energy and climate targets of Finland.

\section{Governance Structure and Funding Sources}

The system is fully operated by the Energy Authority of Finland, which is supervised by the Ministry of the Economy and Employment. The funding will come from the general state budget, i.e., will be collected from taxpayers; there is no specific earmarked tax or charge to fund this scheme. Earlier when designing the feed-in tariff scheme, the plan was to pass the additional cost on to the end-users of electricity as a special charge in the electricity bill, but this turned out to be in a contradiction with the Constitution of Finland, and therefore the extra cost was finally funded from the 
state general budget. The same principle is followed in the funding of the premium tariff auction scheme.

After selection and implementation of the project, the generators will send their monthly generation data to the Energy Authority, which will then pay the premium according to the calculation method specified in the bidding process.

\section{Relevance and Lessons for Indonesia}

The Finnish scheme is an example of a competitive premium tariff scheme. Such schemes are far less used compared with competitive bidding of long-term PPAs. In this report, the exampes of Finland and Uganda represent the premium auction approach.

Indonesia and Finland are also very different from the electricity market perspective. While the Indonesian power market is dominated by the national state-owned monopoly utility, in Finland there is a fully competitive electricity market, where a producer can either sell to the power exchange at prevailing hourly spot price, and also use derivatives (such as forwards and options) to hedge the sales prices in the future. Moreover, a producer can also agree with a wholesale market buyer to sell its generation to this specific buyer as a bilateral over-the-counter transaction. Electricity consumers can buy electricity from whichever producer they want, and the transmission and distribution companies are responsible for operating the grids and distribute this electricity-based regulated transmission and distribution tariffs.

Therefore, the structure of price setting, premium calculation, and the auctioning procedure in Finland is probably not suitable in Indonesia, and are not explained in detail here.

For more information: https://www.roschier.com/newsroom/getting-ready-for-thenew-finnish-renewable-energy-support-scheme/.

\section{F. Accelerating Renewable Energy in Central America}

\section{Background}

The Accelerating Renewable Energy in Central America (ARECA) was established in 2007 to address the financial barriers especially faced by small and mediumsized renewable energy projects in Central American countries. Banks were not comfortable with the perceived risks associated with these projects; did not have expertise to evaluate these projects; had difficulties with the transaction costs involved with such small projects; and consequently the collateral requirements, debt pricing, and other terms of debt for these projects were prohibitive.

The aim of the ARECA was to initiate the market by providing a guarantee scheme, as well as capacity building and technical assistance for project developers and banks in order to improve the debt financing landscape for small and medium-sized renewable energy projects. The scheme has been run by the Central American Bank for Economic Integration (CABEI). 


\section{Description of the Scheme}

\section{Partial Credit Guarantee Scheme}

The ARECA program consists of a very small Partial Credit Guarantee Fund of only $\$ 5$ million, and a small fund for technical assistance of $\$ 600,000$. The technical assistance fund was supposed to be used to cover the remaining technical project design documents to achieve bankability. ARECA has not applied any competitive procedures, calls for proposals, or formalized procedures to solicit proposals from developers, but has identified and evaluated projects on first come, first served basis. The scheme targeted projects up to $10 \mathrm{MW}$ installed capacity.

By 2015, ARECA had supported nine projects by providing a partial credit guarantee. These projects are very small, ranging from about $10 \mathrm{~kW}$ solar photovoltaic systems to $3 \mathrm{MW}$ small hydropower projects, with a combined capacity of only about 7.2 MW. The total outstanding guarantee is $\$ 4.3$ million. In 2015 , ARECA was still evaluating three projects with capacities between $0.6 \mathrm{MW}$ and $5 \mathrm{MW}$ to commit the rest $\$ 700,000$ share of the $\$ 5$ million guarantee fund. ARECA was also able to get a further $\$ 2$ million funding commitment from the Government of Finland, bringing the total capacity of the ARECA Partial Credit Guarantee Fund to $\$ 7$ million.

In ARECA, the guarantee covered $75 \%$ of the debt, but only up to $\$ 500,000$. This low absolute cap for guaranteed loans probably also has been the reason why ARECA has supported very small projects on average. The guarantee fee of ARECA has been only $1.5 \%$ as applied, instead of the more typical range of 3\%-4\%. Coverage ratios and fee structures for individual projects were fixed so far, but there is discussion whether, in the next phase, these should be tailored case by case.

A remarkable achievement for ARECA has been its $0 \%$ default and loss rate so far, i.e., all loans provided by local banks to renewable energy projects have been performing well. To this end, there is discussion regarding increasing the leverage effect of the guarantee fund by increasing the guarantees without increasing the size of the guarantee fund. In practice, this means that, so far, the guarantee fund has had $\$ 1$ available for each dollar it has guaranteed. With the track record and data on portfolio performance gained so far, it is possible for the lenders could to trust the guarantee fund even if it guaranteed more loans than it has actual capital, since the banks themselves have learned to understand renewable energy sector, and they also see that (based on the actual data) it is very unlikely that all projects would default entirely.

\section{Technical Assistance Scheme}

ARECA has provided its technical assistance funding for 13 projects, with the most typical amount being $\$ 80,000$ or close to it, although in a couple of projects the amount has been only about $\$ 10,000-\$ 30,000$. Already these commitments have led to funding commitments exceeding ARECA's own budget, but, as the fund manager, CABEl has been able to use its other sources of funds to complete the limited ARECA technical assistance budget. In addition, CABEI has cofunded 15 
other renewable energy projects with other development finance institutions, totaling $\$ 1.4$ million, including contributions from other development finance institutions. Therefore, between 2007 and 2015, ARECA's limited \$600,000 technical assistance budget had mobilized $\$ 2$ million for 28 renewable energy projects from different funding sources to provide project development funding for developers.

The technical assistance to project developers has been in the form of traditional grants and allocated on first come, first served basis at the sole discretion of the fund manager team at CABEI. However, it has been recently discussed whether ARECA should change the technical assistance grants towards repayable grants or financing instruments for successful projects, if the technical assistance scheme was to be replenished.

An important feature of ARECA has been its strong efforts in gathering lessons and information dissemination. It is likely that ARECA's impact has reached far beyond the project developers and banks directly involved, and that, through the information dissemination activities, the knowledge and skills of these stakeholders have remarkably improved.

\section{Governance Structure and Funding Sources}

The ARECA program has been operatively managed by $C A B E I$ as the executing agency, which is the regional multilateral development bank in Central America, more specifically, CABEl's Department of Development and Competitivity.

The Project Coordination Unit at CABEI Department of Development and Competitivity was very narrowly resourced, consisting of only a project coordinator and a young professional to assist the coordinator. This has been seen as a mistake from the outset, since the active facilitation, project evaluation, support for project developers, and banks across the region as well as information dissemination would require much more personnel. Later, the team was expanded by adding two persons, located in different countries in the region, therefore remarkably improving the interaction between ARECA and the local stakeholders. Also, this was clearly seen as a remarkable increase in the speed of signing guarantee agreements by ARECA.

Since the project was funded by the Global Environment Facility (GEF), the regional office of the United Nations Development Programme (UNDP) has acted as the GEF implementing agency, responsible for day-to-day supervision of $\mathrm{CABEl}$, and monitoring of the fulfillment of the GEF objectives and requirements.

The ARECA Steering Committee consisted of representatives from CABEI, UNDP, the Central American Environment and Energy Commission, and the energy and environment ministries of all Central American countries in which ARECA operated. Also, other stakeholders were occasionally invited to the steering committee meetings, which were held once a year. The steering committee monitored the progress and achievement of the targets by ARECA program, the operational work by the Project Coordination Unit at CABEI, and provided strategic guidance. 
ARECA was initially fully funded by the GEF, but later the Government of Finland provided an additional $\$ 2$ million to the original $\$ 5$ million guarantee fund.

\section{Relevance and Lessons for Indonesia}

The challenges that the ARECA program targeted in Central America were very similar to those identified in the renewable energy sector in Indonesia:

(i) lack of appropriate financing structures,

(ii) high collateral and investor equity requirements,

(iii) lack of interest by large energy market participants in small projects,

(iv) high costs of project development costs, and

(v) lack of sector knowledge by local banks.

Also, the interventions of ARECA to tackle these challenges were very similar to the three funding windows proposed for Indonesia:

(i) improving the catalytic role of CABEl in strategically promoting increased lending on a project finance basis to small and medium-sized renewable energy projects,

(ii) increasing technical and financial capacities of CABEl and the local banking sector to finance these projects,

(iii) realizing a $\$ 5$ million GEF-funded partial credit guarantee facility to leverage the availability of equity and debt financing for renewable energy projects under $10 \mathrm{MW}$, and

(iv) establishing a $\$ 600,000$ technical assistance fund to develop final designs of eligible projects.

The ARECA program has shown that guarantee schemes can have a huge impact and leverage effect, but in order to succeed, all barriers need to be addressed. Since a guarantee can only solve part of typical challenges present in these projects, a successful guarantee instrument has to be complemented with other interventions, including technical assistance and capacity building at both debt provider and borrower sides. In the case of ARECA, technical assistance activity also included broader outreach and information dissemination activities, not only funding and other support for project developers. This was seen as having crucial impact on the development of the whole renewable energy financing market in the region.

Initially, ARECA was clearly underresourced, which was seen as slow implementation and low initial deal flow. The situation was improved when more staff were hired, who were deployed in the field, not only in the CABEl headquarters. As a comparison to REPP, although the latter being also financially much larger, REPP has an operative management team of capable and experienced private sector professionals of about 10 persons, including regional representatives, such financial, technical, and environment experts in the team. The staffing plan and respective budget have to be realistic and take into account the extent to which project level tailoring and structuring are needed. 
Although the guarantee provided partial coverage for credit risk faced by the banks, these still require collateral for the remaining uncovered part, and will typically never have an open position. Therefore, the developers still face the challenge to provide the needed collateral. Also, in the Indonesian context, it has to be considered how the remaining share of the debt will be guaranteed and how the project sponsors can provide the required equity contributions in addition to debt financing.

For more information (final evaluation report of ARECA): https://info.undp.org/docs/ pdc/Documents/HND/00043791\%20ARECA\%20Final\%20Report.pdf.

\section{G. Turkey Sustainable Energy Financing Facility, European Bank for Reconstruction and Development}

\section{Background}

Sustainable energy financing facilities (SEFFs) are the standardized credit line approach of the European Bank for Reconstruction and Development (EBRD) to promote debt financing for renewable energy and energy efficiency projects in its target countries. Through SEFFs, the EBRD extends credit lines to local financial institutions that seek to develop sustainable energy financing as a permanent area of business. Local financial institutions onlend the funds which they have received from the EBRD to their clients, which include small and medium-sized businesses, corporate and residential borrowers, and renewable energy project developers. In addition to credit lines, SEFFs always include a substantial budget and plan for capacity building, technical assistance, marketing, and other implementation support.

In this chapter the SEFF implemented in Turkey (TurSEFF) will be described as an example of EBRD's SEFFs.

\section{Description of the Scheme}

TurSEFF was established in 2010 to provide credit lines to local financial institutions for onlending to small and medium-sized enterprises to finance energy efficiency and renewable energy projects. The credit lines blend commercial lending of EBRD and the Japan Bank for International Cooperation with concessional lending from the Clean Technology Fund (CTF, part of the Climate Investment Funds), the total amount of lending capacity being $\$ 289$ million, most of it ( $\$ 222$ million) coming from EBRD as commercial debt. In addition to credit lines, a substantial amount of technical assistance was provided by the European Union (\$7.5 million) and CTF (\$2.4 million).

\section{Credit Lines}

The credit lines were allocated to local banks according to banks' own interests and activities, although these were naturally incentivized to do so, for example by using technical assistance to do awareness-raising and create demand for the loans in the market. 
All forms of renewable energy with project sizes up to $10 \mathrm{MW}$ were eligible. There were clear eligibility criteria for each project category. In the field of renewable energy and energy efficiency, the maximum size of loans was $\$ 5$ million per project.

Loans were provided on a first come, first served basis. The process involved the project developers sending a formal application with a feasibility study (or similar) for evaluation to the TurSEFF project implementation team and a bank having signed a credit line agreement. The project implementation team make its own evaluation and either approved or reject the project for TurSEFF funding. In parallel, the bank carries out its preliminary credit screening. If the outcomes of both TurSEFF project implementation team and bank are positive, a consultant will prepare a so-called Rational Energy Utilization Plan (REUP). A REUP summarizes the structure of the investment, ensuring it is cost effective and meets eligibility criteria. REUPs also help to identify suppliers and installers of recommended technologies and equipment and support the loan application to the partner bank. TurSEFF also included a system of eligible equipment and suppliers to be used. All this will help to reduce the transaction costs when dealing with small and medium-sized projects.

After a slow start, all funds are committed in credit lines for five local banks within 2-5 years. TurSEFF was so successful that it was later expanded with an establishment of a MidSEFF, targeting medium-sized renewable energy projects, with the maximum loan size increased to $\$ 50$ million.

\section{Technical Assistance}

In all SEFFs, including the TurSEFF, a substantial technical assistance plan with related budget has been mentioned as a key success factor. TurSEFF enjoyed an about $\$ 10$ million technical assistance support (i.e., about 3.3\% of the size of the available credit lines) from the European Union and the CTF. A projet implementation team consisting of both local and international experts was established to manage the implementation of the technical assistance and the TurSEFF as a whole. The technical assistance activities of TurSEFF consisted of the following activities:

(i) Promotion of TurSEFF. Targeted marketing campaigns and public awarenessraising created a recognizable financial brand.

(ii) Capacity building at local partner banks. Training enabled bank staff to identify, evaluate, and process sustainable energy projects. In addition, international and local experts were hired to support partner banks with the development and implementation of lending procedures and policies, including the formulation of eligibility criteria for sustainable energy loans. The experts also helped partner banks to monitor their evolving loan portfolios. This included both "in-the-class" training and "on-the-job" training.

(iii) Capacity building at local businesses. Advisory support was made available to local businesses and technical experts who received on-the-job-training and support in the preparation of energy audits and feasibility studies.

(iv) Monitoring and reporting. Independent experts carried out this task to avoid any conflict of interest during the assessment and evaluation of completed 
subprojects. The experts hired for this task were required to ensure that TurSEFF objectives were met and to confirm the completion of subprojects in accordance with the investment plans.

\section{Governance Structure and Funding Sources}

SEFFs are a "brand" of the EBRD, which was the primary sponsor of the TurSEFF. EBRD always works with other development finance institutions to cofinance the SEFFs. In case of the TurSEFF, the sources of funding are:

\section{Credit Line}

European Bank for Reconstruction and Development: \$222 million commercial debt

Japan Bank for International Cooperation: \$20 million commercial debt

Clean Technology Fund: \$47 million concessional debt

Total: \$289 million

\section{Technical Assistance}

European Union: $\$ 7.5$ million

Clean Technology Fund: \$2.4 million

Total: \$9.9 million

The core of the governance and management structure of the TurSEFF was EBRD's project implementation team, located in the country and consisting of both local and international experts to ensure all needed aspects of expertise, knowledge, skills, and networks needed to operate the facility efficiently. This team worked hands-on and on a daily basis with banks, project developers, and other stakeholders to promote the TurSEFF, identify and evaluate projects, and educate and negotiate with banks. The team is also responsible for monitoring and reporting to the EBRD and other funders to ensure that the facility is working within its mandate and progressing towards its objectives, and that other rules and regulations are followed.

\section{Relevance and Lessons for Indonesia}

The challenges faced by the renewable energy and energy efficiency sector of Turkey, to a large extent, were very similar to the ones faced by Indonesia.

(i) Investors lack familiarity with energy efficiency projects, and therefore misjudge the benefits and risks of such projects. Private sector investors often associate energy efficiency projects with high financial and technical risks and poor financial returns. In addition, upfront transaction costs, which may arise from energy audits and feasibility studies, can discourage investors. These costs can be increased by a lack of experience among the engineering service companies that would develop such projects.

(ii) Banks are not familiar with sustainable energy projects and have insufficient capacity to evaluate them. Most local banks have limited capacity and 
experience in identifying, evaluating, and processing energy efficiency and renewable energy projects. As a result, they offer few, if any, financial products designed specifically to finance sustainable energy projects, and require substantial technical assistance to develop such products.

(iii) Financial resources and dedicated lending facilities are scarce. Sustainable energy measures require long-term funding. In recent years financial institutions have had limited access to long-term financing, and in Turkey banks have traditionally relied on short-term financial products.

The SEFF concept, consisting of a credit line plus extensive technical assistance package, covers many of the similar activities outlined for Indonesia's potential scheme. It does not include viability gap funding and direct financing for project developers to cover costs and share risks of project development phase, but addresses the other aspects.

It is interesting that the TurSEFF started as a small-scale facility, providing loans of only up to $\$ 5$ million only at the project level and, in the subcategory of renewable energy, the maximum capacity was $10 \mathrm{MW}$. In the context of Indonesia, this could be suitable for IPP projects and electrification projects, but many larger (or mediumsized) projects could not benefit. Subject to availability of funds, and based on the success of the TurSEFF for small-scale projects, the TurSEFF was expanded by the introduction of MidSEFF, providing loans up to $\$ 50$ million per project, making it more meaningful for projects of $50 \mathrm{MW}$ or more.

It could be considered also in Indonesia, whether a smaller first phase of the fund could be taken first, supporting mainly IPP and electrification projects. Later, subject to the track record and lessons of the first phase and availability of funding, the fund could be expanded to provide loans for medium-sized projects, whith higher lending cap per project. This approach would give time to provide the PLN with capacity building and technical assistance to help integrate smaller plants in the first phase, and only thereafter dealing with larger individual, possibly intermittent, renewable energy plants.

For more information: http://www.turseff.org/. 


\section{Governance Structure of the Energy Resilience Fund}

\section{A. Introduction}

The Energy Resilience Fund is a public funding intervention mechanism and therefore, in addition to funders, governmental steering is crucial. This is ensured first by having the relevant ministries represented in the steering committee of the ERF. During the fact-finding mission, it became additionally evident that the two governmental/ semigovernmental entities most suitable to take the role as the fund manager would be the PT Sarana Multi Infrastruktur (SMI), a state-owned enterprise engaged in infrastructure project financing with its total capital shares owned by Indonesia through the Ministry of Finance and the BLU under the same ministry and its specific mitigation window under the Ministry of Environment and Forestry.

SMI already operates similar funds in various sectors and has many of the needed skills and expertise to operate the EFF. SMI is also an accredited entity by the Green Climate Fund, showing commitment to manage green funds, and is managing Indonesia's first green bond. However, the fact-finding mission also indicated that the current resources available at the SMI might be insufficient to take this responsibility.

The current understanding is that, in case of SMI being appointed the manager of the ERF, the number of capable personnel to manage the ERF would need to be strengthened. In addition, SMl's experience with viability gap funding is limited and, in the stakeholder meetings, it became evident that it would be recommendable to look for alternative governance and management structures for viability gap funding. For this reason, it is seen feasible to consider the BLU as the manager of the VGF vehicle as an economic incentive mechanism, while SMI would be managing the financial instruments, i.e., PDF and CEF windows.

Of the other relevant stakeholders needed to make the ERF a success the developers, banks, investors, and the PLN seem to be the most crucial ones. Failure of one of these stakeholders can lead to failure of the whole funding scheme by stalling any activities. According to the fact-finding mission, it is questionable whether these stakeholders have the needed expertise and incentives to play their roles to finance and implement renewable energy-based power generation projects. 
Therefore, the ERF should have a strong feature of technical assistance and capacity building offered for these multiple stakeholders, provide concrete additional value to these, and the ERF should be prepared to be the "renewable energy champion" to drive the change, at least initially. Reflecting against one of the main objectives of the ERF to build the market and capabilities, in addition to adding new renewable energy capacity, this means that the fund management and technical assistance activities should have proper budgets to respond to this challenge.

\section{B. Governance and Organizational Structure of the Energy Resilience Fund}

The operational management responsibility of the ERF would be divided between SMI and BLU. SMI would manage the PDF and CEF windows, whereas BLU would manage the VGF window. Using two entities to manage the funding windows may contain a risk of inefficient resourcing, duplication of certain functions, and coordination issues. However, in this case, the division between these could be justified since the PDF and credit enhancement funding windows would be fundamentally different from the viability gap funding window, and therefore different personnel resources and skillsets are required in each.

In project development and credit enhancement funding windows, project development and financial structuring skills are crucial, and these experts need to be experienced in this field. SMI already manages similar funding vehicles, and therefore it can be expected that it has good prerequisites to successfully manage these funding windows. On the other hand, VGF does not require that much project handson project development and financing skills, but rather expertise in running calls for proposals and bidding processes.

Further, it is proposed that the ERF and fund managers SMI and BLU would be supported by a strong team of experts, including local and international experts. Either one or both of these fund managers would contract a service provider through an international competitive bidding process. Since the contract would be a multiyear (and multimillion United States dollars) agreement, the fund managers can expect to attract and acquire the best experts, both domestically and internationally, to work on the fund management. Fund managers would establish a fund management unit consisting of its own personnel and the contracted service provider. This can be done in many ways, and the fund managers need to have certain level of freedom to organize the day-to-day operational fund management work between in-house experts and the contracted service provider.

However, several international experiences have shown the benefits of using an external private sector service provider working as a service provider for a public sector fund manager (or directly under a governing body consisting of funders). In fact, this is a typical arrangement. In practice, all of the case examples and success stories described in chapter $\mathrm{VI}$ include some kind of private sector service provider in the management of the financing vehicles. 
$\mathrm{SMI}$ and BLU would still be the formal and responsible fund manager and do the day-to-day work; manage, monitor, and report the work and progress to a steering committee, consisting of the funders and the relevant ministries. It could also include other crucial stakeholders such as PLN and the financial supervisory authority OJK, at least as observers.

The service provider team would work closely together with fund managers SMI and $\mathrm{BLU}$, but also relatively independently according to the mandate, targets, and clear key performance indicators (KPIs) provided by the steering committee, and supervized by and in close day-to-day cooperation with the SMI. The service provider team would evaluate projects; help negotiating deals between projects, investors, and financiers; and develop and prepare documentation and funding proposals to the SMI. SMI would formally make funding proposals to the steering committee based on the proposals prepared in cooperation with the service provider. The service provider would also identify needs for technical assistance and capacity building activities, and design and implement activities together with SMI and BLU.

Decisions made under each funding window would happen independently of other funding windows, i.e., being selected to receive VGF, PDF, or credit enhancement funding does not automatically imply receiving funding from other funding windows.

At the time of writing, $\mathrm{SMI}$ is in the process of establishing a new fund structure called SDG Indonesia One. According to the concept design, the fund has many similarities with the ERF proposed in this report. However, the SDG Indonesia One will be a broader concept both in terms of sectors covered and instruments to be offered. Since different sectors can be very different from a financing point of view, the SDG Indonesia One fund has to design more detailed sector-specific approaches and instruments. It would be recommendable to develop the renewable energy sector funding activities under SDG Indonesia One and the ERF in a coordinated manner. For example, the concept designs for the ERF as proposed in this report could be utilized when operationalizing the renewable energy sector financing activities within the SDG Indonesia One.

There are certain challenges identified with this structure, of which resourcing and mobilization of the activities is one. Notably, BLU is currently still a nonfunctional entity, and there will be need for proper resourcing to mobilize the BLU, and still there is a risk that it will take time. Also, the current capability and personnel resources of the SMI is probably insufficient and, in addition to an external private sector service provider, also SMl's internal resourcing needs to be strengthened.

It is proposed that, for all funding windows and the needed technical assistance and administration, funding and other resources for a team of 10-15 full-time persons would be reserved, including both funds, and both in-house personnel and the service provider team. These teams should additionally receive management 
and administrative support from at least $\mathrm{SMI}$ and relevant ministries. Of these personnel resource at least two thirds would be working in SMI and its service provider managing the PDF and credit enhancement funding windows, and the rest in the VGF window.

Although the technical assistance and capacity building are shown separately, it should not be considered as a separate funding window, but instead the activities would be embedded in the PDF and credit enhancement funding windows managed by $\mathrm{SMI}$ and used in tandem with these, as explained in the respective chapters in more detail. However, this activity is separately shown here because of to its great importance, resource needs, and the fact that it has to be well-planned and coordinated at the main ERF level in order to achieve the objectives of the ERF, although operationalized through PDF and credit enhancement funding windows.

An important issue is that the PDF and credit enhancement funding will be available to projects and project developers only, whereas technical assistance and capacity building will be also available to all the other relevant stakeholders involved with projects, such as banks, investors, and PLN, not developers and projects only.

One potential issue of concern in the governance structure is the tendency of risk aversion of the financial entities. During the fact-finding mission, some stakeholders expressed their concerns of general risk aversion of financiers, including SMI. The ERF would be exposed to a relatively high level of risk, especially the PDF window, and the manager(s) should be capable and willing to take this risk. This aspect should be addressed by setting clear targets and KPIs to incentivize sufficient (but balanced) risk-taking.

However, even if such incentives were introduced, there is still a potential problem with the so-called "state-loss" issue, meaning that, in case public funds are lost because of a risky investment, the fund manager could face serious legal consequences. This includes both the individuals making investment decisions, higher level directors of these organizations, and also these organizations as such. It was believed by some stakeholders that such state-loss issue is remarkably affecting decision-making in these institutions, and the issue should be explicitly addressed and managed if the ERF was established. Otherwise, any targets or KPIs would not have the desired impacts.

There are three main options proposed for the governance structure of the ERF. These can be further fine-tuned into suboptions. Each of the three main options include SMI and BLU as fund managers. The differences of the options are related to steering committee arrangements, organization, and procurement of the service provider team(s), and the potential linkages between SMI and BLU. The final choice of governance structure depends on the ministries and funding sources, and at this stage it is not possible to make one proposal regarding this aspect. 
Option 1 (Figure 6): Assuming the sources of funding are the same for all three funding windows, the ERF could consist of one steering committee only. It could also be considered to appoint SMI as the advisor of BLU, thereby making it faster to mobilize BLU. In fact, SMI already has a similar advisory role in the PPP scheme where it carries out project evaluations although it is not involved in decision-making in the PPP scheme. It is also possible to think this as an initial setup to mobilize the VGF faster, with more independence of BLU once it is up and running.

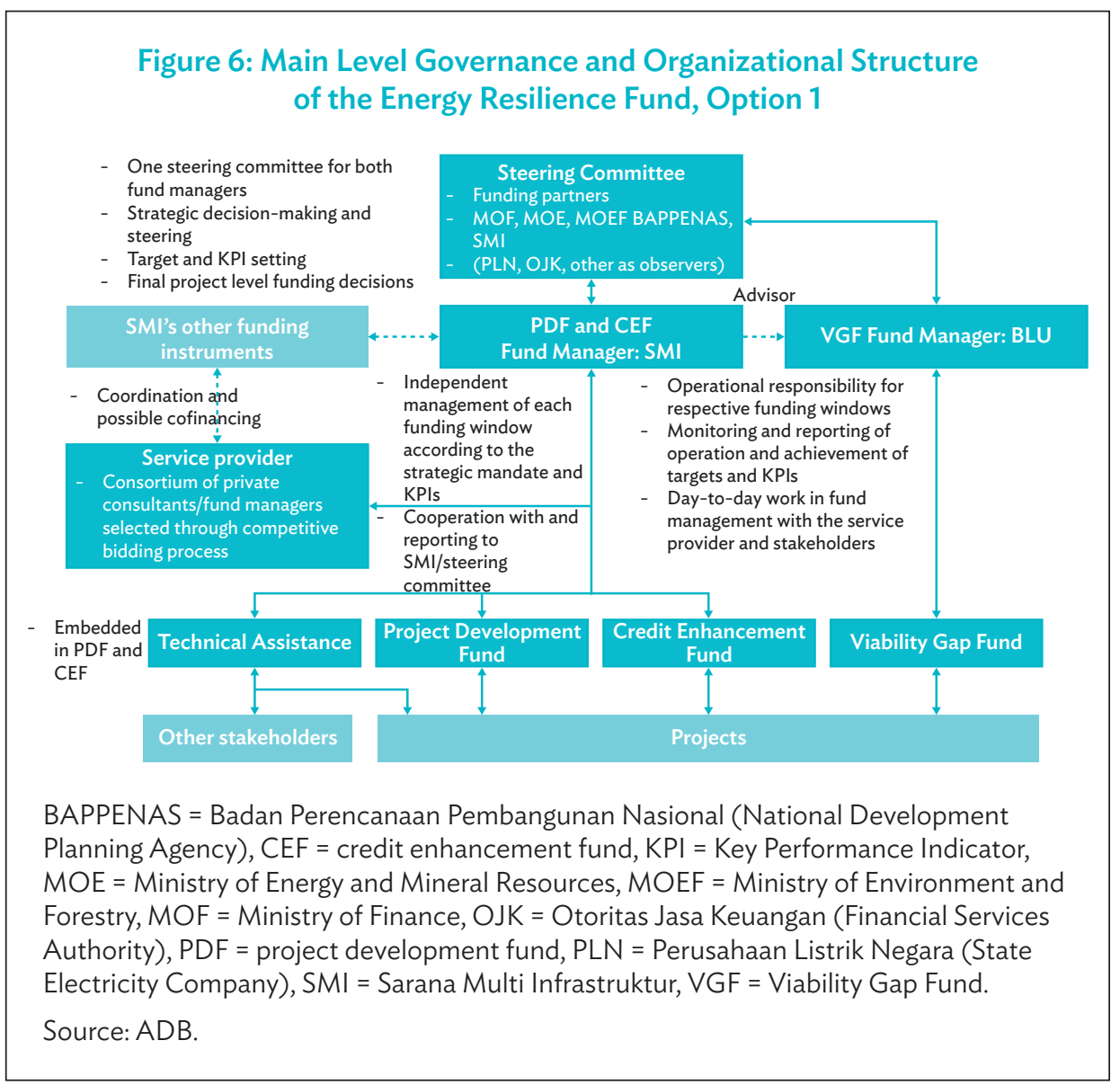


Option 2 (Figure 7): Assuming the sources of funds are different under funding windows, it could be recommendable to have separate steering committees for both $\mathrm{SMI}$ and BLU. Since the ministries and other stakeholders in both streering committees would be largely the same, this would enable sufficient steering group level coordination.

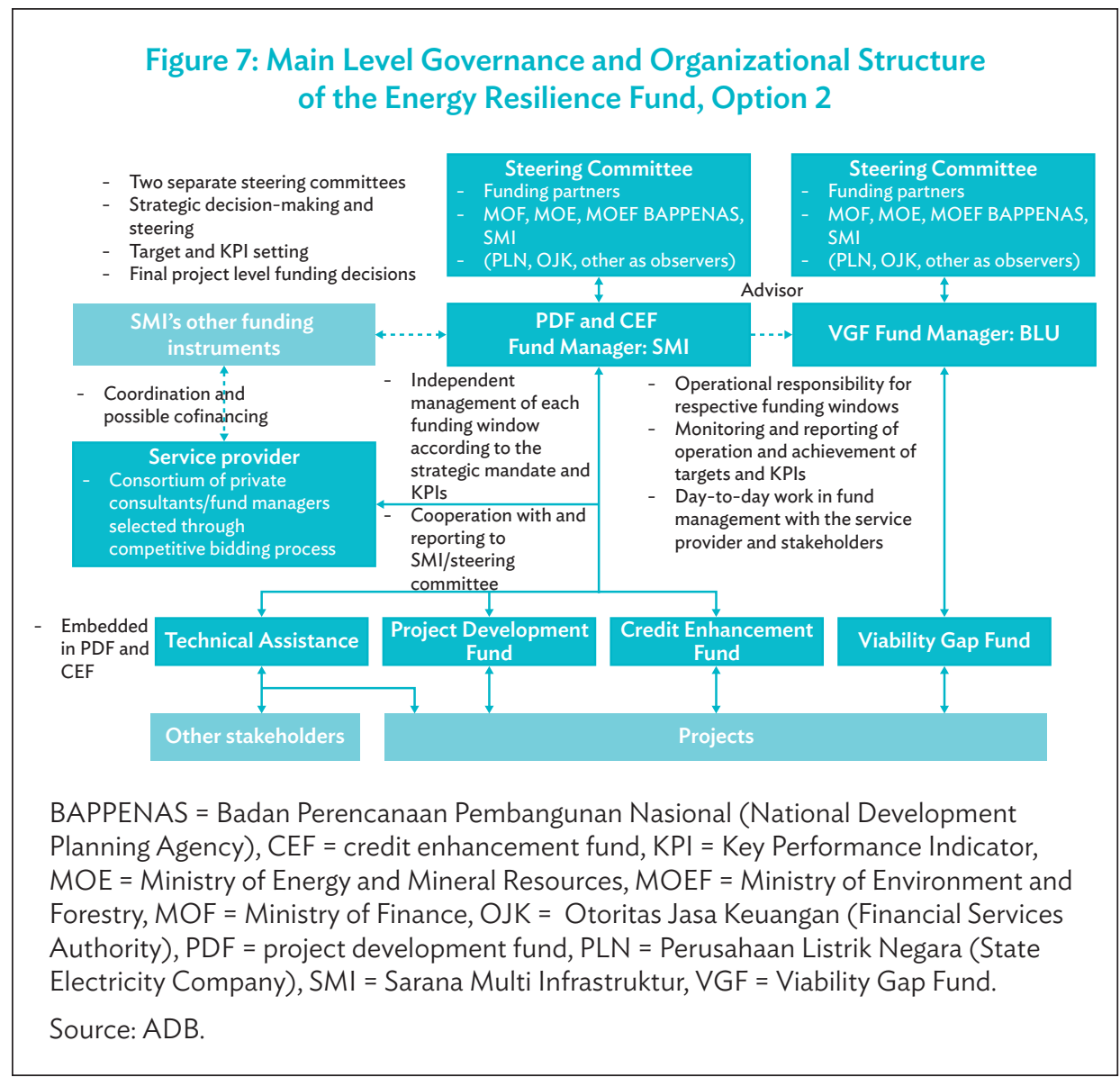


Option 3 (Figure 8): It would also be possible to establish PDF and CEF under the SMI and VGF under the BLU as entirely separate funds and respective governance structures. In this option, SMI does not have an advisory or other role in the BLU process, but the BLU would mobilize itself independently, and would have its own budget to contract a separate service provider for VGF. As mentioned, this alternative might still be efficient since the skill sets needed and the nature of the work are quite different anyway from PDF and CEF.

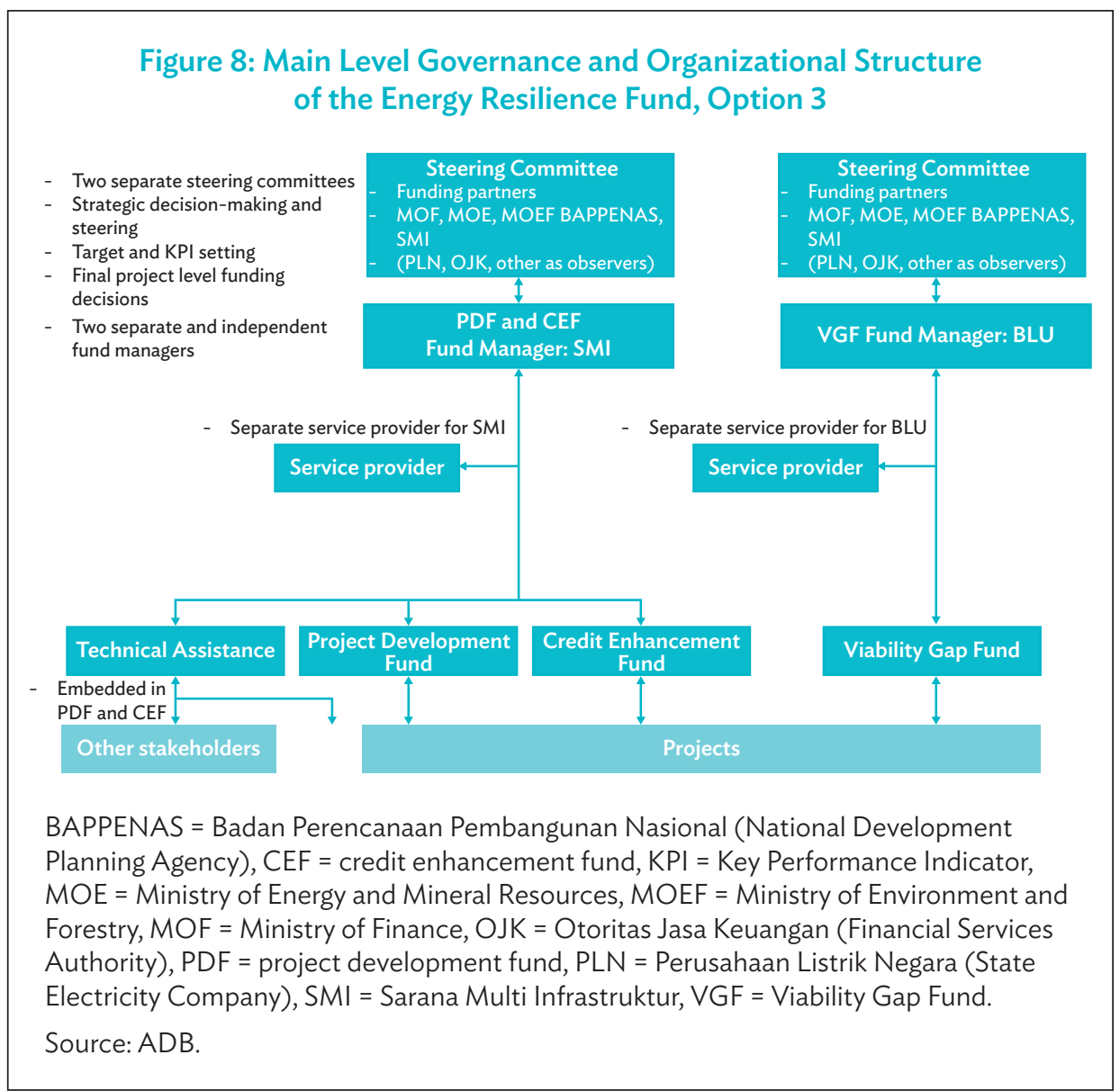




\section{Concept Design of the Viability Gap Fund}

\section{A. Description of the Instrument}

The VGF window would be a competitive bidding process for a premium tariff to top up the power price the developers have already secured through a PPA under the IPP scheme, concession under the electrification scheme, or other. Of the international example cases, it would be close to the competitive auctioning of top-up premium in the GET FiT scheme.

The premium would be payable by the fund to successful bidders in addition to the PPA price paid by PLN under the IPP scheme. Therefore, the projects would have two separate revenue streams from two different counterparties: the power off-taker and the VGF.

The premium tariff would be front-loaded to (i) be more attractive for investors because of the time value for money, (ii) help in construction stage financing by providing a share of VGF right after COD that can be used to refinance part of the construction stage finance, (iii) help in the early years project cash flow when debt service burden is often heavy, and (iv) shorten the time period required by the VGF to be involved and having to monitor the projects, and therefore improving the cost efficiency of the scheme.

\section{B. Eligibility Criteria}

1. The VGF would be available to small-scale projects only (at least IPP and electrification schemes); the size limit could be later expanded to larger projects depending on (a) funding volume, (b) experiences on the VGF scheme, and (c) experience gained by the PLN in the integration of renewable energy generation. (In Turkey, the small-scale scheme was later expanded to medium-sized projects after learning process, good track record, and higher market demand. The GET FiT scheme is being replicated in Zambia after positive experiences and lessons in Uganda.)

2. As a starting point, the VGF would be available to all technologies in all regions located in Indonesia.

3. However, the scheme could also be split according to technologies or regions, if this is seen as politically desirable. For example, there could be specific highpriority regions where the needed premium is expected to be higher than in other regions. If it is seen politically important to prioritize this region, the projects in that region could be allocated a separate bidding window in the auction, where the projects in the region would be competing against each other but not against projects in other regions. This would ensure that the targeted volume of new capacity for this specific region will be achieved. 
4. However, such arrangements will increase the average premium levels and lead to higher administrative cost of the scheme. In addition, if the bidding is broken down into too small windows with too few projects participating in the bidding, it might weaken the competition among projects, also contributing to higher cost of the system. Therefore, such arrangements must be carefully analysed beforehand.

5. The projects should be ready for construction ("shovel-ready") and must have already conditional commitments from all investors and lenders. This is needed to ensure that VGF does not commit funds to projects that will not be implemented.

(a) PPA or concession signed,

(b) grid connection cleared,

(c) financing secured (financing agreements ready with conditions precedent),

(d) needed other agreements in place, and

(e) needed ESIAs done and permits in place.

6. Domestic content requirements and possible other development-related minimum criteria.

\section{Determination of the Premium Tariff}

1. The bidders would be asked to provide a fixed $\$ / M W h$ (or rupiah/MWh) price they would require/need to make the project profitable, and implement it. The bidders can calculate this accurately as they know the financials of their projects, and have the agreement for the respective revenue stream (such as a PPA or a concession) signed when they participate in the auction. Because of the competitive situation, the bidders would have incentive to calculate the absolutely lowest level of top-up premium they would need.

2. The VGF level would be fixed, i.e., no inflation indexes included.

3. The payment would be front-loaded, and $50 \%$ of it would be paid upfront at the COD. The remaining VGF amount would be paid during the first 5 years of operation according to actual generation.

4. The $50 \%$ upfront payment would be calculated based on the estimated generation during 5 years at the commissioning, and would be considered a 50\% advance payment for the years 6-10 of generation. In the end of the top-up premium period (end of year 10), in case the cumulative generation during years 6-10 was lower than expected, the project would be required to repay the advance payment for the part of generation that did not occur (estimated cumulative volume at COD to calculate the advance payment minus actual cumulative volume in the end of the top-up premium period).

5. Alternatlively, the VGF could also be fully paid according to actual generation only during 5-10 years of operation.

6. One option to be explored in more detail would be a repayable VGF. In this structure, VGF would be fully disbursed during the loan period. Once the loan is fully repaid, the project would repay the VGF it has received. For example, the project receives the VGF during the first 5 years of operation, and has a loan with a tenor of 12 years. At the end of year 12 , the project would repay the VGF during years 13-20. Effectively, the VGF in this 
structure would be 20 years loan with 5 years drawdown schedule, 12 years grace period, and zero interest rate.

7. If the VGF need is large, this structure will not work since the repayment would reduce the IRR too much. On the other hand, if the VGF need is relatively small, such repayable VGF could work. In this assignment, it was not possible to calculate this in more detail, and such analyses would need to be made if this idea was to be explored further.

\section{Competitive Bidding Process, Ranking, and Contract Award}

1. Two-stage process with first prequalification round and second RfP round.

2. In the first stage (prequalification) the projects would be ranked according to

(a) experience and technical, organizational, and financial capablities of the project sponsor; and

(b) technical merits and status of the proposed project.

3. Projects meeting the minimum requirement of [e.g., 70]\% of maximum points will pass the prequalification stage, be short-listed to submit a full proposal, and receive the RfP documentation.

4. In the second stage (RfP), the projects would be ranked according to combination of price and quality

(a) (e.g., 70)\% of the points based on price; and

(b) (e.g., 30)\% of the points based on quality/technical proposal.

5. The technical criteria would be based on the eligibility criteria as well as on the prequalification stage scoring. Again, projects should reach at least 70\% of the maximum technical score in order to pass.

6. The financial proposals of projects that pass the minimum technical score would be opened, the lowest bid would get 100 points in financial score, and the rest of the projects would receive their points in relation to the lowest bid: [100 $\times$ lowest bid/own bid] points. For example, if the lowest bid is $\$ 10 / \mathrm{MWh}$, and another bid is $\$ 20 / \mathrm{MWh}$, latter bidder's financial score would be $[100 \times 10 / 20=50$ points $]$.

7. Based in the weighting of price (70\%) and technical score (30\%) the final combined score would be calculated as follows: [financial score $\times 0.7+$ technical score $\times 0.3]$.

8. The projects receiving the highest final combined score would be awarded the top-up premium at the price they have indicated in their proposal ("payas-bid"). The highest-scoring projects would be selected until the financial allocation in the bidding round would be fully committed, therefore setting the limit for projects to be awarded the premium tariff agreement.

9. Example of the schedule of a competitive bidding process:

(a) Submit the expressions of interest (Eols) by developers: deadline 3 months after publishing the prequalification documentation.

(b) Short-list projects by the VGF manager, sending the RfP documentation to the short-listed projects: 3 months after the deadline of Eol submissions.

(c) Submit full proposals: 3 months after short-listing and sending out the RfP documentation. 
(d) Score and rank the full proposals, publish the results, contract award: 2 months after the deadline of full proposals.

(e) Sign the premium tariff agreement between the project company and the VGF mnager: 1 month after contact award.

(f) Financial close and start of construction: within 12 months from signing the premium tariff agreement.

(g) COD: depending on project technology.

10. Therefore, the bidding process would take about 12 months from publishing the prequalification to signing the premium tariff agreement between VGF manager and the project owner. In practice, therefore, the VGF manager would always have to be preparing the new round partly in parallel with running the current round.

11. As an alternative to the combined price and technical scoring, the bidding process could have the technical and quality requirements as eligibility criteria only, and have the eligible projects evaluated and ranked purely based on price only. This could make the evaluation of the bids easier and more efficient.

An illustration of a possible timelime for one bidding round is in Table 2.

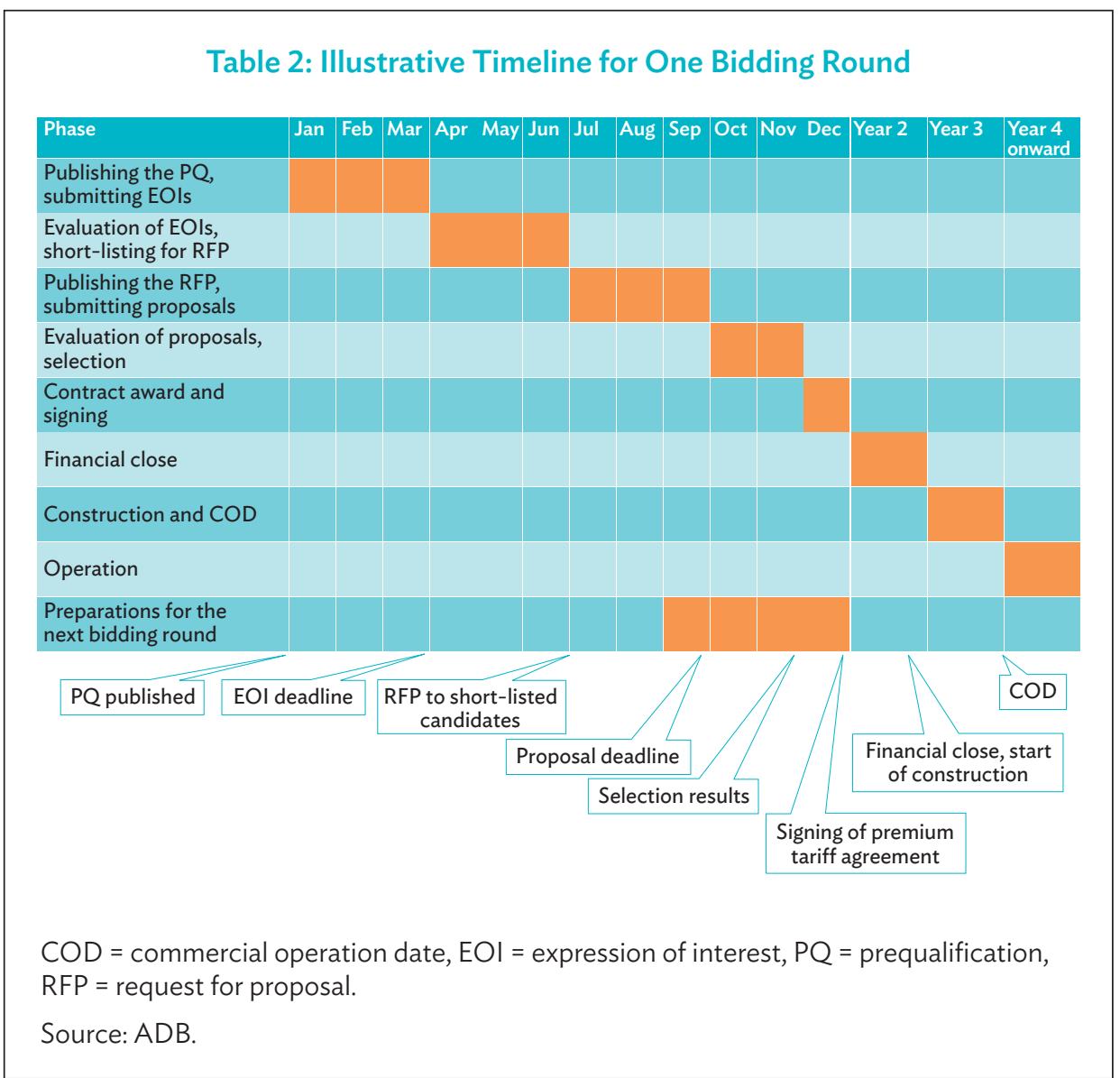




\section{E. Timing and Volume Considerations}

1. The bidding processes would be carried out once a year, five times during a period of 5 years.

2. The total amount of funding and its distribution between individual years and auctions would be defined or at least indicated in the beginning to help developers to develop their projects and businesses better, and to anticipate the upcoming auctions and expected volumes.

3. At least in the beginning, the volume would be indicated as the financial allocation rather than capacity or generation because of the uncertainty regarding the required VGF levels per project. If it turns out that the funding requirements are high, and the VGF had estimated lower support levels beforehand, it could not support as many projects as it planned beforehand, possibly leading to disappointments in the market because of lower-thanexpected volume of projects being awarded.

4. The maximum level of support per MWh and per project should be established before initiating the bidding process. These caps could be published, or they could be used as "hidden caps," which would be used in the scoring process, with financial proposals exceeding either of these caps being automatically rejected.

Figure 9 shows an example of funding requested by four projects in a bidding process. To illustrate the results in various situations, let us think of the two following cases. In both cases, all four projects have received exactly the same technical score (in order to simplify the example). In both cases, the total amount of funding available is $\$ 8$ million.

1. Case 1: There is no maximum caps for support per project or per MWh generated. Projects 1-3 will be awarded a premium tariff agreement since their cumulative VGF need is $\$ 6.5$ million, whereas adding project 4 would lead to exceeding the available budget, and therefore project 4 will be rejected. \$1.5 million will remain uncommitted in this round and can be rolled on to next rounds.

2. Case 2: There is an absolute cap for VGF set at $\$ 12 / \mathrm{MWh}$. Only projects 1 and 2 will be accepted since projects 3 and 4 exceed the maximum $\$ / M W h$ cap, even if there was still budget available to include project 3 in the list of winning projects. Therefore, $\$ 4.5$ million funds will remain uncommitted in this round and can be rolled on to next rounds.

Although a more detailed analysis on the expected premium tariff bids should be made, it can already be seen that the funding requirements may become extensive even if the requests were relatively modest and the VGF was focused on small projects only. As a minimum, the ERF should be prepared to a VGF of roughly $\$ 50$ million as a minimum in order to make a difference. 
Figure 9: Illustrative Example of Bid Premium

Tariff Levels in a Bidding Process

\begin{tabular}{lr}
\hline Project 1, Solar PV 5 MW & \\
Peak load hours per annum & $2,000.00$ \\
Annual generation, MWh/a & $10,000.00$ \\
Cumulative generation, 10 years & $100,000.00$ \\
Bid price for premium, $\$ / \mathrm{MWh}$ & 5.00 \\
Total funding request, $\$$ & $500,000.00$
\end{tabular}

\section{Project 3, Hydro 4 MW}

Peak load hours per annum Annual generation, MWh/a

Cumulative generation, 10 years

Bid price for premium, $\$ / \mathrm{MWh}$

Total funding request, $\$$
$20,000.00$

$200,000.00$

15.00

$3,000,000.00$

\begin{tabular}{lr}
\hline Project 2, Wind 10 MW \\
\hline Peak load hours per annum & $3,000.00$ \\
Annual generation, MWh/a & $30,000.00$ \\
Cumulative generation, 10 years & $300,000.00$ \\
Bid price for premium, \$/MWh & 10.00 \\
Total funding request, $\$$ & $3,000,000.00$
\end{tabular}

\section{Project 4, Hydro 3 MW}

Peak load hours per annum

Annual generation, MWh/a

Cumulative generation, 10 years

Bid price for premium, $\$ / \mathrm{MWh}$

Total funding request, $\$$

$M W=$ megawatt,$M W h$ = megawatt-hour, $M W h / a$ = megawatt hour per annum, $\mathrm{PV}=$ photovoltaic.

Source: ADB.

\section{F. Sanctions and Incentives}

1. Bid bond of [e.g., 3,000] $\$ / M W$ would be required to participate in the bidding process. This should be placed at the same time when submitting the full proposal in the second RfP stage of the process.

2. The bid bond should be in form of a standby letter of credit by a bank located in Indonesia.

3. The bidders who are not successful in the bidding process would have their bid bonds released/cancelled after the award of the VGF to the successful bidders.

4. The winning bidders shall double this bid bond to [e.g., 6,000] \$/MW after being awarded the top-up premium tariff, before signing the premium tariff agreement with the VGF manager (similar to a PPA).

5. The performance bond would be released/cancelled at COD and validation of the actual generation capacity.

6. In case the bidder withdraws from the process during the bidding or implementation phase, the bid bond or completion bond, respectively, would be claimed by the VGF fund manager, as a sanction for the bidder in failing to meet its obligations in the process.

7. In case the project misses the COD set in the premium tariff agreement (the rules of calculating the COD deadline is clearly defined in the RfP documentation already), the VGF manager will be able to claim part of the completion bond on a daily basis until the delayed project achieves the COD. The daily sanction would be [completion bond/180]. Therefore, after 6 months the whole completion bond would be fully depleted.

8. After 12 months of delay from the agreed COD, the VGF manager would have the right to terminate the premium tariff agreement at its sole discretion. 
9. If any of the eligibility criteria of a project is lost during the premium tariff agreement disbursement period (such as a bioenergy project switching to fossil fuels), the VGF manager has the right to terminate the premium tariff agreement at its sole discretion. In such a case, the project owner shall also repay the part of $50 \%$ advance payment it has received, but the respective generation has not been materialized by the date of the termination. For example, if the project has generated $75 \%$ of the expected cumulative generation as estimated at the COD and when determining the absolute amount/cap for the premium tariff available for the project, it has to return $25 \%$ of the received advance payment at the COD, which it has not generated by the termination of the contract. 


\section{Concept Design of the Project Development Fund}

\section{A. Description of the Instrument}

The PDF window would provide reimbursable grants and/or risk finance for development stage projects based on a continuous, bilateral, first come, first served evaluation, negotiation, and contract award process. This process will help to use the public funds more efficiently by increasing the likelihood of project success and by requiring successful projects to repay the funding (possibly with interest).

The projects to be funded through the PDF would be in an advanced stage of project development, i.e., preferably in the feasibility study phase where remarkable progress with regard to technical, economic, environmental and financial analyses, agreements, and permits has been made. The projects to be funded also need to demonstrate an identifiable path to financial close with explicit and detailed cost and timeline estimates.

Based on this identifiable path the developer and the PDF would agree on the sharing of the remaining costs so that all of them will be covered by either of them, therefore not only help projects "move forward" but really "achieve bankability and financial close." Therefore, in addition to advanced and active stage of development, the developer also needs to demonstrate the technical and financial capabilities to finalize the project development according to the detailed cost budget and timeline.

\section{B. Eligibility Criteria}

As the starting point, the PDF should be available to same type, size, and location of projects as the VGF, i.e., target the same main segments.

1. However, unlike the projects eligible for VGF, the projects eligible for PDF are not yet bankable earlier stage projects, often without PPAs or other secured revenue. They have remaining project development costs and risks that need to be covered and taken before reaching bankability. (They can include also projects with PPAs, but which still lack some crucial elements of bankability such as studies and permits.)

2. Although the projects are at an earlier stage, they need to be in "as advanced stage as possible." For example, early stage project ideas should not be considered since they are too far from financial close and have too many uncontrollable uncertainties. There should be no strict and clear-cut criteria for this, but the service provider and fund manager need to evaluate the whole project portfolio, 
and select the most suitable projects taking into account the project volume target of the PDF.

3. In addition to project quality and stage of development, the quality, track record, and resources of the project developer also must be among the eligibility criteria. The project developer needs to demonstrate sufficient capabilities to take the project to financial close.

4. In principle, "additionality" should be also an elibigibility criteria, meaning that the project faces a financing gap, which can be overcome in the existence of PDF. If it is obvious that the project development stage would be financed by the developer even in the absence of the PDF contribution, project development funding would not be additional, and the project should not be eligible for project development funding. In practice, proving additionality or non-additionality is complex and speculative since it requires contrafactual reasoning (what would happen if project development funding was not available). Proving a contrafactual statement at $100 \%$ certainty is impossible by definition. Therefore, although the additionality has to be part of the eligibility check of the projects to enhance the efficiency and leverage of public funding, a robust additionality analysis is not proposed, but rather a commonsense case-by-case evaluation and justification of the financial situation of the project.

\section{Main Terms and Conditions of the Project Development Fund}

Primarily, the PDF would be provided as risk finance for project developers, meaning that it would be repayable with interest or return in the first place, and concessional terms added only as required by a particular project. The main terms and conditions would be as follows:

1. The legal form of the instrument (from the ERF to project) could be either grant or a financial instrument. In case of grant, the structuring would make it effectively a financial instrument, however.

2. Within the boundaries of the investment strategy and more detailed targets by the steering committee, the fund manager and service provider would independently structure the funding to tailor it according to the specific needs, risks, and cash flow profiles of projects.

3. Irrespective of the legal form of the funding (whether a financial instrument or grant) the funding would resemble mezzanine loan or quasi-equity.

4. Funding would be repayable and carry a fixed interest rate.

5. However, the PDF financing would be repayable only in case the project is successful. If the project is not successful and not implemented (the definition to be clearly defined), the project sponsor/developer will not have a repayment obligation, and the financing will not be shown as a liability in the balance sheet of the project company.

6. Funding would be primarily repayable at the financial close (paid out of the construction finance package, which should include this repayment as an explicit investment cost item), but the fund manager and the project sponsor could also agree that the finance can be repayable out of project cash flow during the operational phase. This would help the sponsor to reach 
financial close in case a financing gap still exists after a successful project development stage.

7. Since the pricing of the PDF is likely to have a minor impact on the project IRR, it could be priced, to some extent, at commercial/semicommercial terms, meaning in practice double-digit interest rates. This pricing and repayment schedule should be tailored by the service provider and fund manager to ensure that it will not endanger the financial stability and existence of the project after financial close.

8. From the fund manager/service provider control point of view, in order to minimize administrative burden, a possible quasi-equity structure should include an explicit prearranged exit clause, and not active participation in the decision-making of the project company, since these tasks would add the administrative costs of fund management remarkably. Instead, the PDF financing agreement should include clear rules for the use of funds, covenants protecting the interests of the PDF, sufficient control of the use of funds (e.g., right to audit and approve each payment separately beforehand), and respective sanctions and control mechanisms to act if these rules or covenants are breached (such as termination and early expiration, possible step-in rights).

\section{Selection Process}

The service provider team, together with the fund manager, would identify projects and invite funding requests from these on a continuous basis without a specific solicitation or procurement procedure. Interested developers would submit the required information to the fund manager/service provider. This information should include:

1. background information of the project developer/sponsor;

2. detailed technical, economic, financial, environmental, and social description of the project;

3. activities and milestones achieved so far in project development, with specification of related costs;

4. detailed description of the remaining costs and planned timeline of the project to achieve bankability and financial close; and

5. detailed proposal of the sharing of these costs between the developer and the PDF, covering all the remaining costs in the project development process.

Based on this information, the fund manager and service provider would evaluate and make decisions whether to fund a specific project. The criteria for decision-making would be:

1. overall quality of the project and the developer (only credible projects having high probability of success will be considered, irrespective of the latter criteria; therefore, this is an important eligibility criterion);

2. stage of project development and expected timeline to bankability (more advanced projects to rank higher); 
3. remaining costs of development (the less costs needed to achieve bankability, the higher ranking); and

4. share of the costs borne by the developer (the smaller share of remaining costs requested from the PDF, the higher ranking).

The process looks like a normal investment process of a private fund, being based on bilateral negotiations, evaluation, and enabling detailed structuring and tailoring of the finance. From documentation and decision-making perspective, the process is as follows:

1. initial contact between the developer and the fund manager/service provider, submission of general information by the developer, including an estimation of needed investment;

2. evaluation of general information by service provider; in case the initial eligibility is fulfilled, request for detailed information;

3. submission of full set of information by the developer with a detailed finalization plan, budget, and cost sharing;

4. evaluation and requests for additional information and clarifications by the service provider, close interaction enabling the fund manager to acquire good understanding of the project;

5. in case of a project fulfilling the criteria, proposal prepared by the service provider to the fund manager (or by the fund manager) to start drafting a term sheet (otherwise, rejection of the project and end of process);

6. upon approval by the fund manager, the service provider drafts a term sheet for funding, submits to the developer for review and comments;

7. initial term sheet negotiation between service provider (or fund manager) and developer;

8. once term sheet negotiation is finalized, submission by service provider to fund manager for evaluation and approval; signing of the term sheet between the developer and the fund manager;

9. after signing the term sheet and based on it, drafting of financing agreement, start of due diligence process;

10. submission of the financing agreement for approval by the steering committee and signing by the fund manager, once the agreement negotiation and due diligence are finalized;

11. implementation of the financing agreement; disbursements according to agreed milestones and actual expenses, supervision in procurement of services by the project developer;

12. monitoring and reporting of the project portfolio progress by service provider to fund manager and steering committee; and

13. in case a project reaches financial close, a request for repayment of financing (with possible interest/return) sent by the fund manager; in case of project failure (which needs to be clearly defined in the agreement), write-off by the fund manager.

The possible project evaluation, contract negotiation, and signing process is illustrated in Figure 10. 
Figure 10: Deal Process of the Project Development Fund

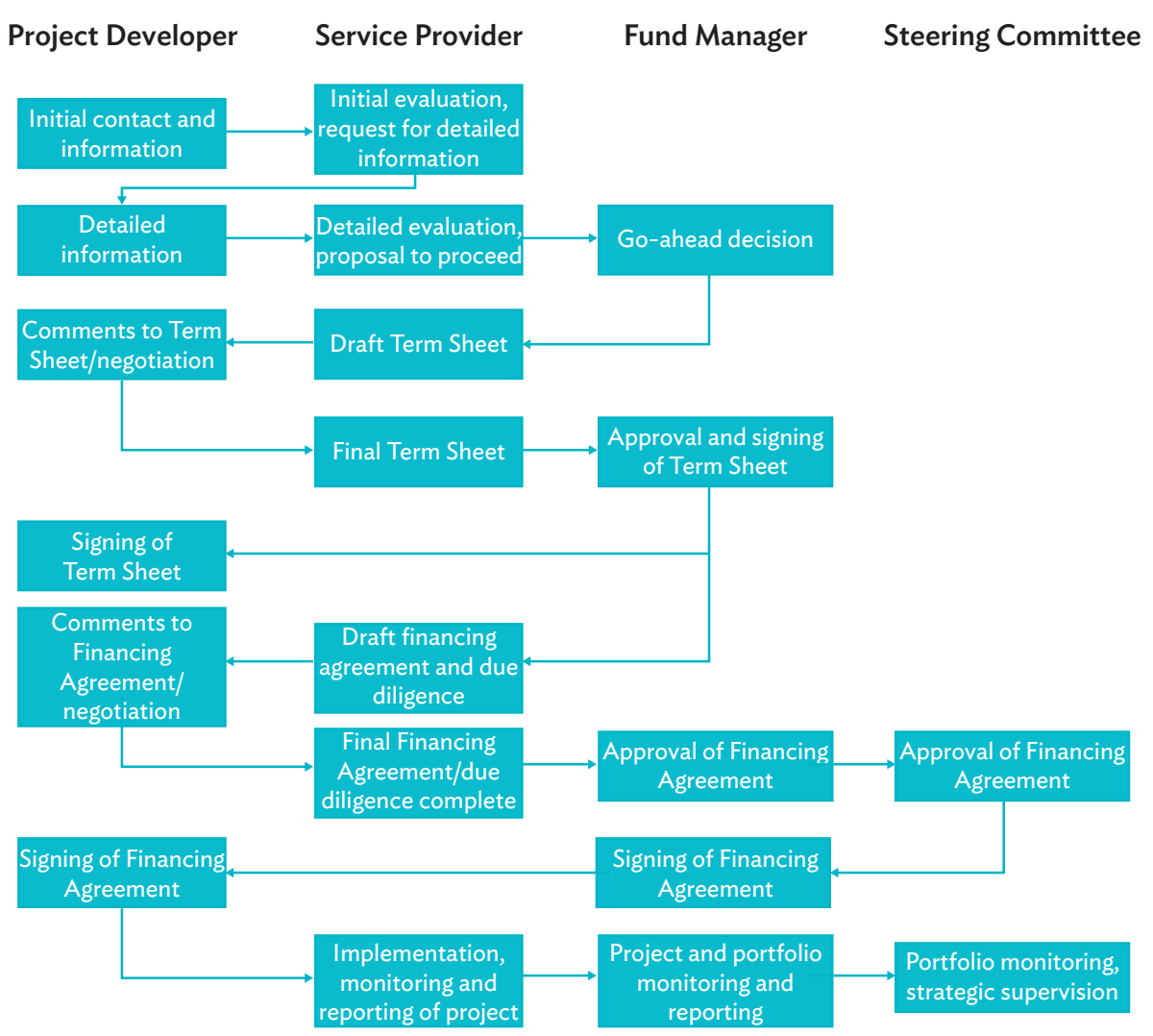

Source: ADB.

\section{E. Timing and Volume Considerations}

The bilateral first come, first served procedure with case-specific tailoring and structuring works well as long as the amount of projects is relatively limited, roughly up to 10 projects per year, preferably less. If the target volume exceeds 10 per annum, it may become more efficient to use CfP and more standardized form of funding. In such case, the financing can be in form of reimbursable grants, i.e., projects need to repay if the projects are implemented, but the terms and conditions of the funding cannot be tailored according to projects, which can make the repayment more difficult for some projects.

In this proposal, the amount of projects receiving PDF is roughly 5-10 per annum, and therefore $25-50$ projects during the 5 years commitment/investment period of the ERF, and therefore the tailored bilateral first come, first served approach is proposed. The service provider team supported by the fund manager can be expected to deal with such volume, in parallel with other tasks and responsibilities. 
Funding need per project can vary considerably. Project development costs can easily be $\$ 1$ million or much more, even in relatively small projects. As it is expected that the project has already incurred considerable project development costs when applying for funding from PDF, and as the developers is required to cover a remarkable share of project development costs by themselves, the typical finaning commitments by the PDF would be in the range of $\$ 100,000-\$ 500,000$ with an average of $\$ 200,000$ $\$ 300,000$ per project. The assumption is that the PDF will not finance the early stage exploration of geothermal projects, which has a specific funding and risk profile and needs to be addressed by specific geothermal energy development funding instruments. Geothermal projects that are applying for project development funding under the ERF are likely to have passed this exploration phase successfully.

Based on the above, a rough range of the funding volume needed in the PDF would be $\$ 5$ million- $\$ 15$ million, which must be understood as the order of magnitude. It must also be noted that some of the first funding commitments to successful projects will be paid back to the ERF during the 5 years' investment period, and these funds can be reinvested in the projects in the later years of the 5 years' commitment period. Therefore, the actual funding need is likely to be slightly smaller. These numbers do not take into account the expenses of fund management and other technical assistance provided by the fund manager and service provider to developers and other stakeholders.

In addition to financing capacity, the PDF will also need a considerable management budget, which is likely to be at least $\$ 1$ million per year during the 5 years investment period, i.e., at least $\$ 5$ million in total during this period, and a much smaller amount after that. This cost is high compared with the relatively limited amount of project development funding. However, if part of the management budget was transferred to investment capacity of the PDF, it could invest in some more projects or larger tickets. But the quality of deals would be worse, leading to more losses.

\section{F. Technical Assistance Linked to the Project Development Fund}

In addition to providing direct funding for project developers, the service provider and fund manager will need to provide both broader capacity building and more projectspecific technical assistance to project developers since one of the main objectives of the ERF is to build the market and capabilities, and improve the investment framework more broadly. The broader capacity building means a planned program of seminars, workshops, trainings, and other events addressing specific project development issues, such as site selection, resource assessment, grid integration, financial planning and fundraising, procurement of equipment. Also, in this process, support from steering group members is expected (funders and relevant ministries, regulators and other stakeholders).

The latter means more ad hoc support of the developers who receive funding from the PDF. These developers often need help and advice in their day-to-day activities, such as identifying suitable investors and financiers (and in the discussions with them) as well as professional service providers to carry out the needed studies and 
analyses. This technical assistance is mainly directed at the developers but can include ad hoc support to other stakeholders related to the project. As an example, in this respect, the PDF could cooperate with the Private Financing Advisory Network (see international experiences and success stories in chapter $\mathrm{VI}$ ) or similar to channel financial advisory services for projects.

Further, the PDF (see also CEF later) should include a plan for information dissemination on best practices and possibly market data. This should be designed in a way that it does not form an obstacle for developers to use project development funding because of confidentiality issues, but at the same time, in a planned way, to make sure that best practices, hard data on risks and other useful market information will be available for a larger audience, including market players, regulators, and policy makers. PDF financing agreements should include specific clauses on certain reporting requirements to enable information collection and disseminaton that does not endanger confidentiality, but at the same time adds value to market players, regulators, and policy makers.

The PDF and related technical assistance should also be planned in close interaction with the PLN as a crucial stakeholder for projects, with a remarkable effort in capacity building and technical assistance directed at PLN too. 


\section{Concept Design of the Credit Enhancement Fund}

\section{A. Description of the Instrument}

The CEF window would consist of either Partial Credit Guarantee Fund or Credit Line Fund, or it could be a combination thereof. In this chapter, both options are included, indicating the combination of the two instruments. The project selection would happen on the basis of a continuous; bilateral; first come, first served evaluation; negotiation; and deal-closing process.

CEF would offer the guarantee and/or credit line for banks at predefined terms, conditions, pricing, and tenors that would be similar to all interested or eligible banks. Primary financing instrument offered would be the guarantee, but CEF could provide credit line instead, depending on banks' capability and interest. The project identification, evaluation, negotiation, and deal-closing process would be primarily driven and managed by banks (and developers). However, as it can be expected that the knowsledge, capacity, and perhaps even the motivation of the banks to evaluate, negotiate, and close renewable energy deals are limited, the service provider and fund manager sould be closely involved in the process to support and motivate participating banks, and ensure that the debt capital market for renewable energy is active.

\section{B. Eligibility Criteria}

The eligibility in the case of CEF needs to be defined for both participating banks and projects. However, for banks, the eligibility criteria can be relatively liberal. The banks need to operate in the corporate and/or project finance market in Indonesia. They should demonstrate capability and interest in promoting their clean energy lending practice, and they should meet the requirements by the financial market regulator OJK. It is suggested that the detailed eligibility criteria will be defined in cooperation with the OJK, who has also worked to establish green lending practices in Indonesia.

Regarding eligibility of projects, as the starting point, the CEF should be available for same type, size, and location of projects as the VGF and PDF, i.e., target the same main segments.

1. However, while the projects eligible for PDF are earlier-stage projects, the projects eligible for CEF should be close to bankable and investment-ready. CEF can provide soft commitments (e.g., comfort letters and indicative nonbinding offers), but not give its full commitment before the projects are ready for construction. In practice, the financing agreement can be signed at the final stages of financial arrangements, but shall have all the actions needed to make the project 
construction ready as conditions of precedent with clear deadlines. By this, CEF will make sure (a) its projects are only used when all needed financing and other conditions to implement the project are absolutely in place, and (b) in case a project is not able to fulfil the conditions precedent, the funds conditionally committed to that project can be freed and used in another project. This is the typical approach by lenders and is suggested for CEF too.

2. In short, the eligibility criteria for projects should mirror the typical requirements by banks, including the project and sponsor quality, bankability of all documentation, agreements, studies, financial projections and revenue certainty, and availability of all other components of financing.

3. In principle, additionality should be also an elibigibility criteria, meaning that the project faces a financing gap, which can be overcome with the existence of CEF. If it is obvious that the project would be fully financed even in the absence of the CEF contribution, the credit enhancement funding would not be additional and the project should not be eligible for credit enhancement funding. In practice, proving additionality or non-additionality is complex and speculative since it requires contrafactual reasoning (what would happen if credit enhancement funding was not available). Proving a contrafactual statement at $100 \%$ certainty is impossible by definition. Therefore, although the additionality has to be part of the eligibility check of projects to enhance the efficiency and leverage of public funding, a robust additionality analysis is not proposed, but rather a common-sense case-bycase evaluation and justification of the financial situation of the project.

\section{Main Terms and Conditions of the Credit Enhancement Fund}

The main terms of the guarantee instrument would be:

1. The guarantee would be partial credit guarantee, i.e., it would offer protection for the lender in all default cases by the borrower, irrespective of the reason (in contrast to partial risk guarantee, which would only cover defaults because of specific risks).

2. The guarantee would be on pari passu basis, meaning that the guarantee would cover only its pro rata share of losses starting from first rupiah/dollar of materialized loss (in contrast to first loss scheme, which would cover $100 \%$ of losses up to a certain amount). This will reduce the risk of moral hazard as lenders and borrowers would have the same incentive to avoid default situations.

3. The guarantee would cover up to $80 \%$ of losses per project, with maximum share of $50 \%$ of total project cost, and average (or target, or typical) guarantee amount being about $70 \%$. Assuming the debt/equity ratio in projects is about 60/40-70/30, the guarantee would end up covering typically about $40 \%-50 \%$ of total investment cost, the rest being covered by investors and financiers.

4. To some extent, the pricing of the fund would be concessional, perhaps in the range of $2 \%-3 \%$ (3\%-5\% possibly being already commercial and possibly 
ensuring the financial sustainability of the guarantee fund), in order to help drive down the total cost of financing of projects.

5. In addition to reducing the total cost of finance for the project, the guarantee scheme would help to extend tenors by providing guarantee tenors between 10 years and 15 years (defined and agreed case by case)

6. The CEF could provide indicative term sheets/conditional financing agreements for the bidders in the VGF scheme to help reduce the premium bid prices, and this link should be actively coordinated and promoted by the fund manager and service provider.

7. The CEF support would be conditional to all project development- and financial close-related aspects as explained above, and therefore, when bidding, the project developer/sponsor would take the risk of possibly being awarded VGF, but not being able to reach financial close and therefore not reaching the eligibility for $C E F$.

The main terms of the credit line instrument would be:

1. The credit lines would be provided for the lenders that could blend the credit lines in their own lending.

2. The maximum amount of funding through the credit line would be $50 \%$ of the total cost, as in the guarantee scheme. For example, in a project having debt/equity ratio of $70 / 30$, the credit line could provide $40 \%-50 \%$, the bank itself 20\%-30\%, and the investor(s) $30 \%$ as equity/mezzanine finance. Even in this case, the investors should be able to provide $20 \%-30 \%$ of additional collateral for the lenders share of the debt. Therefore, the sponsors/investors would still need to be able to provide at least $50 \%$ of the total investment cost in the form of equity and collateral.

3. The disbursements from the fund would be made on a pro rata basis with the lender. For example, if the CEF provides $70 \%$ of the loan for the project through a credit line, and the bank $30 \%$ of the total debt, the individual disbursements during construction stage would always be done on 70/30 basis between the CEF credit line and the lender's own balance sheet.

4. The credit line would have normal eligibility and disbursement criteria typically applied by lenders (see above), and therefore the terms and conditions of the credit line would be similar to normal loans in many aspects.

5. However, the credit line would be priced competitively, meaning single-digit rupiah interest rates (or low-single-digit United States dollar interest rates), driving down the total cost of finaning for projects.

6. In addition, like in the guarantee scheme, the credit line would offer tenors of 10-15 years, helping the financial structuring of projects and improving the equity returns.

7. In the first place, the credit line would not provide specific grace periods and concessional elements, other than pricing and tenor. 


\section{Selection Process}

Like the PDF, the VGF also would be based on ongoing, bilateral, case-by-case negotiations, not CfP or other competitive procedures. This will enable the needed project level evaluation and structuring that is needed to help projects in reaching financial close and using the public funds efficiently at the same time.

This process would be primarily established by the banks, not the CEF, which would merely support banks in their work. Therefore, the information needs and the procedure would be typical loan negotiation processes. The documentation requests would aim to ensure that the projects are bankable (permit procedures and needed studies, assessments and analyses finalized, needed agreements either signed or ready to be signed, all other financing unconditionally committed). Like the loan by the lending bank, the credit enhancement funding/guarantee would become unconditional only when everything is ready for the main equipment purchase/engineering, procurement, and construction agreements to be signed and construction to start. Of course, the agreement could be signed earlier with conditions precedent to be fulfilled before the signed agreement actually enters into force.

Although the project evaluation and negotiation procedure would be tightly linked to banks' own procedures, the CEF would need to play an active role in the identification, evaluation, and due diligence together with the banks. In practice, the developer would approach both a bank (or two to three banks) and the CEF with an initial application and information package. This would create a trilateral process where CEF would provide active support to the developer to run the process and to the potential lender(s) to understand and evaluate the project, and to price and set other terms and conditions of the loan agreement.

Therefore, from the impact of the fund point of view, it is crucial that the CEF would not remain a passive guarantee or credit line provider for the banks, but would actively work in the frontline as a visible player. This requires personnel resources, and deep technical, financial, and project development skills from the fund manager and service provider. Therefore, a crucial success factor of the CEF would be sufficient resourcing of this activity, including both local and international experts.

\section{E. Timing and Volume Considerations}

The CEF, like the ERF as a whole, would have an "investment period" of 5 years, i.e., it would need to be planned so that, by the end of year 5 , all available funds have been fully committed to projects. Since there is likely to be a considerable challenge in building the market itself and creating both demand and supply of funding, the first years will require more market and project identification and technical assistance, which would be seen as lower deal volume in the early years, and increasing towards the end of the investment period. A realistic amount of deals closed in a year could be, for example, a few projects per annum in the beginning, reaching 5 and more after a couple of years, and up to 10 projects in the latter years of the investment period, 
assuming that the banks will play an increasingly active and independent role after the learning phase in the first half of the investment period.

In total, this could mean in the order of magnitude of 25-30 projects receiving credit enhancement funding. This should be seen in relation to the existing pipeline of about 45 IPP projects with PPAs, electrification projects, and possible other project types included in the eligibility criteria of the CEF and the whole ERF. Therefore, the indicative sizing of the CEF could address a remarkable share of the total project portfolio. Depending on the quality and readiness of the fund (and VGF's and PDF's ability to bring projects to bankability and financial close), it might not be recommended to have at least a bigger fund initially, since in that case there would be a risk of the market of bankable projects being too small for the CEF, and therefore part of the funds remaining uncommitted in the end of the investment period.

Assuming the project's average investment cost is somewhere close to $\$ 10$ million, the rough initial sizing assumption for more detailed work could be about $\$ 100$ million- $\$ 150$ million CEF scheme + the needed fund management and technical assistance budget that could add (again rough order of magnitude) $\$ 10$ million- $\$ 15$ million to the total budget. Of course, it has to be kept in mind that most of the funds would be repaid with interest, the latter covering a share of the management and technical assistance budget.

\section{F. Technical Assistance Linked to the Credit Enhancement Fund}

Like the PDF, the CEF should include a large concerted technical assistance and capability-building effort targeted at the key players in the market, primarily the lenders (banks and possible other debt providers) and developers, but also regulators, the PLN, and local service providers (including consultants and engineers), who also play a critical role in making projects bankable.

The technical assistance would mainly happen in the following ways. These activities have turned out to be critical in many other markets to create an active renewable energy market:

1. Broader capacity building through general awareness-raising seminars, and more specific and targeted workshops aimet at improving specific skills of specific stakeholders. For example, the latter can include training for developers and technical consultants in bankable resource assessments, bankable technical and other studies and assessments, training for PLN in grid connection and balance management in grids with variable renewable energy generation.

2. Hands-on work with banks and developers in developing efficient processes to identify and evaluate projects, negotiate loan facilities, and carry out due diligence processes.

3. Active information dissemination work to disclose information on the results of the ERF. This should be designed in a way that it does not form an obstacle for developers, investors, and lenders to use credit-enhancement funding because of confidentiality issues, but at the same time in a planned 
way to make sure that best practices, hard data on risks, and other useful market information will be available for a larger audience. CEF financing agreements might even include specific clauses on certain reporting requirements to enable information disseminaton.

The primary responsibility in carrying out these tasks (as defined in detail in the the strategy, targets, and KPIs) is with the fund manager, which, in turn, would outsource much of the practical activities to the service provider. The fund manager and the steering committee members (relevant ministries and financiers) would also have a role in the technical assistance and capacity building activities.

Regarding technical assistance and capacity building offered for banks, OJK's role also should be strengthened. OJK has already worked for years with banks to promote green lending by providing training and other capacity building. In the stakeholder meetings, it was highlighted that this activity has helped building expertise at the individual level, but more effort should be devoted to achieving institutional level changes. 


\section{Capitalization Structure and Potential Sources of Funding}

he three funding windows (and the related technical assistance and capacity
building), as presented above, are fundamentally different cases from potential
funding sources point of view.

\section{A. Viability Gap Funding}

\section{Type of Viability Gap Funding}

VGF is clearly a subsidy mechanism. In principle, although it could be possible that such premium tariff could be repaid in some cases-being more like very long-term concessional debt-in most cases, such front-loading of cash flow is not sufficient, but the funding needs to be in form of revenue-based subsidy. Moreover, different sectors to be supported can be very different from funders' point of view.

VGF for grid-connected IPP projects complementing the PPA revenues from PLN can be seen as subsidy for PLN, enabling it to buy power cheaper than it could do otherwise. This will enable cheaper electricity for end-users. However, as a starting point, tariff level of gridconnected electricity provided by a state utility should be cost reflective, and such subsidy mechanism may seem questionable from donor perspective.

On the other hand, VGF for electrification projects is contributing to feasibility of projects in areas currently without access to electricity. In such areas, both the higher system costs as well as the lower payment capability of end-users may make such projects unfeasible as a starting point (not to talk about risks), which has justified subsidy interventions by donor countries or their development finance institutions in many similar cases around the world.

Therefore, as an example, the VGF in the IPP sector may be more difficult to justify for any third-party financier, at least unless the Government of Indonesia makes a strong contribution to such VGF scheme. Also, in the electrification sector, the host government contribution would be crucial, but it can also be assumed that the foreign "appetite" for such instrument would be higher because of positive development impacts.

As the viability gap funding is direct support, there are no commercial features in this funding. The VGF is also difficult to blend in any such way that would enable a "commercial tranche" offered for any financier with commercial or semicommercial requirements. Therefore, the VGF is likely to be funded through grants only by such bilateral and international financiers who can provide pure grants. 


\section{Sizing of Viability Gap Funding}

In the scope of this study, it has not been possible to make a detailed analysis of the amount of needed financing for the VGF. This analysis should include analysis of the price levels, tenors, and other terms and conditions of the current and contemplated PPAs; concessions; and other revenue streams of projects being developed. This data should be combined with expert studies on the respective financial modeling of these investments. Although the pricing in the VGF scheme would finally be determined by the competitive bidding process, this analysis is required beforehand to estimate the expected or needed size of the VGF.

However, there is some investment modeling done on the VGF needs, although these calculations have not been published. Based on this modeling work and through discussions with renewable energy experts in Indonesia, it was possible to roughly estimate the order of magnitude of the potential viability gap funding window. The estimate is based on the following assumptions:

(a) The number of projects in 5 years' period would be about 25-30 (i.e., 5-6 projects awarded with VGF per year), with average capacity of $5 \mathrm{MW}$ $10 \mathrm{MW}$, leading to roughly $150 \mathrm{MW}-300 \mathrm{MW}$ of cumulative capacity.

(b) Of the total capacity, $80 \%$ would be small hydro with 7,000 peak load hours per year (about $80 \%$ capacity factor), $10 \%$ would be solar photovoltaic with 1,750 (about $20 \%$ capacity factor), and $10 \%$ wind with 2,600 peak load hours per year (about $30 \%$ capacity factor). This would lead to weighted average of about 6,000 peak load hours per year.

(c) The financial modeling period is 20 years, in line with the current BOOT structure of the PPAs.

(d) The discount rate per annum is $3 \%$. This is considerably lower than a commercial discount rate, and therefore the viability gaps resulting from this example calculation are likely to be underestimations to some extent.

(e) The VGF would be provided at 50\% upfront and then 50\% according to actual generation during the first 5 years, i.e., equal to the assumed 10 years of cumulative generation.

(f) The required premium has been calculated as follows (based on expert opinions):

(i) estimated hydropower viability gap: $\$ 500,000 / \mathrm{MW}$

- assuming 7,000 peak load hours annually, i.e., 70,000 MWh in 10 years, the viability gap per $\mathrm{MWh}$ would be $\$ 500,000 / 70,000 \mathrm{MWh} \approx \$ 7 / \mathrm{MWh}$;

(ii) estimated wind power viability gap: $\$ 400,000 / \mathrm{MW}$

- assuming 2,600 peak load hours annually, i.e., 26,000 MWh in 10 years, the viability gap per $\mathrm{MWh}$ would be $\$ 400,000 / 26,000 \mathrm{MWh} \approx \$ 15 / \mathrm{MWh}$; and

(iii) estimated solar photovoltaic viability gap: $\$ 60,000 / \mathrm{MW}$

- assuming 1,750 peak load hours annually, i.e., 17,500 MWh in 10 years, the viability gap per MWh would be $\$ 60,000 / 17,500 \mathrm{MWh}$ $\approx \$ 3.5 / \mathrm{MWh}$. 
Based on the above assumption, an average VGF need of $\$ 7.5 / \mathrm{MWh}$ can be derived. Table 3 shows potential funding needs at the VGF range of $\$ 5-\$ 10 / \mathrm{MWh}$ and at cumulative installed capacity of $150 \mathrm{MW}-300 \mathrm{MW}$.

\begin{tabular}{|c|c|c|c|c|}
\hline \multicolumn{5}{|c|}{$\begin{array}{c}\text { Table 3: Illustration of Potential Viability Gap Fund Sizing } \\
\text { at Different Assumptions on Support per Megawatt- } \\
\text { Hour and Targeted Cumulative Capacity }\end{array}$} \\
\hline \multirow{6}{*}{ 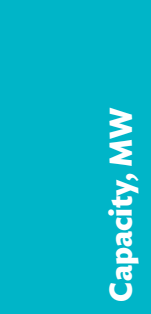 } & \multicolumn{3}{|c|}{ VGF support, \$/MWh } & \\
\hline & & 5 & 7.5 & 10 \\
\hline & 150 & $45,262,550$ & $67,893,750$ & $90,525,000$ \\
\hline & 200 & $60,350,000$ & $90,525,000$ & $120,700,000$ \\
\hline & 250 & $75,437,500$ & $113,156,250$ & $150,875,000$ \\
\hline & 300 & $90,525,000$ & $135,787,500$ & $181,050,000$ \\
\hline $\begin{array}{l}M W=\text { mega } \\
\text { Source: } A D E\end{array}$ & gawatt- & our, VGF = Viab & ty Gap Fund. & \\
\hline
\end{tabular}

From this illustrative example, already it can be seen that, at a relatively low cumulative volumes and support levels, the funding volume of the VGF becomes relatively high, close to $\$ 100$ million after $200 \mathrm{MW}$ cumulative capacity and $\$ 7.5 / \mathrm{MWh}$ is exceeded. This can be compared also against the specific investment cost, whereby a premium level of $\$ 7.5 / \mathrm{MWh}$ is equal to average $\$ 450,000 / \mathrm{MW}$ VGF requirement. Due to time value for money, the subsidy required by investors would be slightly lower if it was provided $100 \%$ as upfront subsidy (since money received by an investor today is more valuable for it, compared with money received in future), but this illustration still shows the order of magnitude.

\section{Sources of Viability Gap Funding}

As mentioned above, the viability gap funding needs to be traditional grant funding from sources operating with such funding. In addition, the contribution by the Government of Indonesia is crucial, especially in the case of VGF for IPP projects.

\section{Therefore, the viability gap funding could be split between IPP/grid-connected projects on one hand, and electrification projects on the other hand. The former} would be entirely/primarily funded by the Government of Indonesia. The latter would be funded for large part/entirely by external climate or development finance.

Examples of potential sources of external climate or development finance could include the following. The listed candidates are either currently large financiers in Indonesia and in the Association of Southeast Asian Nations (ASEAN) region, and/or financers of similar schemes in other countries:

(a) German development cooperation through GIZ (Germany) is already working on a guarantee scheme for IPP projects, shares the same interest. 
(b) Agence Française de Développement (AFD, French Development Agency) (France) is already providing grant financing to fund a guarantee instrument for construction stage financing of related projects in Indonesia.

(c) German development cooperation through KfW (Germany) has designed and implemented the GET FiT scheme in Uganda and Zambia and is actively promoting it as a success story. GET FiT is similar premium tariff based on competitive bidding as suggested for VGF, and the brand could be also used in Indonesia, therefore increasing KfW's interest to replicate the scheme in the country.

(d) The Department of Business, Energy and Industrial Strategy, BEIS (United Kingdom) is cofinancing the GET FiT in Africa together with KfW, as well as many other related initiatives.

(e) The Government of Norway is cofinancing the GET FiT in Africa together with $\mathrm{KfW}$, as well as many other related initiatives.

(f) The European Union is cofinancing the GET FiT in Africa together with KfW, as well as many other related initiatives.

(g) The United States Agency for International Development (United States) is among the largest development financiers in Indonesia and can provide grant financing, and is active in the field globally.

(h) The Japan International Cooperation Agency (Japan) is among the largest development financiers in Indonesia and can provide grant financing, and is active in the ASEAN region.

(i) The Government of Australia is among the largest development financiers in Indonesia and can provide grant financing, and is active in the ASEAN region.

(j) UNDP (international) has shown initial interest for a guarantee scheme for IPP projects in Indonesia.

(k) The Climate Investment Funds (international) is able to provide grant funding combined with multilateral development bank funding. Therefore, participation and leadership by ADB or the World Bank would be needed to mobilize climate investment funding.

(I) The Green Climate Fund (international) is able to provide grant financing for transformative interventions. As an accredited entity by the GCF, SMI would help in applying funding. In principle, also ADB could act as the accredited entity.

\section{B. Project Development Funding}

\section{Type of Project Development Funding}

In principle, project development funding is risk finance, which could be commercial or semicommercial since, if projects are successful and implemented, there is usually a business case to repay a share of development costs, as this is relatively low compared with total investment cost of a project and, therefore, has a limited impact on profitability. This would also decrease the risk of market distortion; both developers would be in a more equal position between themselves (no one receiving pure free money). Also, in cases where private finance may be available, the project development funding would not crowd out private finance as easily, and would therefore cause less capital market distortion. 
Similar schemes have typically been funded by donor grants (such as the similar REPP scheme described in chapter VI.D). This would be the most recommendable form of funding sought in this case too. However, the attractiveness of the scheme from donors' and development and climate finance institutions' perspective could be increased by blending a traditional grant element with a reimbursable grant or equity component. Of more commercial development financial institutions are sought for, a preferred equity or mezzanine loan tranche could be added on top of the reimbursable grant or equity tranche. In principle, these tranches could be split into even more tranches; for example, having both grant, reimbursable grant, equity, and mezzanine loan tranches. If the track record of the PDF is good, the market is expanding, and the PDF is expanded, it could be possible to add a senior loan tranche on top of the initial tranches. However, this is probably not realistic nor needed in the first phase of the PDF. An illustration of the structuring and possible blending is described in Table 4.

\section{Table 4: Basic Structuring and Capitalization of the Project Development Fund (In relation to funding needs)}

Funding Source

Senior loan, in case the PDF is expanded

Preferred equity, mezzanine/junior loan

Reimbursable grant, equity

Grant

PDF = project development fund.

Source: ADB.

\section{PDF Financing Component}

Project development investments in the form of reimbursable grants, mezzanine loans, and/or quasi-equity

Management and technical assistance

In this kind of a blending structure, the grant funding would work as a risk buffer for equity investors, as well as cover the relatively high transaction costs required to successfully run the PDF. In order to strike a balance between equity tranche risks and returns, majority of the equity invested could have a fixed return like a debt instrument and, therefore, not be in form of common/ordinary share. The fund manager and service provider would then set their targets and budget to (i) achieve the investment volume target of the PDF, (ii) provide technical assistance to project developers and other stakeholders, (iii) resource its own management and administrative functions properly but efficiently, and (iv) create the fixed return to equity tranche investors.

\section{Sizing of Project Development Funding}

As already discussed in chapter IX.E, the meaningful funding per project in small to medium-sized renewable energy projects is typically between $\$ 100,000$ and $\$ 500,000$. Smaller than $\$ 100,000$ may not make a difference when real bankable studies, agreements, and related documentation needs to be done, while sums exceeding $\$ 500,000$ start to be excessive compared with total project development 
cost, of which the developers should cover major part. In addition, a remarkable share of project development cost should already be incurred by the developer before the intervention by the PDF, and the remaining costs should be divided between the two. Therefore, the average PDF investment per project would probably fall between $\$ 200,000$ and $\$ 300,000$.

Regarding project volume, the PDF should be able to invest in five projects per annum as a minimum to make a difference in the market, but the project-specific tailoring and structuring of projects may not allow more than 10 investments per annum (probably less). Assuming an investment period of 5 years, the PDF could invest in 25-50 projects (the higher value being probably quite optimistic).

On top of this, the management of the PDF will require a properly large and experienced team, with an annual budget being in the range of \$0.5 million-\$1.0 million.

The size of the PDF could be estimated to be $\$ 5$ million- $\$ 15$ million for investment and $\$ 2.5$ million- $\$ 5$ million for management. This would also include the technical assistance provided by the fund manager and the service provider team.

\section{Potential Sources of Project Development Funding}

For example, bilateral development financial institutions offering commercial or semicommercial financing could be considered. While the grant component could be provided by similar institutions as described in the case of VGF, the equity component could be provided by the same institutions, plus the following:

1. European bilateral development finance institutions such as

(i) Nederlandse Financierings-Maatschappij voor Ontwikkelingslanden N.V. (FMO, Netherlands Development Finance Company) (Netherlands),

(ii) Belgian Investment Company for Developing Countries (BIO) (Belgium),

(iii) Proparco (private sector development finance institution of France), and

(iv) Compañía Española de Financiación del Desarrollo (COFIDES) (Spain).

These institutions have invested in other development and climate finance instruments, targeting financial sustainability as such. In contrast to the bilateral institutions mentioned in case of VGF (such as the AFD), these institutions typically cannot provide grant funding but will rather "invest" or "finance" instruments (such as Proparco, the private sector arm of the AFD).

(b) International impact funds, philanthropies and foundations such as

(i) Grameen Foundation;

(ii) Blue Orchard;

(iii) Oxfam Novib; 
(iv) Rockefeller Foundation;

(v) Packard Foundation's Carol Larson, Susan Phinney Silver;

(vi) Kresge Foundation's Rip Rapson;

(vii) MacArthur Foundation;

(viii) DOEN Foundations;

(ix) Calvert Impact Capital;

(x) Baldwin Brothers;

(xi) MCE Social Capital;

(xii) Facebook Energy Access Program; and

(xiii) Leonardo DiCaprio Foundation.

These instutions have joined bilateral and multinational development and climate finance institutions in financing vehicles aiming at financial sustainability, such as the three first ones investing in TCX, which offers currency risk mitigation instruments in developing countries. The rest have been active in small-scale solar in developing countries. Although all of these have invested in similar risk positions, some of these may be too risk averse for the purposes of PDF.

Also, it has to be noted that many of these may prefer off-grid projects over gridconnected ones, while most of them would probably have no formal restrictions regarding the latter.

\section{Credit Enhancement Funding}

\section{Type of Credit Enhancement Funding}

CEF provides semicommercial funding between the CEF and projects, i.e., the funding to projects include repayment obligations (or in case of a guarantee, the guarantee is intended to be released gradually during the respective debt repayment period. On the other hand, CEF would include relatively heavy management, administration, transaction, and technical assistance costs, which will not be repaid/covered by the projects or other stakeholders. In addition, the CEF guarantee/credit line instrument as such may have to take higher than commercial risks (depending on the detailed mandate and strategy), possibly leading to losses that are higher than the returns from interest and fees paid by project companies.

Therefore, the funding of the CEF instrument could be partly repayable (reimbursable grants or financial instruments) but would need to be partly in form of grants, at least for the share covering the management, administrative, transaction, and technical assistance costs. Therefore, the credit enhancement funding and capitalization structure of the CEF could be similar to the PDF. While the repayments and possible returns from the PDF will occur primarily during a few years from the investments (short term financing), in the case of CEF the funds are committed to long-term guarantees and/or credit lines (10-15 years). However, the basic instruments can be same for both PDF and CEF. The basic structuring of the capitalization of the CEF is shown in Table 5. 


\section{Table 5: Basic Structuring and Capitalization of the Credit Enhancement Fund (In relation to funding needs)}

Funding Source

Senior loan, in case the CEF is expanded

Preferred equity, mezzanine/junior loan

Reimbursable grant, equity

Grant

$\mathrm{CEF}=$ Credit Enhancement Fund.

\section{CEF Financing Component}

Long-term guarantees and/or credit lines for projects in construction stage, committed at financial closing

Management and technical assistance

Source: ADB.

\section{Sizing of Credit Enhancement Funding}

As discussed in chapter X.E, the CEF window could realistically provide funding for 25-30 projects during a 5 years investment period. This indicative sizing of the CEF could address a remarkable share of the total project portfolio, but also acknowledging the probably thin bankable project pipeline that exists currently and can be developed within a few years, and also taking into account that one fund alone should not be funding the whole pipeline (or market portfolio, using the concepts of economic theory).

Assuming the project's average investment cost is somewhere close to $\$ 10$ million, the rough initial sizing assumption for more detailed work could be about $\$ 100$ million-\$150 million CEF scheme + the needed fund management and technical assistance budget that could add (again rough order of magnitude) in the tune of $\$ 15$ million to the total budget (assuming management and technical assistance costs at $2 \%-3 \%$ per annum during the first 5 years investment period, then much lower. Of course, most of the funds would be repaid with interest, the interest/guarantee fee covering a share, or even all of the management and technical assistance budget.

This sizing should be seen as phase 1 of the CEF, aiming to get the current project pipeline alive. If the track record of the CEF is good, and if the market starts expanding, it could be justified to expand the fund, including both increasing its capitalization, but also enabling it to fund larger projects.

\section{Potential Sources of Credit Enhancement Funding}

Since the funding structure of the CEF would be very similar to PDF, the potential funding sources of the PDF described in chapter XI.B.3 would apply to credit enhancement funding too. As a first option, these two funding windows should be "sold" as one investment opportunity to donors and development and climate finance institutions. The VGF instead, although being an integral part of the whole concept, should have a different capitalization structure and also partly different target 
financiers, since it is more a direct subsidy mechanism for targeted projects compared with PDF and CEF, which are primarly financing instruments towards projects.

\section{Summary}

From the above elaboration of total funding needs, a rough order of magnitude of $\$ 150$ million- $\$ 400$ million to be used as funding towards the projects, and $\$ 15$ million- $\$ 20$ million (or $\$ 3$ million- $\$ 4$ million per year) for management, transaction, and technical assistance. These figures should be regarded as examples only, meant to help in rough sizing and conceptualization of the ERF, and the more detailed and realistic estimate will need a lot more data and analysis. Especially, the uncertainty regrading the required viability gap funding is high. The CEF assumption is probably more accurate "ballpark figure," and the estimate for project development funding needs are probably the most realistic one, and could even be considered an estimate, unlike the two other figures.

Table 6 shows the proposed capitalization plan for the ERF split between different components of the ERF. The PDF and CEF returns could also cover a remarkable part of the management and technical assistance funding, depending on to what extent this money needs to be repaid to the funding sources with possible interest/return.

Table 6: Summary of the Capitalization vis-a-vis Components of the Energy Resilience Fund

\section{Source of Funds/Capital Stack}

Quasi-equity/mezzanine debt

Reimbursable grant/equity

Grant

Grant

\section{Energy Resilience Fund Component}

Project development funding and Credit enhancement funding

Viability Gap Fund

Technical assistance and capacity building

Management and administration

Source: ADB. 


\section{Conclusion}

\section{A. General}

The situation of renewable energy market in Indonesia is very challenging, and the sector is facing multiple barriers. In this assignment and report, an attempt has been made to design a set of financial interventions that can help mobilize the sector in its current situation. However, some of the barriers are such that they cannot be solved by financial interventions only, but reforms to legal and regulatory environment, for example, have to be made in parallel. Moreover, the proposed financial interventions are not meant to be a comprehensive long term-solution to decarbonize the Indonesian power sector and achieve the climate targets set in the Nationally Determined Contributions of Indonesia, but rather find solutions to start moving forward and gain experience, build capacity, and improve the investment framework in general by mobilizing and implementing projects in the ongoing project pipeline. New, larger, and more efficient inverventions will be needed in the following phases to respond to the huge power sector investment needs in the coming decade.

The proposed solution is based on an ERF, consisting of three separate funding windows: VGF, PDF, and CEF (Figure 11). A relatively detailed concept for each fund has been presented in this report. However, the proposals should be treated as possible alternatives or even examples at this stage. Also, there could be other types of suitable financial interventions, or the proposed interventions could be implemented in a different way compared with the proposals made in this report. The proposals are based on the current understanding of the challenges and opportunities, but more analysis is needed to shape the concept further and ensure its suitability in the context of the current short-term challenges.

In this chapter, some of the main uncertainties and implementation alternatives are briefly discussed separately regarding each funding window.

\section{B. Viability Gap Fund}

Viability gap funding could be understood as a broader fiscal issue than just the funding options as described in this report. In addition to the mechanisms described here, the analysis could be expanded to various fiscal policy measures, such as green certificates, direct or indirect tax rebates and exemptions, and funding through earmarked taxes and charges. A starting point in this report has been that the measures should be implemented quickly, meaning implementable in the current legal and regulatory context. Therefore, such measures have not been evaluated in more detail in this report, but the report has focused on designs that could be implemented in a stand-alone fund context. Such alternatives 


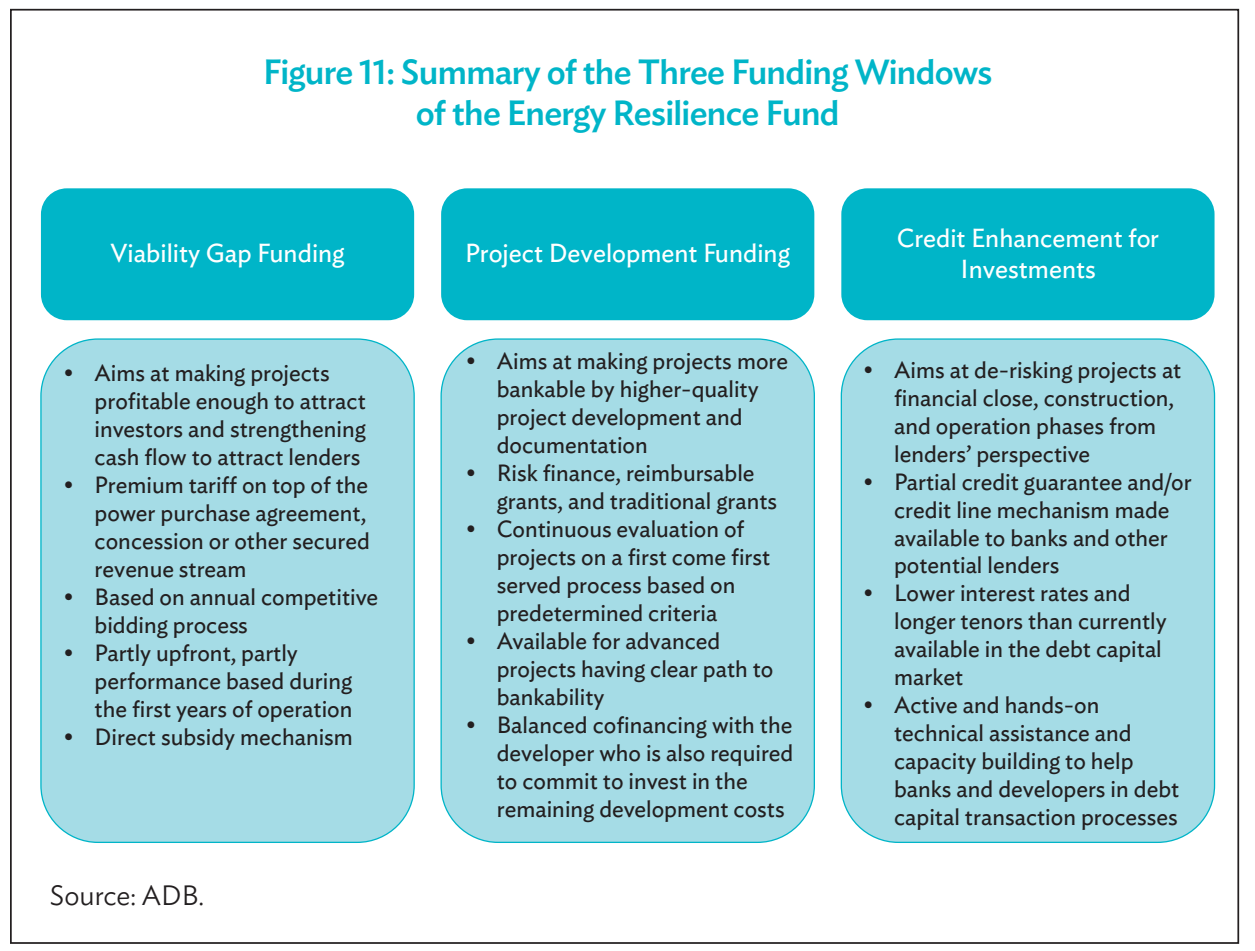

should be explored in more detail, if they emerge as realistic ones in the targeted time frame of this fund.

Especially, regarding the VGF which is likely to be a more direct subsidy mechanism, it could be expected that the Government of Indonesia should make a strong contribution to have serious discussions on any external funding for such mechanism. Furhter, from a funding source perspective, this mechanism could be split into gridconnected and off-grid projects, the government funding being more crucial in the former, while the latter probably being more potential for international climate and development finance.

Partial front-loading of the VGF has been proposed to make the funding more effective from a financial closing point of view. Also, because of time value for money, such front-loading can improve the financial ratios of projects, while such time value for money tends to be of less importance for at least some public funders, or at least they may apply more modest discount rates. However, the front-loading structure also transfers risk from investors to the VFG. Therefore, in the next steps more discussion is required regarding the optimal timing of the VGF payments.

The proposed application and selection process in this report is a two-round bidding process and scoring based on both technical and price. In this scheme, the potential bidders first have to be short-listed through an Eol/prequalification phase, and the short-listed candidates are subsequently asked to submit their full proposals through a CfP procedure. The selection is proposed to be mostly based on price, but partly on quality (or technical proposal). This procedure is typical, but can be relatively burdensome for both bidders and the fund manager. Alternative ways could be: 
1. Having qualitative parameters as eligibility criteria (not basis for scoring), basing the decisions on bid price only, but at the same time accepting only bids that meet the predetermined eligibility criteria.

2. Having a one-round process only, i.e., bidders submitting full proposals only without a preceding Eol/ prequalification round. This could lead to either more or less burdensome process. If the scoring remains quality and price based, such process might be more burdensome than the tworound process. However, if bids can be screened quickly based on quality parameters as eligibility criteria, ineligible bids could be rejected relatively easily, and the procedure could be faster.

Finally, the needed sizing of the VGF is highly uncertain as it was not possible in the context of this assignment to estimate the potential range of needed VGF. The calculations shown in this report should be regarded as illustrative examples only, and not used to sizing decisions as such. This will require more detailed studies on price levels in PPAs and concessions, and cost of generation of various forms of renewable energy generation in Indonesia. Also, more detailed analysis on other PPA terms and conditions is needed to understand potential other PPA challenges in addition to pricing.

An important aspect of the VGF and the whole ERF is the relationship to PLN. Since $\mathrm{PLN}$ is a crucial part of making projects bankable, it is of utmost importance that the ERF will also sufficiently respond to PLN's challenges to help them in playing their role. In this regard, VGF will be the most important funding window since it directly helps PLN's financial situation between the average regional tariffs and renewable energy projects requiring higher tariffs. There was no sufficient interaction with PLN during the assignment, and involving PLN is one of the most important next steps in the implementation process of the ERF.

\section{Project Development Fund}

The proposed PDF is based on a less-competitive procedure, where the developers are not explicitly put to compete directly against each other. Many public funding sources prefer competitive selection procedures, which in practice often means a CfP process. A CfP process can work well in many situations, and especially when the funding terms are very standardized, such as in the case of grants. However, in the case of project development funding, more detailed evaluation, negotiation, structuring, and use of financial instruments can improve the effectiveness of the funding remarkably. In this way, at least some of the funding will be repaid, and the funding is more likely to go to projects that have higher probability of success compared with standardized grant facilities applying a CfP procedure. It is suggested here that the potential funders of the PDF scheme are able and willing to actively find solutions enabling such continuous, bilateral, first come, first served evaluation, negotiation, and selection process, which can be very useful in the context of project development financing.

Such process can work as long as the amount of projects is relatively limited, roughly leading up to 10 projects per year. If the target volume is higher than that, tailored 
structuring at the project level may become burdensome, and a more traditional standardized grant facility approach can work better. However, in that case, it has to be accepted that, although the transaction cost can be lower in relative terms, the effectiveness of the scheme may be lower.

It is important to discuss the project development stage financing appoach in more detail with the domestic and international developers, IPPs, and potential financial investors, since these are the target groups of this intervention. In this assignment, the stakeholder consultation and written material available gave some clear indications on this aspect, but there has not been sufficient interaction with these stakeholders to thoroughly understand the most effective form of intervention would be.

\section{Credit Enhancement Fund}

The primary proposal for CEF would be a Partial Credit Guarantee Fund, but based on the fact-finding mission, it may be a too indirect and distant way of intervention, and some banks might even face lending limits to the sector. Therefore, providing direct finance through credit lines may work better in Indonesia, at least in the beginning. Syndication approach could be even more certain to kickstart some of the projects, since the syndication fund would play an active role by itself instead of relying more on banks' and developers' capability and interest. However, the syndication approach could tie a lot of resources in the fund management team and still lead to limited actively promoted pipeline. The credit line approach can also be structured so that the fund manager is an active player with banks (or between banks and projects), effectively doing financial advisor's work, and therefore make sure that the banks using credit lines are active. This approach has been successfully used by EBRD in its SEFF, such as the TurSEFF in Turkey.

The situation of the banking sector should be analyzed in more detail, more consulations with banks should be carried out, and the OJK should be more closely involved to further specify the most optimal approach in the CEF scheme.

\section{E. Other Approaches}

The proposed ERF has been designed to be as narrow as possible. It aims at establishing just the absolutely crucial interventions to mobilize private sector to provide the rest, in terms of capital, skills, expertise, and other resources. Therefore, it is not proposed to necessarily blend public and private funding at the level of the ERF, but rather make this blending happen at the project level, e.g., investors and international IPPs investing equity directly in the projects both at the project development and construction stages. Although the current concept consists of three forms of financing already, the concept could in principle be further expanded to include even more comprehensive set of financial interventions if seen necessary. There are at least two different aspects that could be considered:

1. Equity instrument. In this concept, it is assumed that (a) the VGF helps making the cash flow profiles of projects attractive for investors and lenders, (b) the PDF helps in sharing costs and risks at the project development 
stage and developing high-quality projects, (c) the CEF enables securing at least large share of needed debt, and (d) these together will make the professional (in many cases international) developers and IPPs interested in acquiring/investing in project development stage projects in Indonesia. These players have the needed equity and skills to develop, build, own, and operate renewable energy investments. In that case, a separate equity instrument is not needed. However, if even these interventions are not enough to attract professional and better resourced developers and IPPs, then a separate equity finance instrument could be considered. However, this would require again a lot more resources for the fund manager, to build, manage, and eventually exit a project equity portfolio. Such equity funding instrument could be a blending facility with grants/first-loss instruments provided by climate and development finance institutions to cushion the fund against losses, therefore making the fund attractive to private sector equity investors, for example, including institutional investors who typically do not want to be actively and directly involved with projects. However, an additional drawback of this approach is that it does not automatically mobilize professional sector-specific investors, developers, and IPPs, who in any case are needed if a solid and growing renewable energy market is to be created in Indonesia. Such investors would not invest in a fund (like institutional investors), but are looking for direct and usually controlling stakes in projects. For this reason, a specific equity fund approach is not proposed as a component in this ERF concept note.

2. Refinancing instrument. Another way to mobilize debt finance would be to provide debt funding or guarantees for construction stage only, and then aim to refinance projects after commissioning at operational stage, once they have proven a sufficient performance level. This would take the construction risk away from lenders. For example, such refinancing scheme could attract institutional investors, such as pension and life insurance funds who are, in principle, interested in (a) long-term stable cash flows and (b) large portfolios. Therefore, a construction stage funding instrument could take short-term fincancing responsibility during the construction and commissioning, and the projects could then be refinanced by a refinancing fund, which would be blended, tranched, and capitalized in the same way as explained above in case of the equity instrument. As an example, the EIB's InnovFin Energy Demonstration Projects (EIB InnovFin EDP) is a guarantee scheme that guarantees a large share (90\%) of the construction stage loan, but does not cover operational stage (EIB 2018). Therefore, it helps remarkably in arranging construction stage loan for projects, but requires that the project owner is able to refinance the project soon after commissioning without a guarantee. This kind of approach could also be possible, but it can be implemented also later. In the first phase, the sector needs to show some volumes coming online, and only then a refinancing scheme can be relevant. The current guarantee and/or credit line instrument could be easily modified and changed to a short-term construction finance instrument, if such refinancing scheme is later seen realistic and feasible. 


\section{References}

European Investment Bank. 2018. InnovFin Energy Demonstration Projects. Luxembourg. http://www.eib.org/en/products/blending/innovfin/products/energy-demo-projects.htm.

Global Energy Transfer Feed-in Tariff Uganda. 2018. Annual Report 2018. Kampala. https://www.getfit-uganda.org/ (accessed 5 September 2018).

Laporan Kinerja Direktorat Jenderal Ketenagalistrikan. 2016. 2016 Performance Report of Directorate General of Electricity. Jakarta.

International Renewable Energy Agency. 2017. Renewable Energy Road Map Indonesia (REMAP Indonesia). Abu Dhabi.

PricewaterhouseCoopers. 2017. Indonesia Power Generation Guide 2017. Jakarta.

Private Finance Advisory Network. 2018. http://pfan.net/ (accessed 5 September 2018).

PT Perusahaan Listrik Negara. 2017. Rencana Umum Penyediaan Tenaga Listrik 2017 (2017 RUPTL). Jakarta.

Renewable Energy Performance Platform. 2018. https://repp.energy/ (accessed 5 September 2018).

Roschier. 2018. Getting ready for the new Finnish renewable energy support scheme. Helsinki. https://www.roschier.com/newsroom/getting-ready-for-the-new-finnish-renewableenergy-support-scheme/ (accessed 5 September 2018).

The Economist. 2018. Economist Intelligence Unit. http://country.eiu.com/indonesia (accessed 5 September 2018).

Turkey Sustainable Energy Financing Facility. 2018. http://www.turseff.org/ (accessed 5 September 2018).

United Nations Development Programme. 2016. ARECA Final Evaluation Report.

New York. https://info.undp.org/docs/pdc/Documents/HND/00043791 ARECA Final Report.pdf. 


\section{Renewable Energy Financing Schemes for Indonesia}

Despite recent efforts by the Government of Indonesia to promote renewable energy investments, fossil fuels continue to account for around $90 \%$ of the national power generation mix. High financing costs and low power purchase agreement tariffs have been identified as major roadblocks for renewable energy investments in the country. This report examines how an Energy Resilience Fund can be designed to overcome the investment challenges by providing financial incentives for renewable energy developers. It makes recommendations for the fund's scope, structure, institutional design, function, and operation. Potential funding sources are also assessed.

\section{About the Asian Development Bank}

ADB is committed to achieving a prosperous, inclusive, resilient, and sustainable Asia and the Pacific, while sustaining its efforts to eradicate extreme poverty. Established in 1966, it is owned by 68 members -49 from the region. Its main instruments for helping its developing member countries are policy dialogue, loans, equity investments, guarantees, grants, and technical assistance. 